\title{
Risks and benefits of regional anesthesia in the perioperative setting
}

Citation for published version (APA):

Bouman, E. A. (2015). Risks and benefits of regional anesthesia in the perioperative setting. [Doctoral Thesis, Maastricht University]. Datawyse / Universitaire Pers Maastricht. https://doi.org/10.26481/dis.20150508eb

Document status and date:

Published: 01/01/2015

DOI:

10.26481/dis.20150508eb

Document Version:

Publisher's PDF, also known as Version of record

\section{Please check the document version of this publication:}

- A submitted manuscript is the version of the article upon submission and before peer-review. There can be important differences between the submitted version and the official published version of record.

People interested in the research are advised to contact the author for the final version of the publication, or visit the DOI to the publisher's website.

- The final author version and the galley proof are versions of the publication after peer review.

- The final published version features the final layout of the paper including the volume, issue and page numbers.

Link to publication

\footnotetext{
General rights rights.

- You may freely distribute the URL identifying the publication in the public portal. please follow below link for the End User Agreement:

www.umlib.nl/taverne-license

Take down policy

If you believe that this document breaches copyright please contact us at:

repository@maastrichtuniversity.nl

providing details and we will investigate your claim.
}

Copyright and moral rights for the publications made accessible in the public portal are retained by the authors and/or other copyright owners and it is a condition of accessing publications that users recognise and abide by the legal requirements associated with these

- Users may download and print one copy of any publication from the public portal for the purpose of private study or research.

- You may not further distribute the material or use it for any profit-making activity or commercial gain

If the publication is distributed under the terms of Article $25 \mathrm{fa}$ of the Dutch Copyright Act, indicated by the "Taverne" license above, 


\section{Risks and benefits of regional anesthesia \\ in the perioperative setting}




\section{Cover design: Greet Mommen}

Production \& print: Datawyse / Universitaire Pers Maastricht

\section{ISBN 9789561594259}

(C) Copyright Esther Bouman, Maastricht 2015

No part of this thesis may be published or reproduced without permission of the author 


\title{
Risks and Benefits of Regional Anesthesia in the Perioperative Setting
}

\author{
PROEFSCHRIFT \\ ter verkrijging van de graad van doctor aan de Universiteit Maastricht, \\ op gezag van de Rector Magnificus, Prof. Dr. L.L.G Soete, \\ volgens het besluit van het college van Decanen, \\ in het openbaar te verdedigen, \\ op vrijdag 8 mei 2015 om 16.00 uur \\ door \\ Esther Alexandra Catharina Bouman \\ geboren op 28 december 1964 te Reuver
}

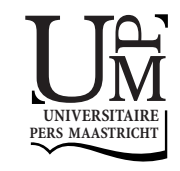




\section{Promotores}

Prof. Dr. M. van Kleef

Prof. Dr. M.A.E. Marcus (HMC, Doha, Qatar)

Prof. Dr. E.A.J. Joosten

\section{Co-promotor}

Dr. H-F Gramke

\section{Beoordelingscommissie}

Prof. Dr. G.W. Schurink, voorzitter

Prof. Dr. N.D. Bouvy

Prof. Dr. J.Th.A. Knape (UMC Utrecht)

Prof. Dr. B. Mochtar

Prof. Dr. G.J. Scheffer (Radboud UMC) 


\section{TABLE OF CONTENTS}

$\begin{array}{lll}\text { Chapter } 1 & \text { Introduction } & 7\end{array}$

Chapter $2 \quad$ Current techniques and strategies for anesthesia in patients 21 undergoing peripheral bypass surgery

Chapter 3 Reduced incidence of chronic post-surgical pain after epidural 39 analgesia for abdominal surgery

Chapter 4 Continuous paravertebral block for postoperative pain compared to general anaesthesia and wound infiltration for major oncological breast surgery

Chapter 5 Boundaries of the thoracic paravertebral space: potential risks and benefits of the thoracic paravertebral block from an anatomical perspective

Chapter 6 Evaluation of two different epidural catheters in clinical practice. Narrowing down the incidence of paresthesia!

Chapter 7 Paresthesia rate of two different epidural catheters: a randomized single-blind non-inferiority trial

Chapter 8 General discussion and Summary

Valorization addendum

Dankwoord

Curriculum Vitae

Publications 

CHAPTER 1

Introduction 



\section{INTRODUCTION}

Regional anesthesia is a commonly practiced mode of anesthesia, widely used, with high efficacy and safety. It can be applied to anesthetize a part of the body, in awake or sedated patients to avoid or complement general anesthesia and to benefit from good analgesia during surgery or peroperatively and also postoperatively. ${ }^{1}$ Until the mid- $19^{\text {th }}$ century regional anesthesia did not exist, ${ }^{2}$ but the discovery of cocaine by Carl Köller in 1884 and the development of less toxic synthetic local anesthetics in the beginning of the $20^{\text {th }}$ century lead to a burst in the development and use of regional anesthetic techniques varying from local wound infiltration, peripheral nerve blocks to neuraxial blockade. $^{2}$

As compared to general anesthesia some benefits and risks of regional anesthesia depend on the technique used whereas others are technique independent. Regional anesthetic techniques can be classified in those with immediate instant effects like direct cardiovascular effects (as hypotension), pulmonary, central and peripheral nervous, neuroendocrine, gastrointestinal effects, effects on temperature, coagulation, ${ }^{3}$ pain control, ${ }^{4}$ patient mobility, and those with delayed affects like discharge and rehabilitation. ${ }^{5}$

Many studies have been performed in order to test the effect of the mode of anesthesia on peri-operative mortality or morbidity. The outcome of these studies were inconsistent and the superiority of regional anesthesia over general anesthesia ${ }^{6}$ could not be documented. In this context it is important to note that a recent study reported a decreased mortality of epidural (local) analgesia as based on a meta-analysis. ${ }^{7}$ Furthermore, data from Cochrane collaboration demonstrated a reduced mortality (Risk ratio 0.71 Confidence Interval $(\mathrm{Cl})$ 0.53-0.94) and pneumonia with a regional anesthetic technique like neuraxial nerve blockade as compared to general anesthesia. No differences were detected for the risk of myocardial infarction after neuraxial nerve blockade as compared to either general anesthesia or a combination of regional and general anesthesia techniques. ${ }^{8}$

Hence the analysis and comparison of the mode of anesthesia in relation to perioperative mortality and morbidity is complicated and recommendations on safety of use are difficult to make because of several reasons:

1 Anesthesia in general is a safe procedure. The incidence of peri-operative death during the first 24 hours in the Netherlands (1995-1997) was 8.8 per 10.000 anesthetics and with an incidence of anesthesia related death of 1.4/10.000 anesthetics. ${ }^{9}$ In the United States the current mortality risk of anesthesia for surgical inpatients is even lower at 0.82 in 100.000. ${ }^{10}$ In Western Australia the anesthesia-related mortality fell from 6.5 per 100.000 procedures in the eighties to 1.7 deaths per 100.000 procedures between 2000-2002, from which 0.2 per 100.000 were anesthesia related. ${ }^{11}$ Therefore, large studies are needed to demonstrate safety of anesthetic procedures. 
2 General anesthesia (GA) is effective, easy to apply and offers optimal surgical conditions, in particular during long lasting procedures. Nevertheless, post-operative cognitive dysfunction and post-operative delirium are frequently associated with $\mathrm{GA}^{12,13}$ as well as cardio pulmonary adverse effects. Hence in order to minimize these complications selected patients could benefit from regional techniques.

3 The development of less invasive surgical techniques like endovascular treatment for aortic aneurysms, laparoscopic hemi-colectomy or robot-assisted prostatectomy may change daily practice without the need for neuraxial local anesthetic blockade. ${ }^{6}$

4 Regional anesthesia requires more specific skills of the individual anesthesiologist due to cooperation and communication with the patient. Furthermore regional anesthesia has a certain failure rate (technique and operator dependent) and has its own complications: local anesthetic toxicity, bleeding, nerve related complications like TNS, peripheral nerve injury, (epi-)dural hematoma, epidural abscess and meningitis and anterior spinal artery syndrome. ${ }^{14,15}$

5 Regional anesthesia is basically a variety of techniques, one more invasive than another and only appropriate for specific indications.

6 Due to the common use of anticoagulant drugs major contra-indications for the use of regional anesthesia do exist. ${ }^{16}$

It is because of these reasons, that studying the risks and benefits of regional versus general anesthetics is complicated. Therefore the use of selective and identified patient populations with high relative risks in complications like hip fracture surgery, obstetrics surgery, abdominal surgery or peripheral bypass surgery may offer major advantages.

Despite the relative high risk of complications in patients after hip fracture surgery insufficient evidence is presented on a different effect of local versus general anesthetics on mortality, cardiovascular morbidity, duration of surgery, incidence of deep vein thrombosis or pulmonary embolus, ${ }^{17-19}$ or postoperative delirium. ${ }^{18}$ Perioperative blood loss in patients with hip fracture surgery may be reduced when regional anesthesia is used and whereas at the same time a reduction in postoperative pain, nausea and vomiting was demonstrated. ${ }^{17}$ For hip fracture surgery only marginal advantages in use of local versus general anesthetics were reported in terms of early mortality and deep vein thrombosis. ${ }^{19}$ For obstetric patients the risk/benefit balance of regional versus general anesthetics was analyzed and reported in 2 reviews from the Cochrane collaboration. ${ }^{20,21}$ In terms of maternal and neonatal outcome no superiority of either regional or general anesthetics was reported. ${ }^{20}$ These findings were further confirmed in high risk patients. ${ }^{22}$ Furthermore both spinal and epidural anesthesia were equally effective in providing intra-operative anesthesia. ${ }^{21}$

Combined general and epidural anesthesia has become a popular technique in abdominal surgery with shown high efficacy and safety. However, the debate whether a regional anesthetic technique like epidural anesthesia is superior to general anesthesia with respect to the improvement on outcome has not been closed yet. ${ }^{23}$ In abdominal surgery extensive clinical experience and research, but also an elaborate availability of 
epidural anesthesia results in major advantages as for instance an effective pain management and the prevention of postoperative pulmonary complications. ${ }^{24-27}$ On the other hand the disadvantages of epidural anesthesia in abdominal surgery are related to the presence of side-effects including arterial hypotension, urine retention, and pruritus, ${ }^{25,27}$ as well as technical difficulties like e.g. multiple punctures and malposition after correct placement but also technical difficulties based on physical characteristics of the catheters.

Also for patients who underwent a peripheral bypass surgery the debate whether epidural anesthesia is superior to general anesthesia with respect to the improvement on outcome is not closed. It should be taken into account that patients who underwent a peripheral bypass surgery might potentially benefit from a mere regional anesthetic approach, as these patients are generally elderly, with significant comorbidities and often use a variety of drugs resulting in an increased risk for anesthesia related complications. ${ }^{10,28}$

Furthermore a comparison of risks and benefits of regional versus general anesthetics is a manifestation of a limited approach and underestimates the following aspects:

1 The potential benefits of combined regional and general anesthesia techniques in high risk population's e.g. vascular surgery.

2 Peripheral arterial disease is an illness with a high prevalence in Europe and North America. This disease is associated with a significant impact on quality of life. Despite advanced medical and endovascular treatments, surgery is often indicated to prevent the consequences of ischemic injury. Usually, these patients do have significant comorbidities resulting in an increased risk for anesthesia related complications.

The development of improved post-operative pain management programs for specific types of surgery like abdominal surgery and major oncological breast surgery.

Optimal postoperative pain relief is currently still an underestimated item as severe pain after surgery has been shown to be a major problem and occurring in $20-40 \%$ of patients. ${ }^{29}$ All together this implies the need for development of complementary advanced anesthetic techniques in order to optimize perioperative pain control.

In view of the above-mentioned considerations and aspects of perioperative anesthesia care we formulated the following research questions:

Research Question 1:

Does regional anesthesia improve outcome of peripheral vascular surgery as compared to general anesthesia?

In order to further analyze the risk and benefits of a regional and/or general anesthetic procedure the focus should be directed towards specific outcomes, like pain, ${ }^{25}, 30$ cardiovascular and pulmonary complications ${ }^{30,31}$ or cancer. $^{32}$ 
A major burden for health systems is chronic postsurgical pain (CPSP). Various factors like the duration of the surgery but also the American Society of Anesthesiologists (ASA) physical status classification of the patient and the level of preoperative fear are main predictors for development of CPSP. ${ }^{33,}{ }^{34}$ Another main predictor for CPSP is acute postoperative pain. $^{34}$ Regional anesthesia decreases acute postoperative pain. However, at present there is limited evidence for a positive effect of regional anesthesia on CPSP. ${ }^{35}$ It has been shown that patients undergoing upper and lower abdominal surgery are at a high risk for acute postoperative pain. ${ }^{36}$

Hence, it is expected that these patients might develop CPSP and we therefore addressed the following Research Question 2:

\section{Does regional anesthesia reduce the incidence of chronic postsurgical pain in} patients undergoing abdominal surgery?

Despite major efforts of regulatory agencies and professional societies to establish clinical practice guidelines ${ }^{37-39}$ effective postoperative pain management remains a significant clinical issue. A number of studies have demonstrated the extent of the problem: one in three operative patients experience pain of more than 3 on a 10 point Visual Analogue Scale (VAS). ${ }^{40-42}$ Insufficiently controlled acute postoperative pain is a risk factor for postoperative complications ${ }^{39}$ and long term adverse outcome e.g. chronic pain, functional limitations and quality of life. ${ }^{33}$ It is therefore that the first step of reducing complications is an effective postoperative pain relief for a surgery with high risk of acute postoperative pain

Thoracic paravertebral block is currently recommended by the Prospect Working Group (www.postoppain.org) as the technique of choice for breast surgery and is associated with less acute postoperative pain than general anesthesia ${ }^{43}$ and CPSP. ${ }^{35}$ Local wound infiltration is a low risk procedure with few side-effects.

From this we formulated the following Research Question 3:

Is there an additional value of regional anesthesia (paravertebral block) with respect to acute postoperative pain compared to local wound infiltration?

There are several techniques to perform a paravertebral block. The oldest method, reappraised by Eason and Wyatt ${ }^{44}$ relies on anatomical landmarks. For this technique, the patient is sitting or placed in a lateral position, 2,5 $-3 \mathrm{~cm}$ lateral to the anatomical midline and a Tuohy needle is inserted at $90^{\circ}$ into the skin and advanced to the rib or transverse process. The needle is then redirected to pass above the bony structures and the paravertebral space is localized with a loss of resistance technique, due to the crossing of the superior costotransverse ligament. If a prolonged block is required an end-hole catheter can be inserted for less than $1 \mathrm{~cm}$ to ensure correct positioning. ${ }^{44,45}$ 
The Eason and Wyatt paravertebral technique based on anatomical landmarks was further modified to enhance safety and efficacy to a nerve stimulator guided method and improved combining both techniques. ${ }^{46,47}$ Others used pressure monitoring, ${ }^{48}$ direct introduction of the paravertebral catheter by the surgeon, ${ }^{49}$ a thoracoscopic paravertebral block $^{50}$ and a paravertebral lamina technique with a more medial approach. $^{51}$

In regional anesthesia the use of ultrasound has become the "gold" standard during the last 10 years. ${ }^{52}$ With the use of ultrasound the regional anesthetic techniques became more safe and efficient as nerves, muscles, blood vessels, pleura and even the spread of local anesthetic peri-neurally can be visualized. ${ }^{52,53}$ However the ultrasound view of the paravertebral space in a transverse scan is obscured by the acoustic shadow of the transverse process. ${ }^{54}$ Furthermore, each of the various techniques to perform a thoracic paravertebral block (TPVB) has its own pitfalls e.g. loss of image of the needle tip, and needle direction towards the spinal canal ${ }^{55-58}$ versus needle direction towards the pleura. ${ }^{59,60}$ In this respect no data exist related to the superiority of one of the thoracic paravertebral block techniques over the others and to our knowledge there are no published randomized controlled trials (RCT) that compare an anatomical landmark technique with an ultrasound technique. In order to further understand not only the effect of the TPVB but also its possible clinical consequences, a detailed description of the anatomical boundaries and the thoracic paravertebral space (TPVS) is important.

Hence we formulated Research Question 4:

\section{What are the anatomical boundaries of the thoracic paravertebral space in view} of potential risks and benefits of the thoracic paravertebral block?

As mentioned before the disadvantages of epidural anesthesia might be related to technical difficulties like e.g. multiple punctures, malposition after correct placement but also to the physical characteristics of the catheters needed for epidural anesthesia. Due to the different physical properties of catheters, both in vitro and in vivo, complication rates and handling characteristics of the catheters may vary significantly. A CE-marking of a medical device indicates that the technical device (here: catheter) meets the essential safety requirements of the European Community (EC) and is appropriate for the purpose it is designed for. In fact CE-marking is a declaration of conformity (Council Directive 93/42/EEC concerning medical devices). In view of this it is important to systematically investigate new industrial products preferably in a clinical setting. This holds true in particular for the epidural catheters as it has been reported that anesthetic devices account for about $2 \%$ of all new marked devices and they do account for $30-40 \%$ of all alerts. ${ }^{61,62}$

Most of the technical problems related to use of epidural catheters e.g. kinking, breakage, clamp problems have been published in case report studies and then technical characteristics of the catheters are not documented. ${ }^{63-79}$ As each type of 
catheter has different physical characteristics this may have severe implications for its use in clinical practice. ${ }^{80-83}$ For epidural catheters common features are tensile strength and stretch resistance, shaft stability, visualization of blood or spinal fluid, no risk of forming loops or knots, softening of catheter. When technical characteristics of a catheter are changed, both the type and the rate of complications may change. Incidence of serious complications is low and one of the more common complications is paresthesia upon catheter insertion. Reported incidences of paresthesia vary between 0.2 and $56 \%$ depending on approach, ${ }^{84}$ patient characteristics, ${ }^{85}, 86$ technique, $^{87-89}$ different catheters ${ }^{68,90}$ and depth of insertion. ${ }^{91}$ Even an incidence as high as $81 \%-89 \%$ was reported. ${ }^{92,93}$ The symptoms of paresthesia during conduct of neuraxial anesthesia are frequently mild and transient. However sometimes these symptoms are that intense, that the procedure must be aborted. Fortunately the incidence of permanent neurological damage of 1out of 20.000-30.000 regional anesthesia procedures for spinal anesthesia and 1out of 25.000 procedures for obstetric epidurals and 1 out of 3600 in other epidurals procedures remains low. ${ }^{94}$ Nevertheless in France two thirds of the patients with neurological deficits reported paresthesia during needle placement or pain on injection. ${ }^{95}$

In order to reduce paresthesia upon catheter insertion the physical characteristics of the catheter were adapted; the material including the catheter tip was softened

In view of the fact that development of paresthesia is an important determinant of final outcome we used this parameter to test 2 types of catheters with different characteristics and formulated Research question 5:

What is the impact of technical characteristics of catheters used in regional anesthesia on the performance in patients scheduled for elective surgery during normal daily practice under thoracic or lumbar epidural anesthesia?

\section{IN CONCLUSION}

The main aim of this thesis is to study various aspects related to the risks and benefits in regional anesthesia. In this respect we focus at the risks and benefits related to the type of surgery (RQ1,Chapter 2). In Chapter 2 we focus on high-risk patients and reviewed the current literature for patients undergoing peripheral bypass surgery (RQ1). In Chapter 3 we address RQ2 and investigated the impact of epidural analgesia in patients at high risk for chronic post-surgical pain. In Chapter 4 (RQ3) we compare two types of regional anesthesia, a paravertebral block with local wound infiltration on the development of acute pain. As the anatomical background of the thoracic paravertebral space and the optimal technique for thoracic paravertebral block remain unclear, we investigate in Chapter 5 the anatomy of paravertebral space in a human cadaver (see 
RQ4). In Chapters 6 and 7 we address the impact of technical characteristics of 2 different epidural catheters on the rate of paresthesia (RQ 5). In Chapter 8 findings we discuss and summarize the results of the studies performed. 


\section{REFERENCES}

1. Bouman EA, Gramke HF, Marcus MA. Paraesthesia in Regional Anaesthesia. In: Paresthesia. Edited by Imbelloni LE: InTech; 2012: 33-44.

2. dos Reis A. Intravenous regional anesthesia--first century (1908-2008). Beginning, development, and current status. Rev Bras Anestesiol 2008, 58(3):299-321.

3. Cwik J. Postoperative considerations of neuraxial anesthesia. Anesthesiol Clin 2012, 30(3):433-443.

4. Liu SS, Wu CL. The effect of analgesic technique on postoperative patient-reported outcomes including analgesia: a systematic review. Anesth Analg 2007, 105(3):789-808.

5. Lirk P, Hollmann M. Outcome after regional anesthesia: weighing risks and benefits. Minerva Anestesiol 2013.

6. Liu SS, Wu CL. Effect of postoperative analgesia on major postoperative complications: a systematic update of the evidence. Anesth Analg 2007, 104(3):689-702.

7. Popping DM, Elia N, Van Aken HK, Marret E, Schug SA, Kranke P, Wenk M, Tramer MR. Impact of Epidural Analgesia on Mortality and Morbidity After Surgery: Systematic Review and Meta-analysis of Randomized Controlled Trials. Ann Surg 2013.

8. Guay J, Choi P, Suresh S, Albert N, Kopp S, Pace NL. Neuraxial blockade for the prevention of postoperative mortality and major morbidity: an overview of Cochrane systematic reviews. Cochrane Database Syst Rev 2014, 1:CD010108.

9. Arbous MS, Grobbee DE, van Kleef JW, de Lange JJ, Spoormans HH, Touw P, Werner FM, Meursing AE. Mortality associated with anaesthesia: a qualitative analysis to identify risk factors. Anaesthesia 2001, 56(12):1141-1153.

10. Li G, Warner M, Lang BH, Huang L, Sun LS. Epidemiology of anesthesia-related mortality in the United States, 1999-2005. Anesthesiology 2009, 110(4):759-765.

11. Gibbs N, Rodoreda P. Anaesthetic mortality rates in Western Australia 1980-2002. Anaesth Intensive Care 2005, 33(5):616-622.

12. Mason SE, Noel-Storr A, Ritchie CW. The impact of general and regional anesthesia on the incidence of post-operative cognitive dysfunction and post-operative delirium: a systematic review with meta-analysis. J Alzheimers Dis 2010, 22 Suppl 3:67-79.

13. Zywiel MG, Prabhu A, Perruccio AV, Gandhi R. The influence of anesthesia and pain management on cognitive dysfunction after joint arthroplasty: a systematic review. Clin Orthop Relat Res 2014, 472(5):1453-1466.

14. Cook TM, Counsell D, Wildsmith JA, Royal College of Anaesthetists Third National Audit P. Major complications of central neuraxial block: report on the Third National Audit Project of the Royal College of Anaesthetists. Br J Anaesth 2009, 102(2):179-190.

15. Horlocker TT. Complications of regional anesthesia and acute pain management. Anesthesiol Clin 2011, 29(2):257-278.

16. Gogarten W, Vandermeulen E, Van Aken H, Kozek S, Llau JV, Samama CM, European Scoeity of A. Regional anaesthesia and antithrombotic agents: recommendations of the European Society of Anaesthesiology. Eur J Anaesthesiol 2010, 27(12):999-1015.

17. Macfarlane AJ, Prasad GA, Chan VW, Brull R. Does regional anaesthesia improve outcome after total hip arthroplasty? A systematic review. Br J Anaesth 2009, 103(3):335-345.

18. Slor CJ, de Jonghe JF, Vreeswijk R, Groot E, Ploeg TV, van Gool WA, Eikelenboom P, Snoeck M, Schmand B, Kalisvaart KJ. Anesthesia and postoperative delirium in older adults undergoing hip surgery. J Am Geriatr Soc 2011, 59(7):1313-1319.

19. Urwin SC, Parker MJ, Griffiths R. General versus regional anaesthesia for hip fracture surgery: a metaanalysis of randomized trials. Br J Anaesth 2000, 84(4):450-455.

20. Afolabi BB, Lesi FE. Regional versus general anaesthesia for caesarean section. Cochrane Database Syst Rev 2012, 10:CD004350. 
21. Ng K, Parsons J, Cyna AM, Middleton P. Spinal versus epidural anaesthesia for caesarean section. Cochrane Database Syst Rev 2004(2):CD003765.

22. Wallace DH, Leveno KJ, Cunningham FG, Giesecke AH, Shearer VE, Sidawi JE. Randomized comparison of general and regional anesthesia for cesarean delivery in pregnancies complicated by severe preeclampsia. Obstet Gynecol 1995, 86(2):193-199.

23. Dabu-Bondoc SM. Regional anesthesia and perioperative outcome: what is new? Curr Opin Anaesthesiol 2004, 17(5):435-439.

24. Amr YM, Yousef AA, Alzeftawy AE, Messbah WI, Saber AM. Effect of preincisional epidural fentanyl and bupivacaine on postthoracotomy pain and pulmonary function. Ann Thorac Surg 2010, 89(2):381-385.

25. Pöpping DM, Zahn PK, Van Aken HK, Dasch B, Boche R, Pogatzki-Zahn EM. Effectiveness and safety of postoperative pain management: a survey of 18925 consecutive patients between 1998 and 2006 (2nd revision): a database analysis of prospectively raised data. Br J Anaesth 2008, 101(6):832-840.

26. Yegin A, Erdogan A, Kayacan N, Karsli B. Early postoperative pain management after thoracic surgery; preand postoperative versus postoperative epidural analgesia: a randomised study. Eur J Cardiothorac Surg 2003, 24(3):420-424.

27. Dolin SJ, Cashman JN. Tolerability of acute postoperative pain management: nausea, vomiting, sedation, pruritus, and urinary retention. Evidence from published data. Br J Anaesth 2005, 95(5):584-591.

28. Christopherson R, Beattie C, Frank SM, Norris EJ, Meinert CL, Gottlieb SO, Yates H, Rock P, Parker SD, Perler BA et al. Perioperative morbidity in patients randomized to epidural or general anesthesia for lower extremity vascular surgery. Perioperative Ischemia Randomized Anesthesia Trial Study Group. Anesthesiology 1993, 79(3):422-434.

29. Gerbershagen HJ, Aduckathil S, van Wijck AJ, Peelen LM, Kalkman CJ, Meissner W. Pain intensity on the first day after surgery: a prospective cohort study comparing 179 surgical procedures. Anesthesiology 2013, 118(4):934-944.

30. Nishimori M, Low JH, Zheng H, Ballantyne JC. Epidural pain relief versus systemic opioid-based pain relief for abdominal aortic surgery. Cochrane Database Syst Rev 2012, 7:CD005059.

31. Pöpping DM, Elia N, Marret E, Remy C, Tramer MR. Protective effects of epidural analgesia on pulmonary complications after abdominal and thoracic surgery: a meta-analysis. Arch Surg 2008, 143(10):990-1000.

32. Cata JP, Hernandez M, Lewis VO, Kurz A. Can Regional Anesthesia and Analgesia Prolong Cancer Survival After Orthopaedic Oncologic Surgery? Clin Orthop Relat Res 2013.

33. Peters ML, Sommer M, de Rijke JM, Kessels F, Heineman E, Patijn J, Marcus MA, Vlaeyen JW, van Kleef M. Somatic and psychologic predictors of long-term unfavorable outcome after surgical intervention. Ann Surg 2007, 245(3):487-494.

34. Grosu I, de Kock M. New Concepts in Acute Pain Management: Strategies to Prevent Chronic Postsurgical Pain, Opioid-Induced Hyperalgesia, and Outcome Measures. Anesthesiology Clin 2011, 29(2):311-327.

35. Andreae $\mathrm{MH}$, Andreae DA. Regional anaesthesia to prevent chronic pain after surgery: a Cochrane systematic review and meta-analysis. Br J Anaesth 2013, 111(5):711-720.

36. Sommer M, de Rijke JM, van Kleef M, Kessels AG, Peters ML, Geurts JW, Gramke HF, Marcus MA. The prevalence of postoperative pain in a sample of 1490 surgical inpatients. Eur J Anaesthesiol 2008, 25(4):267-274.

37. Houweling PL, Molag ML, van Boekel RL, Verbrugge SJ, van Haelst IM, Hollmann MW. ['Postoperative pain treatment' practice guideline revised]. Ned Tijdschr Geneeskd 2013, 157(49):A7005.

38. Miaskowski C. Patient-controlled modalities for acute postoperative pain management. J Perianesthesia Nurs 2005, 20(4):255-267.

39. Nworah U. From Documentation to the Problem: Controlling Postoperative Pain. Nursing Forum 2012, 47(2):91-99.

40. Dolin SJ, Cashman JN, Bland JM. Effectiveness of acute postoperative pain management: I. Evidence from published data. Br J Anaesth 2002, 89(3):409-423.

41. Duncan F, Day R, Haigh C, Gill S, Nightingale J, O'Neill O, Counsell D, Group N. First Steps Toward Understanding the Variability in Acute Pain Service Provision and the Quality of Pain Relief in Everyday Practice Across the United Kingdom. Pain Med 2013. 


\section{CHAPTER 1}

42. Svensson I, Sjostrom B, Haljamae H. Assessment of pain experiences after elective surgery. J Pain Symptom Manage 2000, 20(3):193-201.

43. Thavaneswaran P, Rudkin GE, Cooter RD, Moyes DG, Perera CL, Maddern GJ. Brief reports: paravertebral block for anesthesia: a systematic review. Anesth Analg 2010, 110(6):1740-1744.

44. Eason MJ, Wyatt R. Paravertebral thoracic block-a reappraisal. Anaesthesia 1979, 34(7):638-642.

45. Evans H KS. Paravertebral anesthesia. In: Anesthesiology. Volume 1, edn. Edited by B. D. DE Longnecker NM, Zapol WM. New York, USA: The McGraw-Hill Companies.; 2008: 1009-1024.

46. Boezaart AP, Raw RM. Continuous Thoracic Paravertebral Block for Major Breast Surgery. Reg Anesth Pain Med 2006, 31(5):470-476.

47. Naja MZ, Ziade MF, Lonnqvist PA. Nerve-stimulator guided paravertebral blockade vs. general anaesthesia for breast surgery: a prospective randomized trial. Eur J Anaesthesiol 2003, 20(11):897-903.

48. Mundey DA, Buckenmaier CC, 3rd, Plunkett AR. Loss of resistance technique for paravertebral nerve blockade using the Episure Autodetect Syringe--a case report. Pain Med 2009, 10(5):854-857.

49. Garutti I, González-Aragoneses F, Biencinto MT, Novoa E, Simón C, Moreno N, Cruz P, Benito C. Thoracic paravertebral block after thoracotomy: comparison of three different approaches. European Journal of Cardio-Thoracic Surgery 2009, 35(5):829-832.

50. Klein SM, Nielsen KC, Ahmed N, Buckenmaier III CC, Steele SM. In situ images of the thoracic paravertebral space. Reg Anesth Pain Med 2004, 29(6):596-599.

51. Juttner T, Werdehausen R, Hermanns H, Monaca E, Danzeisen O, Pannen BH, Janni W, Winterhalter M. The paravertebral lamina technique: a new regional anesthesia approach for breast surgery. J Clin Anesth 2011, 23(6):443-450.

52. Marhofer $\mathrm{P}$, Willschke $\mathrm{H}$, Kettner S. Current concepts and future trends in ultrasound-guided regional anesthesia. Curr Opin Anaesthesiol 2010, 23(5):632-636.

53. Jeng $C L$, Rosenblatt $M A$. Intraneural injections and regional anesthesia: the known and the unknown. Minerva Anestesiol 2011, 77(1):54-58.

54. Karmakar M. Ultrasound guided thoracic paravertebral block. In: Atlas of Ultrasound guided procedures in interventional pain management. edn. Edited by Narouze S. New York USA: Springer; 2011: 133-147.

55. Cowie B, McGlade D, Ivanusic J, Barrington MJ. Ultrasound-guided thoracic paravertebral blockade: a cadaveric study. Anesth Analg 2010, 110(6):1735-1739.

56. Luyet C, Eichenberger U, Greif R, Vogt A, Szucs Farkas Z, Morigg| B. Ultrasound-guided paravertebral puncture and placement of catheters in human cadavers: an imaging study. $\mathrm{Br} J$ Anaesth 2009, 102(4):534-539.

57. O Riain S, Donnell BO, Cuffe T, Harmon DC, Fraher JP, Shorten G. Thoracic paravertebral block using realtime ultrasound guidance. Anesth Analg 2010, 110(1):248-251.

58. Renes SH, Bruhn J, Gielen MJ, Scheffer GJ, van Geffen GJ. In-plane ultrasound-guided thoracic paravertebral block: a preliminary report of 36 cases with radiologic confirmation of catheter position. Reg Anesth Pain Med 2010, 35(2):212-216.

59. Hara K, Sakura S, Nomura T, Saito Y. Ultrasound guided thoracic paravertebral block in breast surgery. Anaesthesia 2009, 64(2):223-225.

60. Marhofer P, Kettner SC, Hajbok L, Dubsky P, Fleischmann E. Lateral ultrasound-guided paravertebral blockade: an anatomical-based description of a new technique. Br J Anaesth 2010, 105(4):526-532.

61. Beydon L, Conreux F, Le Gall R, Safran D, Cazalaa JB. Analysis of the French health ministry's national register of incidents involving medical devices in anaesthesia and intensive care. Br J Anaesth 2001, 86(3):382-387.

62. Gilron I. Anaesthesia equipment safety in Canada: the role of government regulation. Can J Anaesth 1993, 40(10):987-992.

63. Alam S. Epidural catheter connector. Can J Anaesth 1996, 43(6):642.

64. Anderson S. Defects in epidural catheters. Anaesthesia 1988, 43(7):604-605.

65. Asai T, Yamamoto K, Hirose T, Taguchi H, Shingu K. Breakage of Epidural Catheters: A Comparison of an Arrow Reinforced Catheter and Other Nonreinforced Catheters. Anesth Analg 2001, 92(1):246-248. 
66. Banwell BR, Morley-Forster P, Krause R. Decreased incidence of complications in parturients with the arrow (FlexTip Plus) epidural catheter. Can J Anaesth 1998, 45(4):370-372.

67. Harris RW. Portex epidural catheters--a change for the worse. Anaesthesia 1984, 39(10):1040-1041.

68. Jaime F, Mandell GL, Vallejo MC, Ramanathan S. Uniport soft-tip, open-ended catheters versus multiport firm-tipped close-ended catheters for epidural labor analgesia: a quality assurance study. J Clin Anesth 2000, 12(2):89-93.

69. Lim YJ, Bahk JH, Ahn WS, Lee SC. Coiling of lumbar epidural catheters. Acta Anaesthesiol Scand 2002, 46(5):603-606.

70. McIntyre DR, Kuwahara B. Paediatric epidural catheter connector problems. Can J Anaesth 1991, 38(4 Pt 1):544.

71. Michael S, Richmond MN, Birks RJ. A comparison between open-end (single hole) and closed-end (three lateral holes) epidural catheters. Complications and quality of sensory blockade. Anaesthesia 1989, 44(7):578-580.

72. Morris GN, Warren BB, Hanson EW, Mazzeo FJ, DiBenedetto DJ. Influence of patient position on withdrawal forces during removal of lumbar extradural catheters. Br J Anaesth 1996, 77(3):419-420.

73. Mourisse J, Gielen MJ, Hasenbos MA, Heystraten FM. Migration of thoracic epidural catheters. Three methods for evaluation of catheter position in the thoracic epidural space. Anaesthesia 1989, 44(7):574577.

74. Pinchak AC, Podlipsky HM, Hagen JF. Mechanical aspects of epidural catheter insertion--prevention of catheter buckling by means of a needle hub insert. Anesthesiology 1983, 59(6):549-553.

75. Roddin MJ, Dancey FM. Kinking of epidural catheters. Anaesthesia 2000, 55(8):831.

76. Rolbin SH, Hew E, Ogilvie G. A comparison of two types of epidural catheters. Can J Anaesth 1987, 34(5):459-461.

77. Sah N, Finegold H. Breakage of epidural catheters in two parturients. Can J Anesth 2003, 50(6):619-620.

78. Tackaberry CJ, Wadsworth R. Epidural catheter clamp fixes too firmly. Anaesthesia 1999, 54(9):914.

79. Wiesel S, Gilron I. Portex epidural catheters. Can J Anaesth 1993, 40(4):397-398.

80. Ates Y, Yucesoy CA, Unlu MA, Saygin B, Akkas N. The Mechanical Properties of Intact and Traumatized Epidural Catheters. Anesth Analg 2000, 90(2):393-399.

81. Eckmann DM. Variations in epidural catheter manufacture: implications for bending and stiffness. Reg Anesth Pain Med 2003, 28(1):37-42.

82. Hutchison GL. The severance of epidural catheters. Anaesthesia 1987, 42(2):182-185.

83. Kundra P, Viswanath SK, Meena DS, Badhe A. Insertion length and resistance during advancing of epidural catheter. J Anesth 2009, 23(4):494-499.

84. Leeda M, Stienstra R, Arbous MS, Dahan A, Th Veering B, Burm AG, Van Kleef JW. Lumbar epidural catheter insertion: the midline vs. the paramedian approach. Eur J Anaesthesiol 2005, 22(11):839-842.

85. Hebl JR, Horlocker TT, Kopp SL, Schroeder DR. Neuraxial blockade in patients with preexisting spinal stenosis, lumbar disk disease, or prior spine surgery: efficacy and neurologic complications. Anesth Analg 2010, 111(6):1511-1519.

86. Spiegel JE, Vasudevan A, Li Y, Hess PE. A randomized prospective study comparing two flexible epidural catheters for labour analgesia. Br J Anaesth 2009, 103(3):400-405.

87. Hebl JR, Kopp SL, Schroeder DR, Horlocker TT. Neurologic complications after neuraxial anesthesia or analgesia in patients with preexisting peripheral sensorimotor neuropathy or diabetic polyneuropathy. Anesth Analg 2006, 103(5):1294-1299.

88. McAndrew CR, Harms P. Paraesthesiae during needle-through-needle combined spinal epidural versus single-shot spinal for elective caesarean section. Anaesth Intensive Care 2003, 31(5):514-517.

89. van den Berg AA, Ghatge S, Armendariz G, Cornelius D, Wang S. Responses to dural puncture during institution of combined spinal-epidural analgesia: a comparison of 27 gauge pencil-point and 27 gauge cutting-edge needles. Anaesth Intensive Care 2011, 39(2):247-251.

90. Bouman EA, Gramke HF, Wetzel N, Vanderbroeck TH, Bruinsma R, Theunissen M, Kerkkamp HE, Marcus MA. Evaluation of two different epidural catheters in clinical practice. narrowing down the incidence of paresthesia! Acta Anaesthesiol Belg 2007, 58(2):101-105. 


\section{CHAPTER 1}

91. Cartagena R, Gaiser RR. Advancing an epidural catheter $10 \mathrm{~cm}$ then retracting it $5 \mathrm{~cm}$ is no more effective than advancing it $5 \mathrm{~cm}$. Journal of clinical anesthesia 2005, 17(7):528-530.

92. Hetherington R, Stevens RA, White JL, Spitzer L, Koppel S. Subjective experiences of anesthesiologists undergoing epidural anesthesia. Reg Anesth 1994, 19(4):284-288.

93. van den Berg AA, Sadek M, Swanson S, Ghatge S. Epidural injection of lidocaine reduces the response to dural puncture accompanying spinal needle insertion when performing combined spinal-epidural anesthesia. Anesth Analg 2005, 101(3):882-885, table of contents.

94. Moen V, Dahlgren N, Irestedt L. Severe neurological complications after central neuraxial blockades in Sweden 1990-1999. Anesthesiology 2004, 101(4):950-959.

95. Auroy Y, Narchi P, Messiah A, Litt L, Rouvier B, Samii K. Serious complications related to regional anesthesia: results of a prospective survey in France. Anesthesiology 1997, 87(3):479-486. 


\section{CHAPTER 2}

Current techniques and strategies for anesthesia in patients undergoing peripheral bypass surgery 


\section{ABSTRACT}

Peripheral arterial disease is an illness with a high prevalence in Europe and North America. The disease is associated with a significant impact on quality of life. Despite advanced medical and endovascular treatments, surgery is often indicated to prevent the consequences of ischemic injury. Usually, these patients do have significant comorbidities resulting in an increased risk for anesthesia related complications. While general anesthesia is commonly used for the majority of the patients, local and regional anesthesia offer several possible advantages such as stable cardiovascular hemodynamic perioperative course, improved postoperative pain relief and prevention of chronic post-surgical pain syndromes. This review will discuss perioperative management, available evidence regarding general anesthesia and various regional anesthetic techniques for peripheral vascular surgery, and the current advises regarding anticoagulants and regional anesthesia. No definitive conclusions can be drawn from the existing literature with respect to superiority of general or neuraxial anesthesia or even regional anesthesia. May be the profits lie in the combination of techniques, a strategy, to overcome the risks of one and use the benefits of the other technique. From circumstantial evidence, it is most likely that the experience of the anesthetic and surgical team is one of the major determinants of perioperative complications independent from the individual anesthesia technique. 


\section{INTRODUCTION}

Lower limb peripheral arterial disease has a prevalence of about $30 \%$ in Europe and North America. The incidence is correlated to the risk of major cardiovascular events. Patients usually have generalized atherosclerosis affecting the cerebral, cardiac, splanchnic and peripheral circulation. ${ }^{1,2}$ The population at risk increases rapidly due to life style and aging. ${ }^{3}$ When analyzing available data, the group of patients undergoing vascular surgery is one of the populations with the highest incidence of perioperative complications, usually related to the underlying cardio-vascular pathology. The main complications are myocardial ischemia or infarction, decompensated heart failure and cerebrovascular complications like stroke and transitory ischemic attack.

The major objective in the management of patients with peripheral vascular disease is to maintain functional status, avoid amputation and reduce overall mortality from cardiovascular disease. Although medical therapy, smoking cessation, exercise therapy and secondary risk modification are cornerstones of therapy, revascularization is often needed.

Peripheral endovascular revascularization in combination with extensive medical therapy showed in a longitudinal follow-up study improvement of symptoms, improved overall functional status and a better quality of life up to 3 years ${ }^{4}$ after the procedure. There appears a trend to perform endovascular instead of surgical procedures among women, who are older and have more advanced disease at initial presentation. ${ }^{5}$ The relative amount of percutaneous transluminal angioplasty or stenting is increasing and often performed in an outpatient setting. ${ }^{5}$ Despite advancing endovascular technique a significant amount patients do need surgical revascularization. ${ }^{1,35}$ In elderly patients admitted for critical limb ischemia, patients treated with bypass surgery had a significantly better functional status than those who received endovascular procedures. ${ }^{6}$ Patients who require vascular surgery for peripheral arterial disease suffer from concomitant co-morbidity: chronic obstructive pulmonary disease (COPD), arterial hypertension, recent history of congestive heart failure, recent myocardial infarction, previous percutaneous coronary intervention (PTCA)/ heart surgery, critical limb ischemia diabetes, chronic renal failure and history of TIA or stroke ${ }^{3,5,7}$ (Table 1). Even nowadays, a 30 day mortality of $2.7 \%$ and major morbidity of $18.7 \%$ was reported in a cohort study using the National Surgical Quality Improvement Program (NSQIP) database which almost doubles in patients who underwent surgery for critical limb ischemia. ${ }^{7}$ Thus, the mortality risk for these patients is higher than reported after coronary artery bypass surgery. ${ }^{8}$ So anesthesia for these high risk surgical patients is still demanding and associated with a high rate of perioperative complications. The available evidence is still inconclusive about the ideal anesthetic technique. General anesthesia with or without endotracheal intubation, neuraxial (e.g. epidural and spinal) anesthesia, peripheral nerve blocks, and local anesthesia combined with monitored anesthesia care have been performed. The majority of studies is still underpowered and meta-analyses 
are performed based on studies of limited methodological quality which limits their value considerably. In the following chapters we discuss the available knowledge on different perioperative strategies and individual anesthetic techniques. Besides the choice of the individual technique, the planning of the perioperative period is of outstanding importance as a significant amount of complications occurs not in the immediate period but in the first 72 hours after surgery. Thus, careful preoperative evaluation (see below) and adequate planning of postoperative facilities, often in a monitored environment, is of value.

Table 1. Comorbidities of patients who require vascular surgery for peripheral arterial disease

\begin{tabular}{ll}
\hline Tobacco use & $40-53 \%^{3,7}$ \\
Alcohol use & $10-12 \%^{3}$ \\
Hypertension & $44-62 \%^{5}$ \\
Recent myocardial infarction & $2.7 \%^{7}$ \\
(Recent )History of congestive heart failure & $3.4-21 \%^{3,5,7}$ \\
Previous PTCA/ heart surgery & $46 \%^{7}$ \\
Critical limb ischemia & $48-74 \%^{5,7}$ \\
chronic renal failure & $4-14 \%^{5}$ \\
Diabetes & $29-54 \%^{3,5,7}$ \\
(severe)COPD & $12-21 \%^{3}$ \\
history of TIA/stroke & $6-16 \%^{3,7}$ \\
Bleeding disorder & $21^{7}$ \\
\hline
\end{tabular}

PTCA percutaneous coronary intervention, COPD chronic obstructive pulmonary disease, TIA transient ischemic attack

\section{Preoperative risk evaluation}

It has been demonstrated that careful preoperative evaluation has additional value in the multidisciplinary treatment approach. ${ }^{9}$ In most centers, the American Society of Anesthesiologists (ASA) classification is used to describe the perioperative risk.

However, in patients at risk for cardiovascular complications, a number of institutions use the revised Lee Score or Revised Cardiac Risk Index in addition. The revised Lee Score is a simple scoring system based on high risk surgery: intraperitoneal, intrathoracic or suprainguinal vascular procedures, ischemic heart disease, history of congestive heart failure, history of cerebrovascular disease, insulin therapy for diabetes, and elevated preoperative creatinin levels ( > $2 \mathrm{mg} / \mathrm{dl}$ or $176 \mathrm{mmol} / \mathrm{l}$ ). With the number of risk factors the risk of major cardiac events rises. ${ }^{10,}{ }^{11}$ Others use a patient risk stratification mainly based on functional status ${ }^{11,12}$ i.e. functional capacity (less or greater than 4 metabolic equivalents (METS) in combination with procedure related risk (low e.g. endoscopic or superficial procedure, intermediate, or high risk like 
aortic and major vascular surgery) and clinical factors like ischemic heart disease, preexisting heart failure, a history of cerebrovascular disease, pulmonary disease, diabetes and renal insufficiency. Preoperative (pro) B Natriuretic Peptide (( pro)-BNP) may also be used to identify high risk patients susceptible for major cardiovascular events. Additional preoperative testing by stress echocardiography, thallium scintigraphy, and coronary angiography should be reserved for patients with poor functional capacity, in which the results of these tests will substantially change the clinical management. ${ }^{12}$ Furthermore, as start of $\beta$-blockade immediately before surgery was associated with serious complications $^{13}$ a gradual start several weeks before the operation is needed if indicated. ${ }^{12}$ The need for an experienced team dealing with these patients was illustrated by the fact that in a recent survey in the Netherlands only $21 \%$ of the noncardiac surgical patients received the recommended preoperative non-invasive cardiac testing, however long term clinical outcomes were almost identical. ${ }^{14}$ This surprising finding could be due to additional value of involvement of experienced clinician in the care of these patients. ${ }^{9}$

\section{Perioperative monitoring}

For patients scheduled for peripheral bypass surgery anesthesia monitoring equipment usually consists of five- lead electrocardiogram with automated ST detection, noninvasive blood pressure monitoring and pulse oximetry. Advanced monitoring, like invasive arterial blood pressure monitoring, central venous pressure and transesophageal echography, is only indicated in high-risk patients, even for minor procedures. Currently a number of (non) invasive monitoring devices is available like esophageal Doppler monitoring and pulse contour cardiac output analysis. The available literature is inconclusive to support advanced hemodynamic monitoring.

\section{Postoperative care}

In the early postoperative phase, monitoring may be of outmost importance. As the preoperative (pro) BNP may be used to identify high risk patients, increased postoperative troponin levels after non-cardiac surgery are an independent predictor of mortality. ${ }^{15}$ In particular, only slight increases in troponin $\mathrm{T}$ are associated with a significant increase in perioperative morbidity and mortality. ${ }^{16,17}$ Therefore a number of centers use regular troponin T measurements in the first 72 hours after surgery and use these values to decide which patients need prolonged monitoring of vital signs and modification of postoperative treatment including rescue PTCA in a subset of patients. 


\section{General anesthesia}

General anesthesia with endotracheal intubation is the most common type of anesthesia (66-85\%) used in infrainguinal bypass surgery. ${ }^{3,7}$ General anesthesia usually offers optimal surgical conditions, in particular in long lasting procedures. However, there are several side effects associated with general anesthesia and controlled mechanical ventilation. In high risk patients, positive pressure ventilation may have an unfavorable effect on cardiac preload and output. General anesthesia compared to spinal anesthesia was associated with the highest rate of cardiac events, and postoperative pneumonia. ${ }^{3,7}$ Results regarding graft failure are conflicting. In the earliest study ${ }^{3}$ a higher graft failure rate was found in patients receiving general anesthesia. However in a more recent analysis from the same database with a total rate of graft failure of $7.4 \%$, general anesthesia was no longer associated with major surgical site complications including graft failure. ${ }^{7}$ The available randomized controlled trials are analyzed in a recent analysis from the Cochrane Collaboration. However, only 4 RCT's comparing these techniques are available, thus the authors concluded that no definitive conclusions can be drawn from the existing literature with respect to superiority of general or neuraxial anesthesia. There were no significant differences in mortality, myocardial infarction or the rate of lower limb amputations. ${ }^{18}$ Pneumonia was less common after spinal or epidural anesthesia, ${ }^{18}$ which is in accordance with a beneficial effect on postoperative pulmonary complications found in patients after open abdominal vascular surgery. ${ }^{19}$ So, it can be hypothesized that regional anesthesia has the potential to decrease the incidence of pulmonary complications.

In the above mentioned studies, general anesthesia combined with controlled mechanical ventilation was studied mainly with older long acting anesthetic drugs. Currently many procedures including carotid endarterectomy ${ }^{20}$ even for geriatric patients are performed safely in out-patient setting with modern short-acting anesthetics $^{21}$ in regional as well as general anesthesia using a supraglottic airway device (laryngeal mask), a technique which is known to reduce the perioperative stress response. $^{22}$ Furthermore general anesthesia can be enhanced by adding various regional anesthetic techniques including local wound infiltration.

In conclusion, no definitive conclusions can be drawn from the existing literature with respect to superiority of general or neuraxial anesthesia or even regional anesthesia. It seems that the performing anesthesia and surgery by an experienced team is one of the major determinants independent from the individual anesthesia technique.

\section{Regional anesthesia}

Regional anesthesia (RA) possesses several qualities including high efficacy and safety. In comparison with general anesthesia, thoracic epidural anesthesia in particular is 
associated with attenuated stress and pro-inflammatory response, increased coronary perfusion, improved tissue perfusion, optimal pain relief, increased gut motility and less inhibition of diaphragmatic activity. ${ }^{23}$ Moreover, an awake patient is able to communicate with caregivers.

Usually, regional anesthesia is divided in neuraxial and peripheral techniques. In the following chapter we discuss the advantages and disadvantages of both techniques.

\section{Spinal anesthesia, combined spinal-epidural anesthesia, and epidural} anesthesia.

Spinal anesthesia is a safe and effective technique which provides excellent analgesia, with limited side effects in relation to spread of the spinal block. In a randomized trial of 101 patients undergoing spinal or general anesthesia, there were no difference in cardiac mortality and morbidity despite a significantly higher incidence of arterial hypotension and bradycardia possibly due to sympaticolysis in the group receiving spinal anesthesia. However, patients undergoing general anesthesia more often developed arterial hypertension. There were no significant differences regarding postoperative confusion, need for further surgery during hospital stay or lower limb amputation, whereas a significantly higher incidence of postoperative pulmonary complications was observed in patients receiving general anesthesia (33\% versus $16 \%){ }^{24}$

Combining spinal with epidural anesthesia (CSE) may extend the duration of the block, provide postoperative analgesia and expand the applicability of the technique. The technique is compared to the other regional techniques not commonly used in vascular surgery.

Epidural anesthesia is another common anesthetic technique for lower limb revascularization. It has been shown to provide stable cardiovascular conditions ${ }^{25}$ comparable rates of cardiac and non-cardiac morbidity, ${ }^{26,27}$ with a lower rate of vascular graft failure at 7 but not at 30 days. ${ }^{27}$ The incidence of reoperations was comparable to general anesthesia. ${ }^{26}$ However, in patients with inadequate or failed regional anesthesia, (i.e technically unable to perform or insufficient to provide adequate anesthesia), the rate of in-hospital deaths (9.4\% versus $1.6 \%$ ) was increased compared to those with a successful regional or general anesthesia. Furthermore, in the same group with a failed regional anesthesia a trend towards increased rate of myocardial infarction and congestive heart failure was found, however the study was underpowered for this outcome. ${ }^{28}$ In a recent Cochrane review in patients undergoing abdominal aortic operations, epidural anesthesia demonstrated a better pain relief, shorter duration of postoperative tracheal intubation, a lower incidence of prolonged mechanical ventilation, myocardial infarction, gastric and renal complications, but no beneficial effects on mortality and other complications. ${ }^{19}$ Epidural analgesia was associated with a reduced incidence of chronic post-surgical pain 6 months after abdominal surgery. ${ }^{29}$ In earlier years, it was hypothesized that the use of epidural 
anesthesia results in a decreased incidence of postoperative neuropathic pain syndromes (phantom pain). However, no evidence exists supporting the use of preemptive analgesia to minimize the risk of chronic pain after amputation for critical ischemia of peripheral vascular disease. ${ }^{30}$ Currently, a multi-center study is addressing this issue (PLATA study). ${ }^{31}$

For all neuraxial techniques complexity and duration of the procedure may limit use in clinical practice and no randomized controlled trials exist addressing this issue.

\section{Systemic anticoagulants and regional anesthesia}

The continuous use of perioperative anticoagulants and platelet aggregation inhibitors is a cornerstone in the secondary prevention of cardiovascular complications in patients with atherosclerotic disease. Thus, it is highly recommended to continue this therapy throughout the perioperative period. ${ }^{32}$

The use of these medications may limit the use of neuraxial anesthesia in patients with peripheral arterial disease, (Table 2) as the anesthesia techniques require a time interval between the last dose of the anticoagulant and the puncture. Moreover, if a catheter technique is used, it is necessary to stop anticoagulation again, because there is a time interval needed before the catheter can be safely removed.

For heparin, unfractionated and low molecular weight, anti-Xa agents, direct thrombin inhibitors, and vitamin $\mathrm{K}$ antagonists the European Society of Anaesthesiology (ESA) guidelines recommend to postpone neuraxial blockade until two times elimination half time of the specific drug. If dabigatran is used, a neuraxial catheter technique is not recommended. $^{33,34}$ (Table 2 )

Platelet aggregation inhibitors are often continued during the perioperative phase, but the ESA guidelines strongly recommend a time interval between the administration of most platelet aggregation inhibitors and a neuraxial blockade. With the exception of acetylsalicylic acid, a drug free interval of 7 days pre-procedure is recommended. Restart of anti-platelet drugs must be delayed until removal of epidural catheters. (Table 2)

However the recommended time intervals only apply for patients with normal renal function. Besides patients with peripheral arterial disease often suffer from impaired renal function. Furthermore co-medication e.g. heparin use may also prolong safety intervals. $^{34}$ 
Table 2. Recommended time-intervals for anti-coagulants and neuraxial blockade by European Society of Anaesthesiology (ESA) ${ }^{29}$

\begin{tabular}{|c|c|c|c|c|}
\hline Drug class & Drug & $\begin{array}{l}\text { Laboratory } \\
\text { testing }\end{array}$ & $\begin{array}{l}\text { Time interval before } \\
\text { intervention }\end{array}$ & Time interval next dose \\
\hline \multirow[t]{3}{*}{ Heparin (P) } & Unfractionated & $\begin{array}{l}\text { Platelet count } \\
\text { ( } T>5 \text { days) }\end{array}$ & $4-6 h$ & $1 \mathrm{~h}$ \\
\hline & LMWH ( 1dd) & $\begin{array}{l}\text { Platelet count } \\
\text { ( } T>5 \text { days) }\end{array}$ & $12 \mathrm{~h}$ & $4 \mathrm{~h}$ \\
\hline & LMWH (2dd) & $\begin{array}{l}\text { Platelet count } \\
\text { ( } T>5 \text { days) }\end{array}$ & $24 h$ & $4 \mathrm{~h}$ \\
\hline \multirow[t]{2}{*}{ Heparin $(T)$} & Unfractionated & $\begin{array}{l}\text { Platelet count } \\
\text { ( } \mathrm{T}>5 \text { days), aPTT }\end{array}$ & $\begin{array}{l}\text { 4-6h iv } \\
8-12 \mathrm{~h} \mathrm{sc}\end{array}$ & $1 \mathrm{~h}$ \\
\hline & LMWH & $\begin{array}{l}\text { Platelet count } \\
\text { ( } T>5 \text { days })\end{array}$ & $24 h$ & $4 \mathrm{~h}$ \\
\hline \multirow[t]{6}{*}{ Anti-Xa agents } & Fondaparinux ( $\mathrm{P})$ & Anti X-a & $32-42 h$ & $6-12 h$ \\
\hline & Fondaparinux ( $\mathrm{T}$ ) & & contraindicated & \\
\hline & Idrabiotaparinux & & contraindicated & \\
\hline & Rivaroxiban & & extreme caution $22-26 \mathrm{~h}$ & $4-6 h$ \\
\hline & Apixaban & & extreme caution $26-30 \mathrm{~h}$ & $4-6 h$ \\
\hline & Danaparoid & & contraindicated & \\
\hline \multicolumn{2}{|c|}{ Direct thrombinDesirudin } & aPTT, ECT & 8-10h, avoid combinations & $2-4 h$ \\
\hline \multirow[t]{3}{*}{ inhibitors } & Lepirudin & aPTT, ECT & 8-10h, avoid combinations & $2-4 h$ \\
\hline & Argatroban & aPTT, ECT, ACT & $4 \mathrm{~h}$ & $2 \mathrm{~h}$ \\
\hline & Dabigatran & & contraindicated & \\
\hline $\begin{array}{l}\text { Vitamin } \mathrm{K} \\
\text { antagonists }\end{array}$ & $\begin{array}{l}\text { acenocoumarol, } \\
\text { phenprocoumon, } \\
\text { warfarin }\end{array}$ & INR $<1,4$ & & after catheter removal \\
\hline \multirow{7}{*}{$\begin{array}{l}\text { Platelet } \\
\text { aggregation } \\
\text { inhibitors }\end{array}$} & $\begin{array}{l}\text { Acetylsalicylic } \\
\text { acid/aspirin }\end{array}$ & & NA & NA \\
\hline & NSAID's & & NA & NA \\
\hline & Ticlopidin & & 10 days & after catheter removal \\
\hline & Clopidogrel & & 7 days & after catheter removal \\
\hline & Prasugel & & $7-10$ days & $6 \mathrm{~h}$ after catheter removal \\
\hline & Ticagrelor & & 5 days & $6 \mathrm{~h}$ after catheter removal \\
\hline & Cilostazol & & 5 days & $5 \mathrm{~h}$ after catheter removal \\
\hline $\begin{array}{l}\text { Glycoprotein } \\
\text { Ilb/IIla }\end{array}$ & Abciximab & & $\begin{array}{l}\text { used only in acute coronary } \\
\text { syndromes }\end{array}$ & $\begin{array}{l}\text { catheter removal } 48 \mathrm{~h} \\
\text { after dose }\end{array}$ \\
\hline inhibitors & $\begin{array}{l}\text { Tirofiban, } \\
\text { Eptifibatide }\end{array}$ & & & $\begin{array}{l}\text { catheter removal 8-10 } \mathrm{h} \\
\text { after dose }\end{array}$ \\
\hline
\end{tabular}

P prophylactic, T therapeutic, 1dd once daily, 2dd twice daily, NSAID non steroid anti-inflammatory drug, aPTT activated partial tromboplastin time, ECT ecarin clotting time, ACT activated clotting time, INR international normalized ratio, h hour, iv intravenous, sc subcutaneous, NA not applicable 


\section{Peripheral nerve blocks}

\section{General considerations}

Unlike the upper limb, the lower limb sensory innervation derives from two plexus, the lumbar and the sacral plexus, which makes a total anesthetic block more complex than for the upper limb. Due to this divergence in nerve supply it is almost always necessary to block more than one peripheral nerve to provide sufficient anesthesia for sufficient surgical anesthesia. A number of peripheral nerve blocks have been described for lower limb surgery e.g. the lumbar plexus block for infrainguinal artery bypass graft surgery and femoral-popliteal bypass surgery. ${ }^{35}$ However, femoral-popliteal bypass surgery can also be performed with a combined sciatic and femoral nerve block. ${ }^{36}$ Arterial bypass surgery below the knee can be performed with a combined popliteal and saphenous block. Although frequently published in case reports and case series ${ }^{35-37}$ there are no randomized controlled trials comparing peripheral nerve blocks with general, spinal or epidural anesthesia.

The use of ultrasound has increased the success rate of peripheral nerve blocks substantially ${ }^{38,39}$ and may increase safety of the techniques. ${ }^{34}$ Before the implementation of ultrasound, all lower plexus blocks were performed using an anatomical landmark or nerve-stimulation technique and required relatively large amounts of local anesthetics to obtain a safe and reliable block. These large amounts increase the risk of toxic plasma levels of local anesthetics resulting in potential life threatening systemic side effects like seizures, syncope and cardiac arrhythmias. ${ }^{39}$ Furthermore as these techniques were done without visualization of nervous or vascular structures, the risk of inadvertent vascular, intrafascicular or intraneural puncture was always present. However with the introduction of ultrasound guided nerve blocks in the last decades, good visibility of anatomical structures like muscles, vessels and nerves is possible now. Thus, a significant reduction in the amount of local anesthetics potentially reducing the incidence of side effects and avoiding potential complications is now possible. ${ }^{40}$ Furthermore, blockade of multiple nerves blocks can be performed and provide excellent anesthesia quality for infrainguinal vascular surgery. Especially in the elderly, where even lower volumes can be used, this is a potential advantage. ${ }^{41}$ (Table 3 )

Table 3. Lower limb blocks, volume local anesthetic needed

\begin{tabular}{ll}
\hline Peripheral nerve block & Volume local anesthetic needed \\
Lumbar plexus & $25-35 \mathrm{ml}$ \\
Femoral nerve & $10-20 \mathrm{ml}$ \\
Proximal Sciatic nerve & $15-20 \mathrm{ml}$ \\
Popliteal Sciatic nerve & $20-30 \mathrm{ml}$ \\
Saphenus nerve & $5-10 \mathrm{ml}$ \\
\hline
\end{tabular}

$\mathrm{ml}$ milliliters 
Guidelines for performing neuraxial blockades do not apply for superficial peripheral techniques like axillary plexus or femoral nerve block in patients using systemic anticoagulants as bleeding complications are less serious compared to neuraxial blockades. Even in the anticoagulated patient peripheral nerve blocks may seem an eligible choice due to the enhanced visibility with ultrasound and the possibility of adequate treatment in case of inadvertent vascular damage. However this is not the case for lumbar plexus block and paravertebral block. Retroperitoneal hematoma is considered a major complication. Therefore if these blocks are performed, the same precautions as for neuraxial blockade are applied. ${ }^{33}$

A number of peripheral nerve blocks ${ }^{35,36,42-45}$ have been described to perform infrainguinal vascular surgery. (Figure 1)

\section{Lumbar plexus block}

The lumbar plexus block or psoas compartment block is a variant of a paravertebral block. This block provides anesthesia and analgesia of the entire lumbar plexus including anterolateral and medial thigh, knee and saphenous nerve below the knee. In recumbent position, the anesthesiologist aims for the lumbar plexus via a paravertebral approach using a loss of resistance or nerve stimulation guided technique. It is the most complete block ventral side. (Figure 1) Major disadvantages include high volume of local anesthetic, possible epidural and spinal spread of local anesthetics, and possible retroperitoneal and spinal hematoma.

\section{Femoral nerve block}

The femoral nerve arises from the ventral rami of the third and fourth lumbar nerve roots and descends through the psoas major muscle to pass behind the inguinal ligament to enter the femoral triangle which is formed by the inguinal ligament, the sartorius muscle and the adductor longus muscle. The nerve supplies sensory innervation to the anterior aspect of the thigh and knee. (Figure 1) The lateral aspect of the leg is supplied by the lateral cutaneous nerve which is not anesthetized by a sole femoral nerve block and is located more lateral in proximity of the anterior superior iliac spine.

There are several approaches to block the femoral nerve. The ultrasound guided technique, where the nerve is visualized alongside the vascular structures in the inguinal canal, may be the safest method, since nerve and vascular structures are directly visualized. The femoral nerve is blocked after penetrating the fascia lata and fascia iliaca and injecting local anesthetic solution around the nerve to create a pool of local anesthetic solution around the nerve. The femoral nerve block is suitable as a continuous technique. 


\section{Lumbar plexus block}
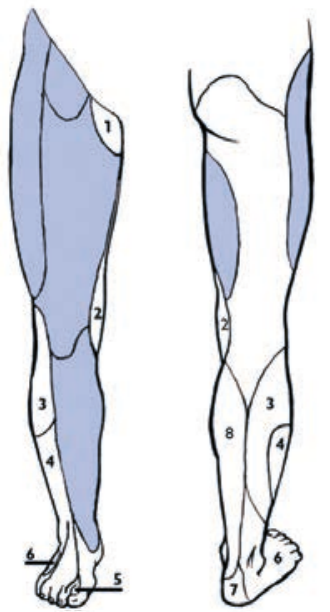

Combined Sciaticl Femoral Nerve block

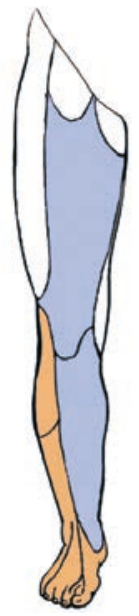

\section{Femoral nerve block}
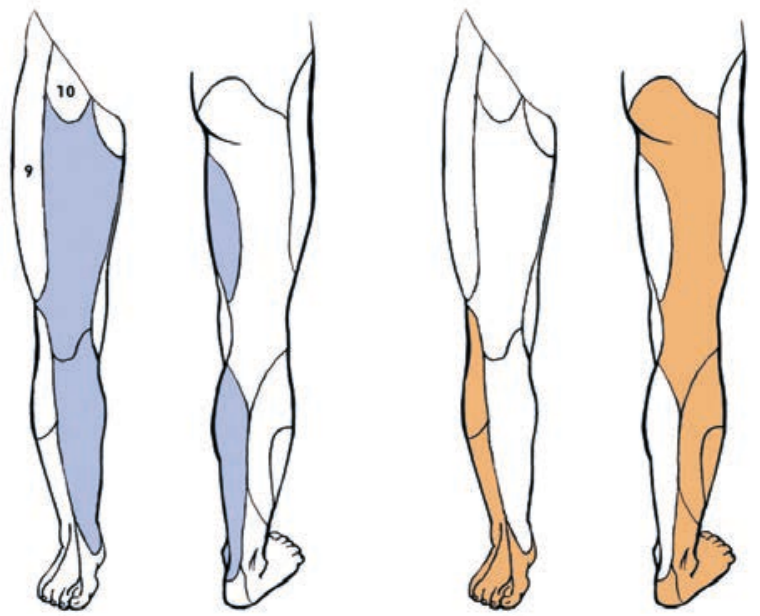

Sciatic nerve block

- subgluteal approachı
Sciatic nerve block - popliteal approach

\section{Saphenus nerve block}

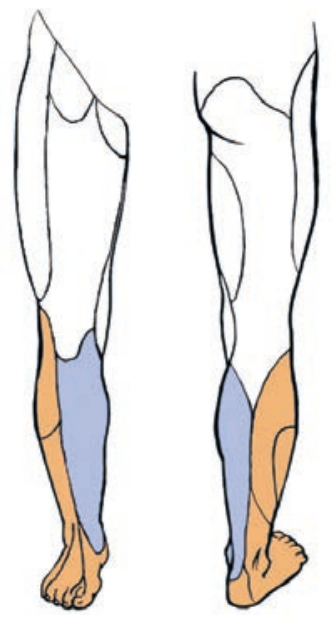

Numbers represent:

1 Ilioinguinal nerve

2 Obturator nerve

3 Common peroneal nerve

4 Superficial peroneal nerve

5 Deep peroneal nerve

(webspace between digitus 1 and 2)

6 Sural nerve

7 Tibial nerve

8 Saphenus nerve

9 Lateral cutaneous nerve

10 Genitofemoral nerve

Figure 1. Lower limb blocks: nerve supply and dermatomes anesthetised White areas are not blocked by the chosen technique.

When anesthesia of the lateral or medial aspect of the thigh is also required a three-inone block can be performed. This block, usually performed with a high volume technique requires three separate injections at the lateral cutaneous nerve of the thigh, the femoral nerve and the obturator nerve. 
Sciatic nerve block (subgluteal versus popliteal approach)

The sciatic nerve is the largest peripheral nerve in the human body and arises from the sacral nerve roots. A sciatic nerve block results in anesthesia of the skin of the posterior aspect of the thigh, hamstring, and biceps femoris muscles, part of the hip and knee joint and the entire leg below the knee with the exception of the skin of the medial aspect of the lower leg. (Figure 1) The sciatic nerve can be easily visualized by ultrasound in the lateral decubitus or prone position. Using a curved ultrasound probe with a frequency of $2-8 \mathrm{MHz}$ the nerve is usually visualized at the subgluteal crest between 5 and 11 centimeters depth. The nerve can be followed all the way to the popliteal crest and can be blocked at every level. Alternatively, the anterior approach have been described. However, this approach has not reached wide acceptance due to the fact that the posterior femoral cutaneous nerve, cannot be not blocked simultaneously. ${ }^{43}$ Besides the anterior part is not easily visible by ultrasound, which reduces the safety of the procedure.

For surgery at the lower leg, the sciatic nerve can also be block at the level of the popliteal fossa just before dividing into the tibial and common peroneal nerve. Ultrasound guidance offers a good visualization of the sciatic nerve in relation to the vascular structures and posterior muscles of the thigh. The nerve is usually located between the biceps femoris and semimembranosus muscle. A popliteal block is an easy block to be performed.

\section{Saphenus nerve block}

The saphenus nerve, a part of the femoral nerve which supplies the medial aspect of the calf. In case of surgery of the lower limb a combination of a sciatic nerve block at the popliteal fossa and saphenous nerve block are required to provide adequate anesthesia of the lower leg. The saphenous nerve runs alongside the femoral artery throughout the thigh. It contains sensory nerves only, so a stimulation based technique will not provoke any motor response. However, the nerve usually can be easily visualized by ultrasound.

\section{Local anesthesia}

There are no randomized controlled trials comparing local anesthesia versus general anesthesia or local anesthesia versus regional anesthesia for peripheral vascular surgery. A recent study showed that infra-renal aortic endovascular repair was feasible under local anesthesia strategy in $75 \%$ of the patients. ${ }^{46}$

In general local infiltration alone or in combination with a peripheral nerve block has been considered for patients not eligible for standard anesthesia, ${ }^{44,45}$ and successfully applied in a case series of 86 patients. ${ }^{47}$ However, relatively high amounts $(80-100 \mathrm{ml})$ of local anesthetics with additional $40 \mathrm{ml}$ for harvesting arm vein are needed. ${ }^{45}$ Accompanied by intravenous sedation, the injection of $0.5 \%$ or $1.0 \%$ lidocaine in 
combination with additional sedation at the moment of painful stimuli during various infrainguinal reconstruction procedures were performed. Conversion to general anesthesia was required in 4 patients (5\%), whereas patient discomfort and disorientation occurred in 3 patients. Furthermore a mortality rate of $2 \%$ with $2 \%$ non-fatal myocardial infarction was reported. ${ }^{47}$

A matter of concern remains that inadequate regional anesthesia induce patients stress and may affect outcome. ${ }^{28,47}$ On the other hand general anesthesia for procedures that can readily be performed under local anesthesia may add an additional risk resulting in an increase in mortality. ${ }^{48}$ This implies that the need for additional sedation during monitored anesthesia care and thus the presence of an experienced anesthesiologist a prerequisite for the safe conduction of these procedures.

\section{Emergency surgery}

For emergency surgery the same principles apply. However in the emergency situation other factors may determine the anesthetic technique of choice e.g. is there an acute bleeding or ischemic situation. Moreover, the coagulation status is a matter of discussion. Moreover, even in big hospitals, the availability of anesthesiologists familiar with all local anesthesia techniques usually cannot be guaranteed during a 24/7 period.

\section{CONCLUSION}

Based on the current literature no evidence is available to consider one technique superior to another or to recommend a specific anesthetic strategy. So, the choice of anesthetic technique must be made on individual risk-benefit estimations, patient and surgical preferences and anesthetic skills to combine the advantages of general and regional anesthesia in peripheral vascular surgery. Moreover, in these patients, the individual comorbidity of the patients and in particular the use of anticoagulant medication has a significant impact on the choice of the anesthetic technique. 


\section{REFERENCES}

1. Allaqaband S, Kirvaitis R, Jan F, Bajwa T. Endovascular Treatment of Peripheral Vascular Disease. Curr Probl Cardiol 2009, 34(9):359-476.

2. Mourad J-J, Cacoub P, Collet J-P, Becker F, Pinel J-F, Huet D, Sevestre-Pietri M-A, Priollet P. Screening of unrecognized peripheral arterial disease (PAD) using ankle-brachial index in high cardiovascular risk patients free from symptomatic PAD. J Vasc Surg 2009, 50(3):572-580.

3. Singh N, Sidawy AN, Dezee K, Neville RF, Weiswasser J, Arora S, Aidinian G, Abularrage C, Adams E, Khuri S et al. The effects of the type of anesthesia on outcomes of lower extremity infrainguinal bypass. J Vasc Surg 2006, 44(5):964-968; discussion 968-970.

4. Safley DM, House JA, Laster SB, Daniel WC, Spertus JA, Marso SP. Quantifying improvement in symptoms, functioning, and quality of life after peripheral endovascular revascularization. Circulation 2007, 115(5):569-575.

5. Lo RC, Bensley RP, Dahlberg SE, Matyal R, Hamdan AD, Wyers M, Chaikof EL, Schermerhorn ML. Presentation, treatment, and outcome differences between men and women undergoing revascularization or amputation for lower extremity peripheral arterial disease. J Vasc Surg 2013: [Epub ahead of print].

6. Vogel TR, Petroski GF, Kruse RL. Functional status of elderly adults before and after interventions for critical limb ischemia. J Vasc Surg 2013: [Epub ahead of print].

7. LaMuraglia GM, Conrad MF, Chung T, Hutter M, Watkins MT, Cambria RP. Significant perioperative morbidity accompanies contemporary infrainguinal bypass surgery: an NSQIP report. J Vasc Surg 2009, 50(2):299-304, 304 e291-294.

8. Afilalo J, Rasti M, Ohayon SM, Shimony A, Eisenberg MJ. Off-pump vs. on-pump coronary artery bypass surgery: an updated meta-analysis and meta-regression of randomized trials. European heart journal 2012, 33(10):1257-1267.

9. Flynn BC, Silvay G. Value of specialized preanesthetic clinic for cardiac and major vascular surgery patients. The Mount Sinai journal of medicine, New York 2012, 79(1):13-24.

10. Lee TH, Marcantonio ER, Mangione CM, Thomas EJ, Polanczyk CA, Cook EF, Sugarbaker DJ, Donaldson MC, Poss R, Ho KK et al. Derivation and prospective validation of a simple index for prediction of cardiac risk of major noncardiac surgery. Circulation 1999, 100(10):1043-1049.

11. Vernick W, Fleisher LA. Risk stratification. Best practice \& research Clinical anaesthesiology 2008, 22(1):121.

12. Manley AM, Reck SE. Patients with vascular disease. The Medical clinics of North America 2013, 97(6):1077-1093.

13. Devereaux PJ, Yang H, Yusuf S, Guyatt G, Leslie K, Villar JC, Xavier D, Chrolavicius S, Greenspan L, Pogue J et al. Effects of extended-release metoprolol succinate in patients undergoing non-cardiac surgery (POISE trial): a randomised controlled trial. Lancet 2008, 371(9627):1839-1847.

14. Hoeks SE, Scholte op Reimer WJ, Lenzen MJ, van Urk H, Jorning PJ, Boersma E, Simoons ML, Bax JJ, Poldermans D. Guidelines for cardiac management in noncardiac surgery are poorly implemented in clinical practice: results from a peripheral vascular survey in the Netherlands. Anesthesiology 2007, 107(4):537-544.

15. Levy M, Heels-Ansdell D, Hiralal R, Bhandari M, Guyatt G, Yusuf S, Cook D, Villar JC, McQueen M, McFalls $E$ et al. Prognostic value of troponin and creatine kinase muscle and brain isoenzyme measurement after noncardiac surgery: a systematic review and meta-analysis. Anesthesiology 2011, 114(4):796-806.

16. van Waes JA, Nathoe HM, de Graaff JC, Kemperman H, de Borst GJ, Peelen LM, van Klei WA. Myocardial injury after noncardiac surgery and its association with short-term mortality. Circulation 2013, 127(23):2264-2271.

17. Devereaux PJ, Chan MT, Alonso-Coello P, Walsh M, Berwanger O, Villar JC, Wang CY, Garutti RI, Jacka MJ, Sigamani A et al. Association between postoperative troponin levels and 30-day mortality among patients undergoing noncardiac surgery. JAMA 2012, 307(21):2295-2304. 
18. Barbosa FT, Juca MJ, Castro AA, Cavalcante JC. Neuraxial anaesthesia for lower-limb revascularization. Cochrane Database Syst Rev 2013, 7:CD007083.

19. Nishimori M, Low JH, Zheng H, Ballantyne JC. Epidural pain relief versus systemic opioid-based pain relief for abdominal aortic surgery. Cochrane Database Syst Rev 2012, 7:CD005059.

20. Doberstein CE, Goldman MA, Grossberg JA, Spader HS. The safety and feasibility of outpatient carotid endarterectomy. Clinical neurology and neurosurgery 2012, 114(2):108-111.

21. Ornek D, Metin S, Deren S, Un C, Metin M, Dikmen B, Gogus N. The influence of various anesthesia techniques on postoperative recovery and discharge criteria among geriatric patients. Clinics 2010, 65(10):941-946.

22. Kahl M, Eberhart LH, Behnke H, Sanger S, Schwarz U, Vogt S, Moosdorf R, Wulf H, Geldner G. Stress response to tracheal intubation in patients undergoing coronary artery surgery: direct laryngoscopy versus an intubating laryngeal mask airway. J Cardiothorac Vasc Anesth 2004, 18(3):275-280.

23. Carli F, Kehlet H, Baldini G, Steel A, McRae K, Slinger P, Hemmerling T, Salinas F, Neal JM. Evidence basis for regional anesthesia in multidisciplinary fast-track surgical care pathways. Reg Anesth Pain Med 2011, 36(1):63-72.

24. Cook PT, Davies MJ, Cronin KD, Moran P. A prospective randomised trial comparing spinal anaesthesia using hyperbaric cinchocaine with general anaesthesia for lower limb vascular surgery. Anaesth Intensive Care 1986, 14(4):373-380.

25. Damask MC, Weissman C, Todd G. General versus epidural anesthesia for femoral-popliteal bypass surgery. J Clin Anesth 1990, 2(2):71-75.

26. Christopherson R, Beattie C, Frank SM, Norris EJ, Meinert CL, Gottlieb SO, Yates H, Rock P, Parker SD, Perler BA et al. Perioperative morbidity in patients randomized to epidural or general anesthesia for lower extremity vascular surgery. Perioperative Ischemia Randomized Anesthesia Trial Study Group. Anesthesiology 1993, 79(3):422-434.

27. Dodds TM FM, Walsh DB, , Surgenor SD MD, Mark P. Yeager MP. Clinical Outcomes after Lower Extremity Revascularization: A Comparison of Epidural and General Anesthesia. J App Res 2007, 7(3):238-249.

28. Bode RH, Jr., Lewis KP, Zarich SW, Pierce ET, Roberts M, Kowalchuk GJ, Satwicz PR, Gibbons GW, Hunter JA, Espanola CC. Cardiac outcome after peripheral vascular surgery. Comparison of general and regional anesthesia. Anesthesiology 1996, 84(1):3-13.

29. Bouman EA, Theunissen M, Bons SA, van Mook WN, Gramke HF, van Kleef M, Marcus MA. Reduced Incidence of Chronic Postsurgical Pain after Epidural Analgesia for Abdominal Surgery. Pain practice : the official journal of World Institute of Pain 2013: [Epub ahead of print].

30. Ypsilantis E, Tang TY. Pre-emptive analgesia for chronic limb pain after amputation for peripheral vascular disease: a systematic review. Annals of vascular surgery 2010, 24(8):1139-1146.

31. Lirk P, Stadlbauer KH, Hollmann MW. ESA Clinical Trials Network 2012: PLATA--Prevention of Phantom Limb Pain After Transtibial Amputation: randomised, double-blind, controlled, multicentre trial comparing optimised intravenous pain control versus optimised intravenous pain control plus regional anaesthesia. Eur J Anaesthesiol 2013, 30(5):202-204.

32. Chassot PG, Marcucci C, Delabays A, Spahn DR. Perioperative antiplatelet therapy. American family physician 2010, 82(12):1484-1489.

33. Gogarten W, Vandermeulen E, Van Aken H, Kozek S, Llau JV, Samama CM, European Scoeity of A. Regional anaesthesia and antithrombotic agents: recommendations of the European Society of Anaesthesiology. Eur J Anaesthesiol 2010, 27(12):999-1015.

34. Kozek-Langenecker SA. New anticoagulants: perioperative considerations. Wiener medizinische Wochenschrift (1946) 2011, 161(3-4):63-67.

35. Basagan-Mogol E, Turker G, Yilmaz M, Goren S. Combination of a psoas compartment, sciatic nerve, and T12-L1 paravertebral blocks for femoropopliteal bypass surgery in a high-risk patient. J Cardiothorac Vasc Anesth 2008, 22(2):337-339.

36. Yazigi A, Madi-Gebara S, Haddad F, Hayeck G, Tabet G. Combined sciatic and femoral nerve blocks for infrainguinal arterial bypass surgery: a case series. J Cardiothorac Vasc Anesth 2005, 19(2):220-221. 
37. Yazigi A, Madi-Gebara S, Haddad F, Hayeck G, Tabet G. Intraoperative myocardial ischemia in peripheral vascular surgery: general anesthesia vs combined sciatic and femoral nerve blocks. J Clin Anesth 2005, 17(7):499-503.

38. Danelli G, Fanelli A, Ghisi D, Moschini E, Rossi M, Ortu A, Baciarello M, Fanelli G. Ultrasound vs nerve stimulation multiple injection technique for posterior popliteal sciatic nerve block. Anaesthesia 2009, 64(6):638-642.

39. Jeng CL, Torrillo TM, Rosenblatt MA. Complications of peripheral nerve blocks. Br J Anaesth 2010, 105 Suppl 1:i97-107.

40. Casati A, Baciarello M, Di Cianni S, Danelli G, De Marco G, Leone S, Rossi M, Fanelli G. Effects of ultrasound guidance on the minimum effective anaesthetic volume required to block the femoral nerve. Br J Anaesth 2007, 98(6):823-827.

41. Pavicic Saric J, Vidjak V, Tomulic K, Zenko J. Effects of age on minimum effective volume of local anesthetic for ultrasound-guided supraclavicular brachial plexus block. Acta Anaesthesiol Scand 2013, 57(6):761-766.

42. Hadzic A.Hadzic's Peripheral Nerve Blocks and Anatomy for ultrasound-guided regional anesthesia. New York: MC Graw-Hill Companies, Inc; 2012.

43. Murray JM, Derbyshire S, Shields MO. Lower limb blocks. Anaesthesia 2010, 65 Suppl 1:57-66.

44. Atkinson CJ, Ramaswamy K, Stoneham MD. Regional anesthesia for vascular surgery. Seminars in cardiothoracic and vascular anesthesia 2013, 17(2):92-104.

45. Mackay CA, Razik W, Simms MH. Local anaesthetic for lower-limb revascularization in high-risk patients. Br J Surg 1997, 84(8):1096-1098.

46. Geisbusch P, Katzen BT, Machado R, Benenati JF, Pena C, Tsoukas Al. Local anaesthesia for endovascular repair of infrarenal aortic aneurysms. European journal of vascular and endovascular surgery : the official journal of the European Society for Vascular Surgery 2011, 42(4):467-473.

47. Barkmeier LD, Hood DB, Sumner DS, Mansour MA, Hodgson KJ, Mattos MA, Ramsey D. Local anesthesia for infrainguinal arterial reconstruction. American journal of surgery 1997, 174(2):202-204.

48. Bakker EJ, van de Luijtgaarden KM, van Lier F, Valentijn TM, Hoeks SE, Klimek M, Verhagen HJM, Stolker RJ. General Anaesthesia is Associated with Adverse Cardiac Outcome after Endovascular Aneurysm Repair. European journal of vascular and endovascular surgery : the official journal of the European Society for Vascular Surgery 2012, 44(2):121-125. 



\section{CHAPTER 3}

\section{Reduced incidence of chronic post-surgical pain after epidural analgesia for abdominal surgery}

Esther A. Bouman, Maurice Theunissen, Sabrina A. Bons, Walther N. van Mook, Hans-F. Gramke, Maarten van Kleef, Marco A. Marcus

Pain practice 2014;14:E76-84. 


\section{ABSTRACT}

Background: Chronic post-surgical pain (CPSP) is a common complication of surgery with a high impact on quality of life. Peripheral and central sensitization caused by enhanced and prolonged afferent nociceptive input are considered important mechanisms for CPSP. This case-control study investigated whether epidural analgesia, by blocking afferent input, can reduce the incidence of CPSP after open abdominal surgery.

Methods: Six months after surgery, Short-Form-36 Health Survey (SF-36) pain scores, possible predictors of chronic pain, and quality of life were assessed. Patients treated with epidural analgesia in combination with general anesthesia (epidural group, $\mathrm{N}=51$ ) were compared to patients receiving general anesthesia alone (general anesthesia group, $\mathrm{N}=50$ ). Multivariate analysis was performed by logistic regression analysis.

Results: 26 (25.7\%) patients experienced chronic pain, 9 in the epidural group (17.6\%), 17 in the general anesthesia group (34\%), crude odds ratio (OR) 0.42 (95\% confidence interval ( $\mathrm{Cl}$ ) 0.16-1.05). After adjustment for the most prominent predictors of CPSP, such as age, sex, pre-operative pain and acute postoperative pain, the OR for chronic pain in the epidural group was 0.19 (95\% Cl 0.05-0.76).

Patients with CPSP reported a significantly lower quality of life compared to patients without CPSP (SF-36 total score median (IQR) 39.2 (27.2-56.7) versus 84.3 (69.9-92.5, $p<0.001)$ and a lower level of long time global perceived recovery (70.0\% (50.0-80.0) versus $90.0 \%$ (80.0-100.0), $p<0.001)$.

Conclusion: Chronic post-surgical pain occurs in a significant number of patients six months after open abdominal surgery. Postoperative epidural analgesia may reduce the incidence of CPSP after abdominal surgery. 


\section{INTRODUCTION}

In the last decade there has been growing interest in the occurrence, development, and prevention of chronic post-surgical pain (CPSP). CPSP is a serious complication of surgery with a potentially high impact on the quality of daily life. ${ }^{1-3}$ It has been defined as pain related to a surgical procedure, extending beyond the time course of the natural healing process and persisting for at least two months. Other medical causes (e.g. recurrent malignancy or chronic infection) for persisting pain as well as a pre-existing pain condition should be ruled out. ${ }^{4} \mathrm{~A}$ high incidence of CPSP is reported after a broad spectrum of surgical procedures e.g. mastectomy 20 - 50\%, amputation $50-85 \%$, cardiac surgery 30 - 55\%, hip replacement $12 \%$, caesarean section $6 \%$, thoracotomy 5 $65 \%$ and the chronic pain level is severe in $2-10 \%$ of the patients. ${ }^{5,6}$ For abdominal surgery in particular the estimated risk of CPSP is about 20\%. (18\% for gastrointestinal surger, $^{3} 5-32 \%$ for hysterectomies $\left.{ }^{7-9}\right)$. For laparoscopic procedures it may be less $(5 \%$ for laparoscopic cholecystectomy ${ }^{10}$ ).

Epidural analgesia has become a popular analgesic technique for abdominal surgery with high efficacy and safety. However, the debate whether epidural analgesia improves outcome has not been settled. ${ }^{11}$ With regard to development of CPSP insufficiently controlled acute postoperative pain is one of the best predictors of CPSP. ${ }^{12}$ Furthermore, epidural analgesia has proven to be effective in perioperative pain management and is superior to systemic intravenous analgesia with opioids. ${ }^{13-16}$ Peripheral and central sensitization are considered important mechanisms in the etiology of CPSP. ${ }^{17,18}$ By blocking afferent input before the surgical trauma, sensitization and CPSP might be prevented. $^{19,20}$

Only a few reports exist on the effect of epidural analgesia in relation to the development of CPSP. In a study with a small group undergoing thoracic surgery, comparison of postoperative epidural analgesia alone to postoperative analgesia accompanied by intraoperative epidural analgesia showed epidural analgesia administered before surgery reduced the incidence of CPSP. ${ }^{21}$ For abdominal surgery, a randomized controlled study with 85 patients showed a beneficial effect on acute postoperative and long-term pain up to 12 months after surgery in patients who received perioperative epidural analgesia. ${ }^{22}$ However, all patients received combined therapy with ketamine intravenously. In a recent Cochrane review it was concluded that for thoracotomy epidural anesthesia may reduce the risk for CPSP six months after surgery. However, this conclusion cannot be extended to other surgical interventions or regional anesthesia techniques. ${ }^{23}$

The present case-control study was designed to investigate whether the use of epidural analgesia in combination with general anesthesia can reduce the incidence of CPSP in open abdominal surgery six months after surgery. Furthermore, to determine which patients may benefit most from the procedure an analysis of predictors was performed. 


\section{METHODS}

\section{Design}

In this case-control study, consecutive elective open abdominal surgery patients who either received 'epidural analgesia in combination with general anesthesia' or 'general anesthesia alone' were compared. This study was approved by the local Medical Ethics Committee and written informed consent from all participants was obtained.

\section{Patients}

The study was based on the database of a previously performed cohort study on inhospital surgical patients. ${ }^{12,24,25}$ All patients scheduled for elective surgery under general or regional anesthesia in the Maastricht University Medical Center+ (MUMC+) were enrolled. Exclusion criteria were: age under 18 years, need for acute surgery, cardiac surgery or caesarean section, need for surgery requiring postoperative mechanical ventilation, and communicative or cognitive limitations interfering with pain measurements. Unless contraindicated, according to hospital guidelines, epidural anesthesia was offered during the preoperative assessment as an adjunct to general anesthesia to all patients undergoing open abdominal surgery.

Patients with epidural analgesia received bupivacaine $0.125 \%$ 4-8 $\mathrm{mL} \cdot \mathrm{h}^{-1}$ with sufentanil $1 \mu \mathrm{g} \cdot \mathrm{mL}^{-1}$ added for patients younger than 70 years of age, according to the hospital protocol. In case of inadequate pain reduction (Visual Analogue Score $>4$ ) the epidural catheter was tested with a bolus dose of $5 \mathrm{~mL}$ lidocaine $1 \%$ and the maintenance dose was increased by $2 \mathrm{~mL} . \mathrm{h}^{-1}$. In case of failure, the treatment was individually adapted according to instructions provided by the staff anesthesiologist in charge of the acute pain service. In case of catheter dislocation or ongoing malfunctioning the catheter was removed. In general, the epidural catheter was removed on the second postoperative day, but if required the treatment was continued.

Patients with patient controlled intravenous analgesia ( $\mathrm{PCIA}$ ) using piritramide started with a bolus dose of $1 \mathrm{mg}$, lock-out interval of 5 minutes and no background infusion. In case of inadequate pain relief the bolus dose was increased.

All patients were managed according to the institutional perioperative pain protocol. All patients received paracetamol (acetaminophen) $1000 \mathrm{mg}$, four times daily, combined with non-steroidal anti-inflammatory drugs (NSAIDs) unless contraindicated on regular basis. In case of severe postoperative pain intravenous loading with piritramide was provided at the recovery room. This analgesic regimen was supplemented by intramuscular injections of piritramide $(0.1-0.3 \mathrm{mg} / \mathrm{kg})$, six times daily, on an "on demand" basis, if neither a continuous regional analgesia technique nor PCIA was applied.

Data collection started the day before surgery and was continued until Day 4 after surgery. Patients were asked to complete questionnaires and to keep a pain diary (pain 
VAS three times a day). During hospital stay patients were visited two times a day by members of the study team. Six months after surgery, patients received a questionnaire booklet by post for follow-up data collection. After 14 days, in case of no reply, another questionnaire was send.

For follow-up analysis 625 participants were available of whom 51 patients received epidural analgesia in combination with general anesthesia (epidural group) for abdominal surgery. All were selected as the index group. The reference group was extracted from the same cohort and existed of 133 patients who all received open abdominal surgery under general anesthesia. From this group 50 patients were matched by type of surgery, sex and age (general anesthesia group). None of the patients in the epidural or general anesthesia group underwent other surgical procedures during the follow-up period. (Figure 1)

\section{Baseline data and predictors of CPSP}

Data were collected regarding sex, age, weight, ASA classification, pre-operative pain using the Short-Form-36 Health Survey (SF-36) bodily pain subscale, type of surgery, malignancy, duration of surgery, type of analgesia, medication use, adverse effects and length of hospital stay. The effect of several known potential risk factors of CPSP was evaluated. ${ }^{5,6,26,27}$

Postoperative pain scores at rest, movement and when coughing were recorded 3 times a day using the Visual Analogue Scale (VAS), ranging from 0 to 100 , up to Day $4 .^{28}$ Maximum VAS was defined as the highest VAS score (at rest, movement, or when coughing) per day during the first four postoperative days.

\section{Primary outcome measure: pain at six months}

Pain at follow-up after six months was assessed using the SF-36 bodily pain subscale. ${ }^{29}$ Pain intensity is measured on a 6-point scale from 1 (no pain) to 6 (very severe pain), and pain interference with normal work on a 5-point interference scale from 1 (no interference) to 5 (extremely) during the last four weeks. The SF-36 bodily pain subscale is recalculated according to the SF-36 manual to a scale ranging from 0 to100 ( 0 = very severe pain, $100=$ no pain). Chronic pain is defined as SF-36 bodily pain subscale score of 60 or less. This cut-off value of 60 is analogue to the performance indicator "postoperative pain" used by the Dutch Health Care Inspectorate in $2006{ }^{30}$

\section{Secondary outcome measures}

Quality of life was assessed using the SF-36. ${ }^{29}$ Furthermore, long-term recovery was estimated with an 1-item Global Surgical Recovery index (GSR) ranging from 0 to $100 \%{ }^{31}$ 


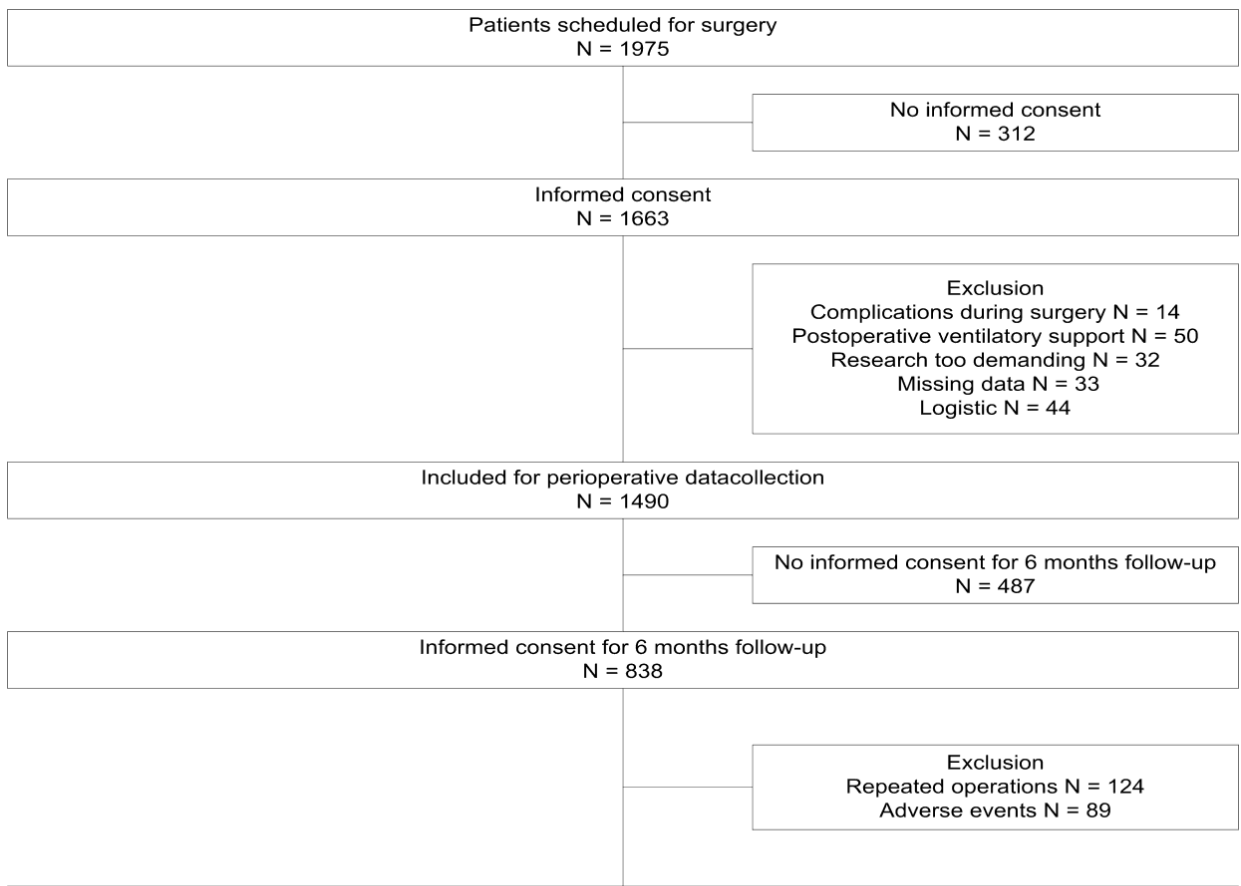

Cases available for 6 months evaluation $\mathrm{N}=625$

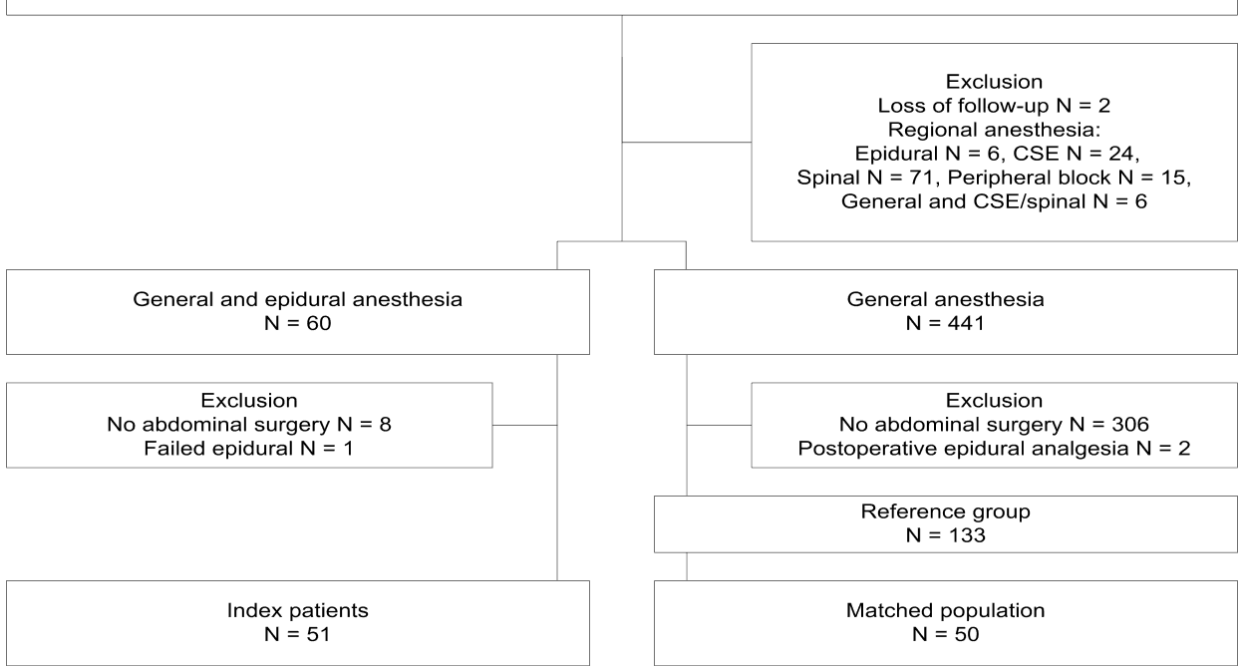

Figure 1. Flow chart of inclusion procedure 


\section{Statistical analysis}

Baseline characteristics were analyzed using Student's-t distribution, Fisher's exact test, Chi-squared test, and the Mann-Whitney $U$ test. Odds ratios (OR) for the development of CPSP were obtained by bivariate logistic regression analysis with a dichotomized SF36 bodily pain subscale score using a cut-off point of 60 as dependent variable and baseline characteristics as independent variables.

To evaluate whether the use of epidural analgesia combined with general anesthesia reduces the incidence of CPSP, a stepwise logistic multivariate analysis was performed. Variables that showed a bivariate association with outcome $(p<0.1)$ were considered for multivariate analysis. Adjustment for potential differences in baseline characteristics was performed. Variables that did not contribute to a better model fit (Nagelkerke $\mathrm{R}^{2}$ and block $\left.\chi^{2}(\mathrm{df})\right)$ were not entered in the final model. For multivariate analyses a $p$ value $<0.05$ was considered as statistically significant. Analyses were performed with the Statistical Package for the Social Sciences (SPSS version 16, Chicago, Illinois, USA).

\section{RESULTS}

\section{Baseline data}

Patient characteristics of both groups are shown in Table 1. Open general surgical, gynecological or urological abdominal procedures were performed. There we no significant differences between groups regarding age, sex, weight and ASA category as well as levels of pre-operative pain (VAS baseline and SF-36 pain). The pain scores (maximum VAS) on the day of surgery (Day 0) and the first postoperative day (Day 1) were significantly lower in the epidural group compared to the general anesthesia group. $(p<0.001)$ (Figure 2)

\section{Primary outcome: pain at six months}

Overall, $25.7 \%$ of the participants suffered from CPSP (SF-36 bodily pain score of 60 or less after 6 months): 9 patients (17.6\%) in the epidural group and 17 patients (34\%) in the general anesthesia group. (crude odds ratio 0.42 (95\% confidence interval (Cl) $0.16-$ 1.05)) (Table 2)

Unadjusted logistic regression analysis with SF-36 bodily pain at 6-month follow-up as the dependent variable identified the following possible predictors: pre-operative SF36 bodily pain $\leq 60$, maximum VAS $\geq 40$ on Day 0 , maximum VAS $\geq 40$ on Day 2 , maximum VAS $\geq 40$ on Day 4 , age $\geq 70$ years, ASA III, and complications as reported by the patient. No relationship was found regarding malignancy, type, duration of surgery, or length of hospital stay. The main predictors are shown in Table 2. 


\section{CHAPTER 3}

Table 1. Baseline data

\begin{tabular}{|c|c|c|}
\hline Patient characteristics & $\begin{array}{l}\text { Epidural } \\
(N=51)\end{array}$ & $\begin{array}{l}\text { General anesthesia } \\
(\mathrm{N}=50)\end{array}$ \\
\hline Age (years) & $57.2(12.7)$ & $52.7(14.8)$ \\
\hline Sex M / F & $23 / 28$ & $14 / 36$ \\
\hline Weight (kilograms) & $73.7(9.7)$ & $76.0(18.8)$ \\
\hline ASA I / II / III & $12 / 28 / 11$ & $18 / 19 / 13$ \\
\hline SF-36 pain baseline & $76(50-100)$ & $69(45-100)$ \\
\hline VAS pain baseline & $1(0-3)$ & $2(0-11)$ \\
\hline \multicolumn{3}{|l|}{ Type of surgery: } \\
\hline Hysterectomy & 11 & 13 \\
\hline Gastro-intestinal & 18 & 16 \\
\hline Nephrectomy & 4 & 4 \\
\hline Prostatectomy & 6 & 2 \\
\hline Other & 12 & 15 \\
\hline \multicolumn{3}{|l|}{ Epidural catheter } \\
\hline Thoracic / Lumbar & $41 / 10$ & NA \\
\hline Sufentanil yes / no / missing & $34 / 16$ / 1 & NA \\
\hline Duration $>2$ days $/ \leq 2$ days & $26 / 25$ & NA \\
\hline \multicolumn{3}{|l|}{ Postoperative piritramide } \\
\hline $\mathrm{PCIA} / \mathrm{IM}$ & NA & $11 / 39$ \\
\hline
\end{tabular}

$\mathrm{M} / \mathrm{F}=$ male $/$ female, ASA Class = American Society of Anesthesiology Classification, SF-36 pain = Short-Form36 Health Survey bodily pain score (0-100), VAS = Visual Analogue Scale (0-100), Mean (SD), median $\left(25^{\text {th }}-75\right.$ percentile $(\mathrm{IQR}))$, or number. NA not applicable. $\mathrm{PCIA}=$ patient controlled intravenous analgesia, $I \mathrm{M}=$ intramuscular.

Table 2. Main predictors of CPSP

\begin{tabular}{llcccc}
\hline Predictors & & $p$ & Crude OR (Cl) & $p$ & Adjusted OR (CI) \\
\hline Anesthesia & Epidural vs General & 0.064 & $0.42(0.16-1.05)$ & 0.019 & $0.19(0.05-0.76)$ \\
SF-36 pain baseline & $\leq 60$ vs $>60$ & $<0.001$ & $10.43(3.59-30.30)$ & $<0.001$ & $20.83(4.92-88.22)$ \\
Sex & M vs F & 0.822 & $0.90(0.36-2.26)$ & 0.114 & $0.32(0.08-1.31)$ \\
Age (years) & $>70$ vs $\leq 70$ & 0.004 & $5.14(1.68-15.79)$ & 0.005 & $11.46(2.06-63.58)$ \\
ASA & III vs I/II & 0.012 & $3.50(1.31-9.33)$ & & NE \\
Max VAS Day 2 & $\geq 40$ vs $<40$ & 0.022 & $3.91(1.22-12.50)$ & 0.019 & $6.54(1.36-31.42)$ \\
Malignancy & No vs Yes & 0.181 & $2.10(0.71-6.23)$ & & NE \\
Complications & No vs Yes & 0.033 & $0.31(0.10-0.91)$ & & NE \\
Duration of surgery (hours) & $\geq 2$ vs $<2$ & 0.167 & $1.59(0.82-3.05)$ & & NE \\
\hline
\end{tabular}

vs = Versus, SF-36 pain = Short-Form-36 Health Survey bodily pain score (0-100), M/F = male/female, VAS = Visual Analogue Scale (0-100), SD = standard deviation, ASA Class = American Society of Anesthesiology Classification, $\mathrm{OR}=$ odds ratio, $\mathrm{Cl}=95 \%$ confidence interval, $\mathrm{NE}=$ not entered in the final model. 


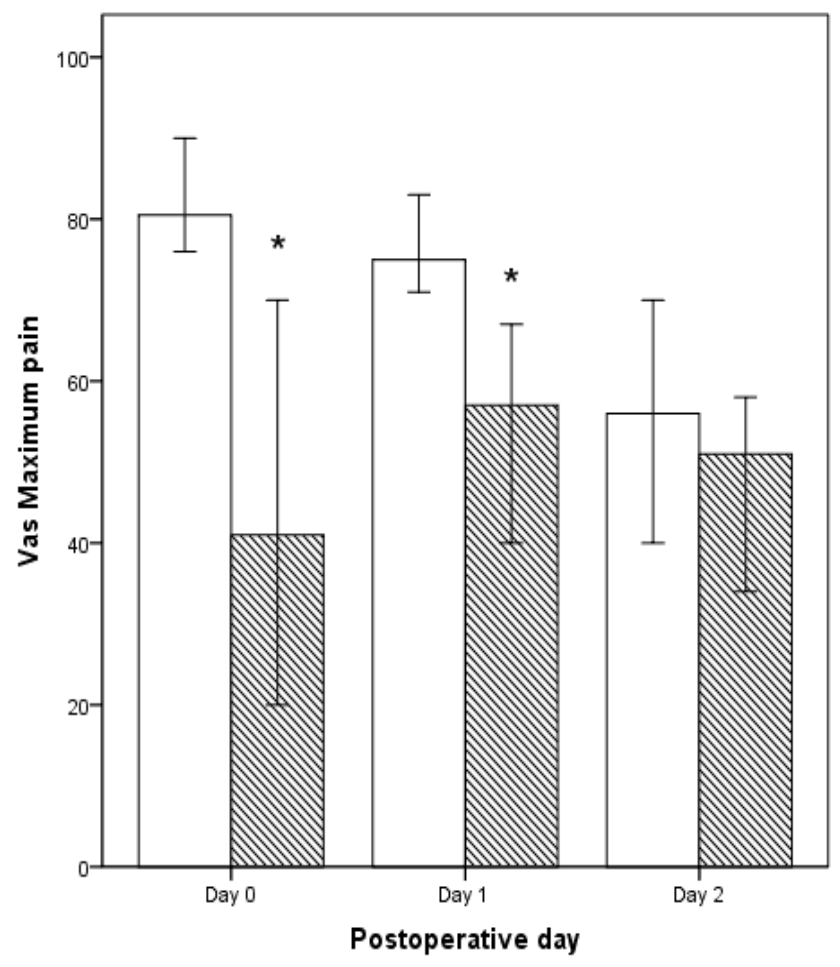

Figure 2. Maximum VAS pain Days 0-2

VAS = Visual Analogue Scale (0-100). White columns: general anesthesia group; shaded columns: general and epidural anesthesia group. Day of surgery = postoperative Day 0, first postoperative = Day 1 , and second postoperative day = Day 2 . Values are median (95\% confidence interval), $* p<0.001$.

Consecutive stepwise logistic regression with the dependent variable SF-36 bodily pain score was performed. Type of anesthesia was evaluated in the first step, followed by age, sex, and pre-operative SF-36 bodily pain in step 2 (Nagelkerke $\mathrm{R}^{2} 0.466$, block $\chi^{2}(3)$ 33.18, $p<0.001$ ). In step 3, maximum VAS on Day 2 was added (Nagelkerke $R^{2} 0.533$, block $\chi^{2}$ (1) 6.11, $p=0.01$ ). Even though the bivariate logistic regression analysis with the maximum VAS on the day of surgery and Day 4 showed a significant association with CPSP, they were not entered in the model because they did not contribute to a better model fit. Finally, in step 4 we analyzed ASA classification and complications reported by patients which did not significantly contribute to a better model fit. (Nagelkerke $\mathrm{R}^{2}$ 0.550 , block $\chi^{2}$ (2) 1.73, $p=0.422$ ) After adjustment for age, sex, pre-operative SF-36 bodily pain, and maximum VAS on Day 2 the OR for chronic pain after 6 months in the epidural group was 0.19.(95\% Cl 0.05-0.76) (Table 2) 


\section{Secondary outcomes}

The quality of life (SF-36 total score, scale 0-100) at follow-up were not significant different for both groups: 74.6 (50.9-90.1) for the epidural group and 77.4 (50.9-89.7) median (IQR) for general anesthesia. Also no effects were found for both groups on long time global perceived recovery.

Patients who were classified as CPSP reported a significantly lower quality of life (SF36 total score) compared to patients without CPSP: 39.2 (27.2-56.7) versus 84.3 (69.9$92.5, p<0.001)$. They also had a lower level of long time global perceived recovery: (70.0\% (50.0-80.0) versus 90\% (80.0-100.0), $p<0.001)$.

\section{DISCUSSION}

In this case-control study, the use of perioperative epidural analgesia after open abdominal surgery showed an association with reduced incidence of CPSP at six months.

Studies on the effect of epidural anesthesia compared to general anesthesia with regard to the occurrence of chronic pain are scarce. In patients receiving thoracotomy epidural anesthesia may reduce the risk of CPSP 6 months after surgery. ${ }^{32}$ Surgery is associated with hyperalgesia and allodynia. ${ }^{33}$ The concomitant inflammatory response may lead to an enhanced, more intense or longer lasting pain perception. ${ }^{34}$ Enhanced and prolonged afferent nociceptive input is a common factor in models explaining the transition from acute to chronic pain. ${ }^{26,33,35,36}$ This input may cause structural changes in the spinal cord as well as in various structures in the brain. Also a very intense noxious stimulus is known to provoke such changes. ${ }^{37}$ Considering the above, we investigated whether epidural analgesia, by blocking afferent input, can reduce the incidence of CPSP after abdominal surgery. Furthermore, if high VAS scores (at rest, after movement or when coughing) during the first four postoperative days are predictive for CPSP.

The results of this study support the conclusions of Lavand'homme who described a significant reduction in CPSP after abdominal surgery with either spinal anesthesia or perioperative epidural analgesia. ${ }^{20,22}$ Katz et al. showed reduced hyperalgesia and reduced morphine use with pre- but not with intra-operative use of epidural analgesia, ${ }^{19}$ and reported reduced pain disability at 3 weeks but not at 6 months after major gynecologic surgery. ${ }^{38}$ Haythornthwaite found no significant differences between general and epidural anesthesia regarding CPSP six months after abdominal surgery. ${ }^{39}$ Possible reason for different findings is that epidural analgesia it is not always effective. Incorrect placement of catheters, catheter migration and asymmetric spread of local anesthetics, inaccurate puncture level, and technical problems with the catheter are well known causes for treatment failures. ${ }^{40}$ 
In our study, epidural analgesia resulted in better acute pain treatment compared with general anesthesia only. This efficacy of epidural analgesia for acute pain relief is in accordance with the literature. ${ }^{13,14,41,42}$

The SF-36 bodily pain subscale was used to assess a composite score of pain intensity along with interference with daily work. The overall incidence of CPSP in our study group was $25.7 \%$. This overall incidence is in line with previously reported studies. ${ }^{3,8,9,43}$ In the epidural group in our study we found a $17.6 \%$ incidence of CPSP; in the general anesthesia group it was 34\%. Furthermore, patients with CPSP reported a low quality of life and incomplete recovery. This confirms that CPSP is a clinically relevant problem.

This long-term follow-up study revealed that the predictors of the development of CPSP are: acute postoperative pain, age $\geq 70$ years, ASA III, and complications reported by the patient. No relationship was found regarding sex, length of hospital stay, malignancy, and type or duration of surgery. The maximum pain score on the second postoperative day was a better predictor in our final model than the pain score on any other day. This could be due to the fact that in our study group, half of the epidural catheters were removed on the second postoperative day. The question remains whether the incidence of CPSP will decrease by increasing the duration of epidural pain treatment. Young age is a known predictor of CPSP. ${ }^{12,44}$ However it was no significant predictor of CPSP in our population. In fact older patients suffered more from CPSP. Maybe the relative high mean age of the study population is attributable to this effect.

A limitation of the current study was that the concept of chronic pain was not elaborated to the fullest extent: a characterization of the pre- and postoperative pain in terms of type, duration, intermittence, and location could have provided additional information. The study group was heterogeneous regarding surgical procedures and anesthesia technique, but the postoperative pain treatment was strictly according to an established hospital protocol, monitored by the acute pain service. Furthermore patients with other types of surgery in the intervening period were excluded. In addition, the effect of tumor recurrence was not assessed, nor was the effect of postoperative chemo- or radiotherapy. However, the study groups were comparable with regard to malignancies.

One of the strengths of this study is that we accounted for pain intensity as well as pain interference by using the SF-36 bodily pain subscale six months after surgery. Additionally, all data were gathered prospectively.

Chronic post-surgical pain occurs in a significant number of patients six months after abdominal surgery. Postoperative continuous epidural analgesia is associated with a significantly reduced risk of CPSP. Best predictors of CPSP are pre-operative pain, age > 70 , and a high level of acute pain on Day 2. The occurrence of CPSP is accompanied by perceived low quality of life and incomplete recovery. 


\section{ACKNOWLEDGEMENTS}

The authors thank M.L. Peters for her valuable comments on the manuscript.

This study was conducted with departmental funding and supported by a grant from The Netherlands Organization for Scientific Research (Zon-MW), grant no. 110000007. The department of Anaesthesiology receives payments of Grünenthal for consultancy activities of M. Marcus. 


\section{REFERENCES}

1. Eriksen JR, Poornoroozy P, Jorgensen LN, Jacobsen B, Friis-Andersen HU, Rosenberg J. Pain, quality of life and recovery after laparoscopic ventral hernia repair. Hernia 2009, 13(1):13-21.

2. Gerbershagen HJ, Özgür E, Straub K, Dagtekin O, Gerbershagen K, Petzke F, Heidenreich A, Lehmann KA, Sabatowski R. Prevalence, severity, and chronicity of pain and general health-related quality of life in patients with localized prostate cancer. Eur J Pain 2008, 12(3):339-350.

3. Bruce J, Krukowski ZH. Quality of life and chronic pain four years after gastrointestinal surgery. Dis Colon Rectum 2006, 49(9):1362-1370.

4. Macrae WA. Chronic pain after surgery. Br J Anaesth 2001, 87(1):88-98.

5. Kehlet $\mathrm{H}$, Jensen TS, Woolf CJ. Persistent postsurgical pain: risk factors and prevention. Lancet 2006, 367(9522):1618-1625.

6. Macrae WA. Chronic post-surgical pain: 10 years on. Br J Anaesth 2008, 101(1):77-86

7. Brandsborg B, Dueholm M, Nikolajsen L, Kehlet $H$, Jensen TS. A prospective study of risk factors for pain persisting 4 months after hysterectomy. Clin J Pain 2009, 25(4):263-268.

8. Brandsborg B, Nikolajsen L, Kehlet H, Jensen TS. Chronic pain after hysterectomy. Acta Anaesthesiol Scand 2008, 52(3):327-331.

9. Loos MJ, Scheltinga MR, Mulders LG, Roumen RM. The Pfannenstiel incision as a source of chronic pain. Obstet Gynecol 2008, 111(4):839-846.

10. Bisgaard T, Rosenberg J, Kehlet H. From acute to chronic pain after laparoscopic cholecystectomy: a prospective follow-up analysis. In: Scand J Gastroenterol. vol. 40; 2005: 1358-1364.

11. Dabu-Bondoc SM. Regional anesthesia and perioperative outcome: what is new? Curr Opin Anaesthesiol 2004, 17(5):435-439.

12. Peters ML, Sommer M, de Rijke JM, Kessels F, Heineman E, Patijn J, Marcus MA, Vlaeyen JW, van Kleef M. Somatic and psychologic predictors of long-term unfavorable outcome after surgical intervention. Ann Surg 2007, 245(3):487-494.

13. Block BM, Liu SS, Rowlingson AJ, Cowan AR, Cowan JA, Jr., Wu CL. Efficacy of postoperative epidural analgesia: a meta-analysis. JAMA 2003, 290(18):2455-2463.

14. Jorgensen H, Wetterslev J, Moiniche S, Dahl JB. Epidural local anaesthetics versus opioid-based analgesic regimens on postoperative gastrointestinal paralysis, PONV and pain after abdominal surgery. Cochrane Database Syst Rev 2000(4):CD001893.

15. Nishimori M, Ballantyne JC, Low JH. Epidural pain relief versus systemic opioid-based pain relief for abdominal aortic surgery. Cochrane Database Syst Rev 2006, 3:CD005059.

16. Pöpping DM, Zahn PK, Van Aken HK, Dasch B, Boche R, Pogatzki-Zahn EM. Effectiveness and safety of postoperative pain management: a survey of 18925 consecutive patients between 1998 and 2006 (2nd revision): a database analysis of prospectively raised data. Br J Anaesth 2008, 101(6):832-840.

17. Dirks J, Moiniche S, Hilsted KL, Dahl JB. Mechanisms of postoperative pain: clinical indications for a contribution of central neuronal sensitization. Anesthesiology 2002, 97(6):1591-1596.

18. Wilder-Smith $\mathrm{OH}$, Arendt-Nielsen L. Postoperative hyperalgesia: its clinical importance and relevance. Anesthesiology 2006, 104(3):601-607.

19. Katz J, Cohen L, Schmid R, Chan VW, Wowk A. Postoperative morphine use and hyperalgesia are reduced by preoperative but not intraoperative epidural analgesia: implications for preemptive analgesia and the prevention of central sensitization. Anesthesiology 2003, 98(6):1449-1460.

20. Lavand'homme P, De Kock M. The use of intraoperative epidural or spinal analgesia modulates postoperative hyperalgesia and reduces residual pain after major abdominal surgery. Acta Anaesthesiol Belg 2006, 57(4):373-379.

21. Obata H, Saito S, Fujita N, Fuse Y, Ishizaki K, Goto F. Epidural block with mepivacaine before surgery reduces long-term post-thoracotomy pain. Can J Anaesth 1999, 46(12):1127-1132. 


\section{CHAPTER 3}

22. Lavand'homme P, De Kock M, Waterloos $\mathrm{H}$. Intraoperative epidural analgesia combined with ketamine provides effective preventive analgesia in patients undergoing major digestive surgery. Anesthesiology 2005, 103(4):813-820.

23. Andreae $\mathrm{MH}$, Andreae DA. Local anaesthetics and regional anaesthesia for preventing chronic pain after surgery. Cochrane Database Syst Rev 2012, 10:CD007105.

24. Sommer M, de Rijke JM, van Kleef M, Kessels AG, Peters ML, Geurts JW, Gramke HF, Marcus MA. The prevalence of postoperative pain in a sample of 1490 surgical inpatients. Eur J Anaesthesiol 2008, 25(4):267-274.

25. Peters ML, Sommer M, van Kleef M, Marcus MA. Predictors of physical and emotional recovery 6 and 12 months after surgery. Br J Surg 2010, 97(10):1518-1527.

26. Katz J, Seltzer Z. Transition from acute to chronic postsurgical pain: risk factors and protective factors. Expert Rev Neurother 2009, 9(5):723-744.

27. Perkins FM, Kehlet $\mathrm{H}$. Chronic pain as an outcome of surgery. A review of predictive factors. Anesthesiology 2000, 93(4):1123-1133.

28. Jensen MP, McFarland CA. Increasing the reliability and validity of pain intensity measurement in chronic pain patients. Pain 1993, 55(2):195-203.

29. McHorney CA, Ware JE, Jr., Lu JF, Sherbourne CD. The MOS 36-item Short-Form Health Survey (SF-36): III. Tests of data quality, scaling assumptions, and reliability across diverse patient groups. Med Care 1994, 32(1):40-66.

30. IGZ. Het resultaat telt 2006, Prestatie-indicatoren als onafhankelijke graadmeter voor de kwaliteit van in ziekenhuizen verleende zorg. In. Edited by Inspectie voor de Gezondheidszorg mvV, Welzijn en Sport; 2007: 69-77.

31. Kleinbeck SV. Self-reported at-home postoperative recovery. Res Nurs Health 2000, 23(6):461-472.

32. Andreae $\mathrm{MH}$, Andreae DA. Local anaesthetics and regional anaesthesia for preventing chronic pain after surgery. Cochrane Database Syst Rev 2012, 10:CD007105.

33. Grosu I, de Kock M. New Concepts in Acute Pain Management: Strategies to Prevent Chronic Postsurgical Pain, Opioid-Induced Hyperalgesia, and Outcome Measures. Anesthesiology Clin 2011, 29(2):311-327.

34. Steyaert A, De Kock M. Chronic postsurgical pain. Curr Opin Anaesthesiol 2012, 25(5):584-588.

35. Gupta A, Gandhi K, Viscusi ER. Persistent postsurgical pain after abdominal surgery. Techniques in Regional Anesthesia and Pain Management 2011, 15(3):140-146.

36. Sandkuhler J. Models and mechanisms of hyperalgesia and allodynia. Physiol Rev 2009, 89(2):707-758

37. Latremoliere A, Woolf CJ. Central Sensitization: A Generator of Pain Hypersensitivity by Central Neural Plasticity. J Pain 2009, 10(9):895-926.

38. Katz J, Cohen L. Preventive analgesia is associated with reduced pain disability 3 weeks but not 6 months after major gynecologic surgery by laparotomy. Anesthesiology 2004, 101(1):169-174.

39. Haythornthwaite JA, Raja SN, Fisher B, Frank SM, Brendler CB, Shir Y. Pain and quality of life following radical retropubic prostatectomy. J Urol 1998, 160(5):1761-1764.

40. Hermanides J, Hollmann MW, Stevens MF, Lirk P. Failed epidural: causes and management. Br J Anaesth 2012, 109(2):144-154.

41. Amr YM, Yousef AA, Alzeftawy AE, Messbah WI, Saber AM. Effect of preincisional epidural fentanyl and bupivacaine on postthoracotomy pain and pulmonary function. Ann Thorac Surg 2010, 89(2):381-385.

42. Brodner G, Van Aken H, Gogarten W. [Regional anesthesia for postoperative pain control]. Anasthesiol Intensivmed Notfallmed Schmerzther 2007, 42(1):32-41.

43. Borly L, Anderson IB, Bardram L, Christensen E, Sehested A, Kehlet H, Matzen P, Rehfeld JF, Stage P, Toftdahl DB et al. Preoperative prediction model of outcome after cholecystectomy for symptomatic gallstones. Scand J Gastroenterol 1999, 34(11):1144-1152.

44. Poobalan AS, Bruce J, King PM, Chambers WA, Krukowski ZH, Smith WC. Chronic pain and quality of life following open inguinal hernia repair. Br J Surg 2001, 88(8):1122-1126. 


\section{CHAPTER 4}

\section{Continuous paravertebral block for postoperative pain compared to general anesthesia and wound infiltration for major oncological breast surgery}

Esther A.C. Bouman, Maurice Theunissen, Alfons G. Kessels, Kristien B.M.I. Keymeulen, Elbert A.J. Joosten, Marco A.E. Marcus, Wolfgang F. Buhre, Hans-Fritz Gramke 


\section{ABSTRACT}

We hypothesized that improved acute postoperative pain relief will be achieved using general anesthesia (GA) either in combination with continuous thoracic paravertebral block (GA-cPVB) or single shot (GA-sPVB) as compared to GA supplemented by local wound infiltration (GA-LWI) after unilateral major breast cancer surgery.

A randomized controlled trial was conducted in 46 adult women in a day-care or short-stay hospital setting after major breast cancer surgery. Pain-intensity was measured using an 11-point visual analogue scale (VAS) until postoperative day 2. GAsPVB was stopped due to slow inclusion.

No significant difference in VAS score was noted between GA-LWI (VAS median 0.5 (interquartile range 0.18-2.00)) and GA-cPVB, (VAS $0.3(0.00-1.55, p=0.195)$ ) 24 hours after surgery or at any point postoperatively until postoperative day 2 .

We conclude that both GA-LWI and GA-CPVB anesthetic techniques are equally effective in treatment of acute postoperative pain after major oncological breast surgery. As GA-LWI is easily to perform with fewer complications and it is more costeffective it should be preferred over GA-cPVB. 


\section{INTRODUCTION}

Optimal acute postoperative pain relief after major surgical breast surgery is still a matter of debate. After major oncological breast surgery patients still suffer from acute postoperative pain. Data of our own patient population ${ }^{1}$ showed that $22 \%$ of the patients reported mean VAS of $>40$ (of a scale $0-100$ ) on the first postoperative day after major breast surgery. This was confirmed in a recent cohort study with a reported mean pain score of 3.82 (SD 2,47) on the postoperative day $1 .{ }^{2,3}$ In this context, a paravertebral block (PVB) which provides a unilateral segmental nerve block is advocated as the technique of choice for breast surgery. ${ }^{4}$ Previous studies observed improved acute postoperative pain management, ${ }^{5-9}$ less nausea, ${ }^{6-8}$ faster recovery from anesthesia, ${ }^{6}$ earlier hospital discharge, ${ }^{8}$ and reduced incidence of chronic postoperative pain when PVB is used. ${ }^{10}$ The lower incidence of postoperative nausea and vomiting (PONV) and the faster recovery makes PVB an attractive analgesic approach to day care surgery, as a significant amount of the surgical procedures are currently performed in this setting. (in the Netherlands $51 \%{ }^{11}$ ) The majority of studies only compared general anesthesia (GA) with PVB and systemic pain therapy with the use of intravenous opioids. However, in daily practice local wound infiltration (LWI) with local anesthetics is commonly used complementary to systemic analgesics for postoperative pain relief. ${ }^{12-14}$ Therefore, the use of GA with PVB (GA-PVB) should be compared to GA with LWI (GALWI).

In this study, the primary objective was to determine analgesic effects of a GA combined with PVB as compared to GA with LWI in patients undergoing major breast surgery in day or short stay hospital setting. We hypothesized that better acute postoperative pain relief 24 hours after surgery (Day 1) could be achieved using GA-PVB as compared to GA-LWI.

\section{METHODS}

This study was carried out in compliance with the Helsinki Declaration. Following approval by the medical ethics committee of Maastricht University Medical Center+ (reference number MEC 05-105), written informed consent and registration at www.clinicaltrials.gov identifier: NCT00547989, patients were included in a prospective, open, randomized controlled trial. The study population consisted of adult women scheduled for one-sided, major breast cancer surgery. Surgical procedures included wide local excision (WLI), mastectomy and modified radical mastectomy (MRM) Sentinel node procedure, axillary dissection, or immediate prosthetic breast reconstruction was mandatory in case of WLI and optional in case of mastectomy or MRM.

All patients were ASA class I or II and planned for day care or short stay surgery. Exclusion criteria were as follows: contra-indication for regional anesthesia, coagulation 
disorders, infection at point of insertion, infection in thoracic cavity, tumor in paravertebral area, history of pleurectomy, and history of allergic reaction to contrast medium or local anesthetics.

Patients were randomized in two phases, using a computer generated list. First, patients were assigned to GA plus local wound infiltration (GA-LWI) or GA plus PVB (GA$P V B)$. Secondly, patients in the PVB group were then randomized either in a subgroup with single shot PVB (GA-sPVB)) or in a subgroup with continuous PVB (GA-cPVB) using a paravertebral catheter and patient controlled analgesia.

Patients in groups GA-SPVB and GA-CPVB received a thoracic paravertebral block preoperatively according to a standard technique described in detail elsewhere. ${ }^{9,}{ }^{15} \mathrm{~A}$ member of the study group (either EB or $H G$ ) performed all procedures. Briefly, a 20 Gauge catheter (B.Braun Melsungen AG, Melsungen, Germany) was inserted $3 \mathrm{~cm}$ into the paravertebral space at thoracic level 3-4, using an 18 Gauge Tuohy cannula needle. After a test dose of $3 \mathrm{ml}$ ropivacaine $0.75 \%$, a total dose of $0.25 \mathrm{ml} / \mathrm{kg}$ ropivacaine $0.75 \%$ was injected. Postoperatively, the position of the catheter was confirmed by thoracic X-ray and injection of 2-3 ml contrast medium (lohexol $240 \mathrm{mg} \mathrm{I/ml,} \mathrm{Om-}$ nipaque GE Healthcare B.V. The Netherlands) via the catheter.

Induction of GA was performed with propofol 2-3 mg/kg and sufentanil 0.1-0.2 $\mu \mathrm{g} / \mathrm{kg}$ at induction, rocuronium $0.6 \mathrm{mg} / \mathrm{kg}$ to facilitate endotracheal intubation or laryngeal mask airway. Maintenance of anesthesia was performed according to hospital practice in general with sevoflurane/air (0.9-1.3 MAC) and additional boluses of sufentanil as clinically deemed necessary.

Surgery was performed by or under close supervision of a dedicated staff surgeon.

Patients in group GA-CPVB received continuous infusion of ropivacaine $0.2 \%$ at $5 \mathrm{ml} / \mathrm{h}$ plus an optional patient controlled bolus of $5 \mathrm{ml}$ (lock-out interval: one hour) (Easypump RA 400-5 PCA, B. Braun Melsungen AG, Melsungen, Germany). Adjunct postoperative analgesia in all groups consisted of paracetamol (4x1000mg) fixed dose and a non-steroidal anti-inflammatory drug (NSAID) (naproxen or diclofenac) in combination with piritramide and ondansetron as required. Day care patients were allowed to stay overnight in case of delayed recovery.

Patient baseline characteristics age, length, weight, ASA classification, and surgical data were recorded. At the PACU, vital signs on arrival and nausea (Numeric Rating Scale, NRS 0-10) were registered. The primary outcome measure, postoperative pain, was measured using a visual analogue scale ranging from 0 to 10 (VAS). A pain score of less than 4 on the VAS was considered as sufficient for postoperative analgesia. ${ }^{16}$ Postoperative pain was measured on arrival at the PACU, on discharge from the PACU, and from then on three times per day (at 8.00-14.00-20.00 hr.) for two postoperative days. After discharge from the PACU the patients used a pain diary to record the pain scores. In addition, patients were asked to report the use of analgesics as well as the overall satisfaction with pain treatment (5-point-verbal rating scale). Initially a GA-sPVB patient group was planned and included in which the paravertebral catheter was 
removed at the PACU after an additional dose of $10 \mathrm{ml}$ ropivacaine $0.2 \%$. However, due to very low inclusion rate of patients in the GA-sPVB group the Medical Ethical Committee suggested to stop the inclusion of patients into this group.

Patients in group GA-LWI received local wound infiltration with10 ml bupivacaine $0.25 \%$ before wound closure according to the standard procedure for extended mamma surgery as used in our hospital. (MUMC+, the Netherlands)

In order to o detect a 1.5 (SD 1.5) VAS pain score difference at 24 hours after surgery ${ }^{6}$ with a power of $80 \%$ and a significance level of $5 \%$, our analysis revealed that 16 patients needed to be included per group. Assuming a drop-out of $10 \%$, we decided to include 18 patients per group.

Baseline data and secondary outcomes were analyzed using student's t-test and Fisher Exact Tests for parametric data, Mann Whitney U-tests for non-parametric data, and Chi-square tests for categorical data. Multivariate analysis of the primary VAS score outcome was performed using a multilevel linear model. Differences between GA-LWI and GA-CPVB as a function of time were assessed with the intervention and time as fixed effects. Interaction between treatment group and time was assessed.

Adjustment for covariates, age, ASA-classification, perioperative opioid use, and type of surgery was entered in the model. For the primary outcome measure, substitution of missing data was not performed as the multilevel linear model is sufficiently robust in handling missing data.

All data were analyzed according to the intention to treat principle, using the Statistical Package for the Social Sciences (SPSS version 18, Chicago, Illinois, USA). A $p$ value $<0.05$ was considered statistically significant.

\section{RESULTS}

Trial recruitment was scheduled from October 2006 to April 2011. A total of 449 patients were screened. The proportion of eligible patients was 53\% (238) of whom $19 \%$ (46) gave informed consent. (Figure 1) An interim analysis was performed in October 2009. Due to low inclusion rate it was decided to exclude the GA-sPVB group from analysis. The present analysis is therefore based on a total of 36 patients: GA-CPVB $(n=18)$ and GA-LWI $(n=18)$. No relevant significant differences were noted between groups with regard to baseline characteristics or type of surgery. (Table 1) Patients in the GA-LWI group received significantly more opioids intraoperative than patients in the GA-cPVB group. (Table 1)

There was no significant difference in the primary outcome parameter VAS score between GA-LWI (VAS median 0.5 (0.18-2.00)) and GA-cPVB, (VAS median 0.3 (0.00-1.55, $p=0.195)) 24$ hours after surgery. No difference in VAS score between GA-LWI and GACPVB was noted at any time point postoperatively until postoperative day 2. (Figure 2) 


\section{Enrollment}

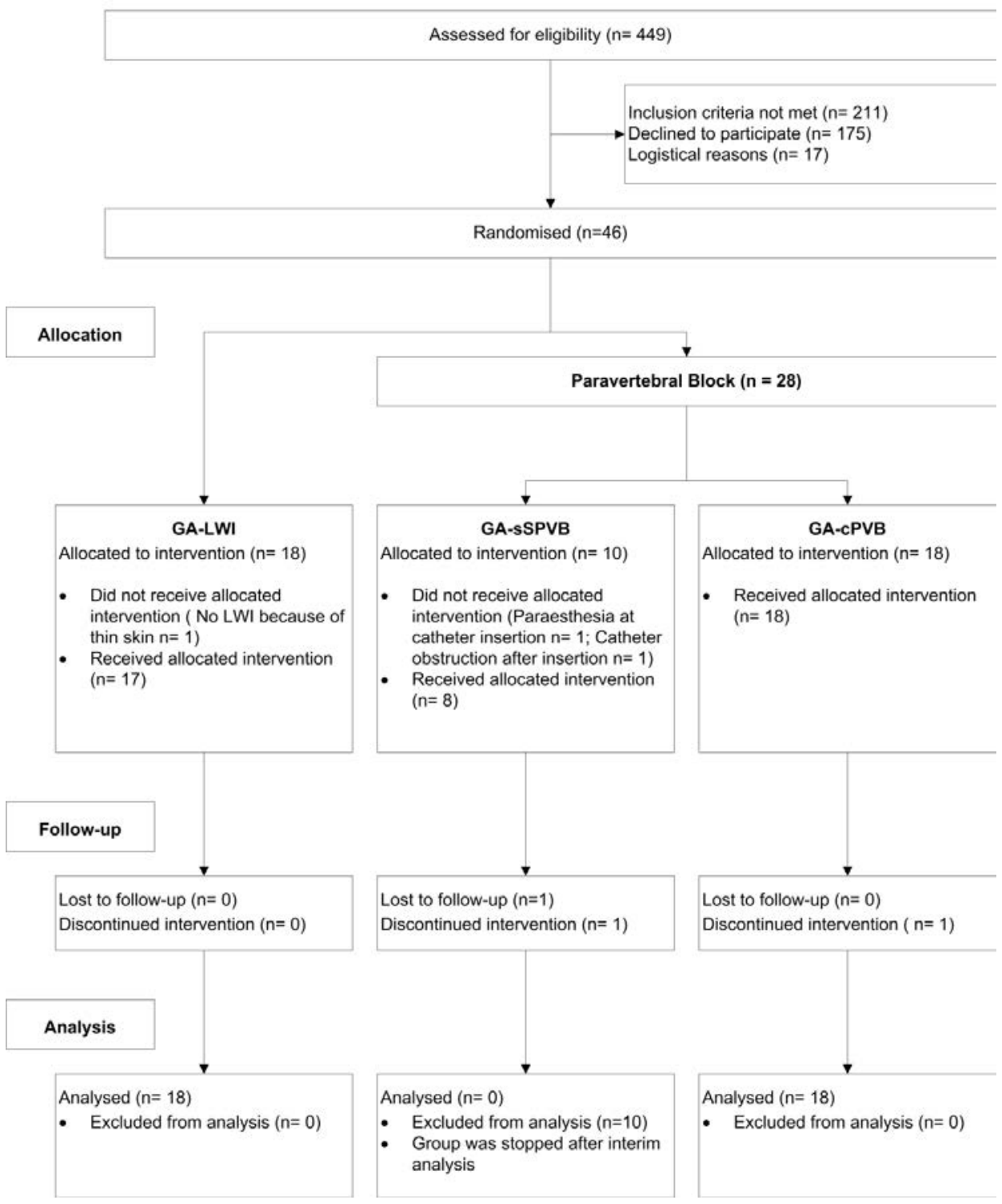

Figure 1. Consort flow chart

GA-LWI: general anesthesia and local wound infiltration, GA-sPVB: general anesthesia and single shot paravertebral block, GA-cPVB: general anesthesia and continuous PVB. 
Table 1. Population characteristics and intraoperative data

\begin{tabular}{|c|c|c|c|}
\hline & $\begin{array}{l}\text { GA-LWI } \\
n=18\end{array}$ & $\begin{array}{l}\text { GA-cPVB } \\
n=18\end{array}$ & $p$ value \\
\hline Age (years) & $57.9(13.8)$ & $60.9(12.7)$ & 0.52 \\
\hline Length (cm) & $166.7(6.9)$ & $165.6(4.2)$ & 0.55 \\
\hline Weight (kg) & $70.8(17.5)$ & $67.4(9.43)$ & 0.47 \\
\hline ASA I/ II & $9 / 9$ & $5 / 13$ & 0.17 \\
\hline Airway TT/LMA & $11 / 7$ & $10 / 8$ & 0.74 \\
\hline Total dose sufentanil ( $\mu \mathrm{g})$ & $33.1(10.6)$ & $25.1(9.5)$ & 0.024 \\
\hline Intraoperative infusion ( ml) & $1194(300)$ & $1428(379)$ & 0.048 \\
\hline Duration of anesthesia (hours) & $2.50(0.69)$ & $2.57(0.66)$ & 0.78 \\
\hline Duration of surgery (hours) & $1.98(0.61)$ & $2.09(0.58)$ & 0.58 \\
\hline Type of surgery & & & 0.25 \\
\hline $\begin{array}{l}\text { Lumpectomy / Ablatio / MRM } \\
+ \text { /- sentinel node }\end{array}$ & 12 & 7 & \\
\hline $\begin{array}{l}\text { Ablatio / MRM } \\
+ \text { Axillary node }\end{array}$ & 3 & 6 & \\
\hline $\begin{array}{l}\text { Ablatio / MRM + Plastic surgery } \\
\text { +/- Axillary node }\end{array}$ & 3 & 5 & \\
\hline
\end{tabular}

GA-LWI: general anesthesia and local wound infiltration, GA-cPVB general anesthesia and continuous PVB, TT: tracheal tube; LMA: laryngeal mask airway

MRM: modified radical mastectomy. Values are numbers or mean (SD).

Moreover, no significant differences between GA-LWI and GA-CPVB were noted in the number of patients that used opioids on the day of surgery, although the amount of opioids used was significantly lower in GA-CPVB as compared to GA-LWI. (Table 2) This difference in the amount of opioids per patient was not associated with a difference in the incidence of postoperative nausea or the need for anti-emetic drugs in the PACU. Patient satisfaction questionnaire revealed equal results in GA-LWI and GA-CPVB. (Table 2)

The placement of the paravertebral catheter was successful in all patients. A vascular puncture occurred in one patient. The median indwelling time from start of surgery was 43.3 (IQR 41.7-46.3) hours.

Analysis of the course of pain on postoperative Days 1 and 2 using the multilevel linear model with VAS pain score as a function of time (hours) as the dependent variable revealed that the effect on postoperative pain did not differ between GA-CPVB and GA-LWI.

The postoperative time course (hours) and the interaction between intervention and time were significant predictors of postoperative VAS-pain score in both GA-LWI and GA-cPVB. (Table 3) 


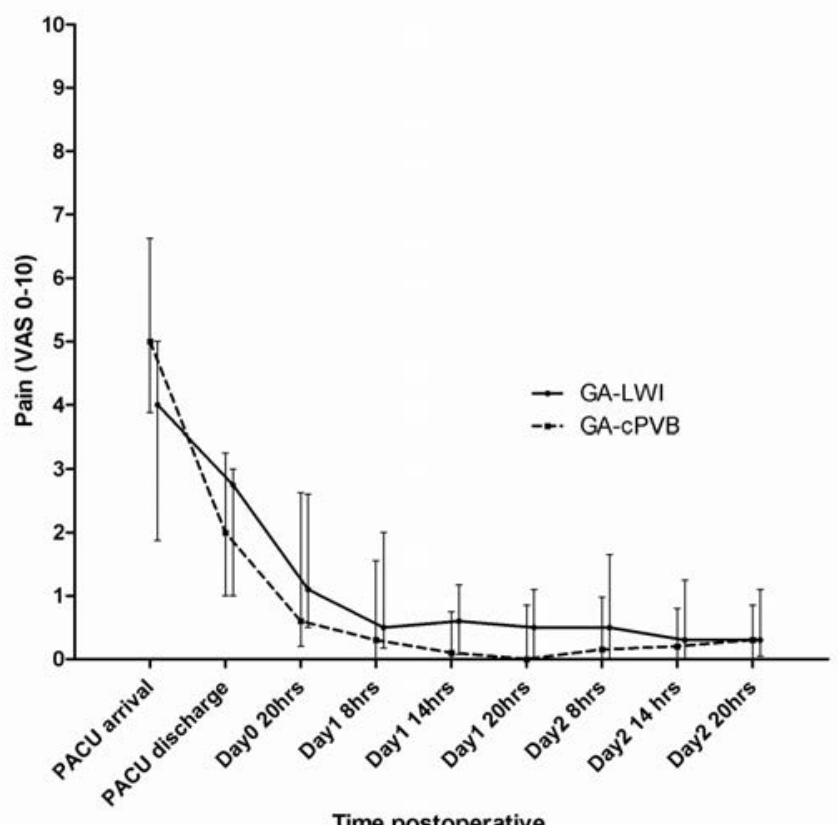

Time postoperative

Figure 2. Postoperative pain scores

Values are VAS pain, median IQR. PACU: post anesthetic care unit.

Table 2. PONV, postoperative opioid use and satisfaction with analgesic treatment

\begin{tabular}{llll}
\hline & $\begin{array}{l}\text { GA-LWI } \\
\mathrm{n}=18\end{array}$ & $\begin{array}{l}\text { GA-cPVB } \\
\mathrm{n}=18\end{array}$ & $p$ value \\
\hline PACU Nausea at discharge & $0.9(1.4)$ & $1.0(1.5)$ & 0.82 \\
PACU anti-emetic use & $13 / 4 / 1$ & $14 / 4 / 0$ & 1.00 \\
(yes / no / missing) & & & \\
Opioid use day 0 (yes / no / missing) & $7 / 10 / 1$ & $6 / 12 / 0$ & 0.63 \\
Piritramide day 0 (mg) & $7.5(0-26)$ & $1.5(0-8)$ & 0.03 \\
Satisfaction with treatment & & & \\
Bad - Moderate & 0 & 1 & \\
Good & 2 & 2 & \\
Very good - Excellent & 13 & 14 & \\
missing & 3 & & \\
\hline
\end{tabular}

GA-LWI: general anesthesia and local wound infiltration; GA-cPVB: general anesthesia and continuous paravertebral block. Values are numbers, mean (SD), or mean (range). 
Table 3. Multilevel analysis parameter estimates of fixed effects

\begin{tabular}{lllll}
\hline Parameter & Estimate & \multicolumn{2}{l}{$95 \% \mathrm{Cl}$} & \multirow{2}{*}{$p$ value } \\
\cline { 2 - 4 } & & Lower Bound & \multicolumn{1}{l}{ Upper Bound } & \\
\hline GA-cPVB & -0.283 & -1.287 & 0.721 & 0.57 \\
Time after surgery & -0.052 & -0.064 & -0.039 & 0.000 \\
GA-cPVB* Time & -0.023 & -0.041 & -0.005 & 0.012 \\
Age & 0.081 & -0.027 & 0.043 & 0.64 \\
ASA & -0.223 & -1.073 & 0.628 & 0.60 \\
Additional axillary dissection & 0.184 & -0.847 & 1.215 & 0.72 \\
Additional immediate & 0.715 & -0.522 & 1.952 & 0.25 \\
prosthetic breast & & & & 0.54 \\
reconstruction & 0.130 & -0.030 & 0.056 & \\
Total dose sufentanil & & & & \\
\hline
\end{tabular}

GA-cPVB: general anesthesia and continuous paravertebral block, cPVB * Time: interaction effect between intervention and time after surgery.

Initially, VAS-pain score decreased rapidly; thereafter a slight decrease in pain intensity was observed which lasted several hours, for both groups. (Figure 2) The average reduction of 0.5 on VAS at postoperative day 1 is attributed to continuous paravertebral block using PCA. Assessment of potential confounding factors like age, ASA classification, and type of surgery did not reveal significant effects (Table 1)

Thoracic X-ray confirmed the correct position of the paravertebral catheter and revealed no pneumothorax. The contrast medium mainly spread along the thoracic paravertebral space $(n=11)$ a cloud like pattern $(n=3)$ an intercostal spread $(n=2)$ or a combination of paravertebral and intercostal spread $(n=2)$. (Figure 3)
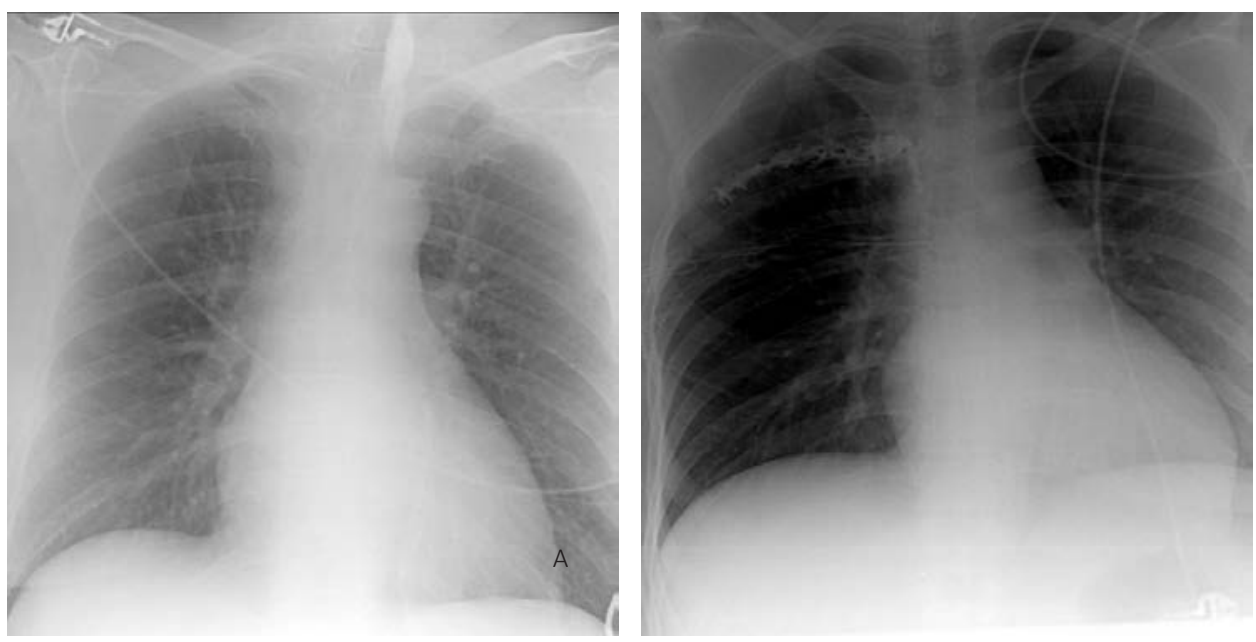

Figure 3. A and B Examples radiographic contrast medium spread in patients with continuous paravertebral block A: spread in thoracic paravertebral space. B:Intercostal spread of radiographic contrast medium. 
We observed only minor complications after GA-cPVB: minor bleeding at the puncture site in one patient, premature catheter dislocation in another patient. Furthermore, three patients complained about back pain, and one patient was not capable of pushing the PCA button.

\section{DISCUSSION}

The results of the present study suggest that general anesthesia combined with local wound infiltration (GA-LWI) and continuous paravertebral infusion of local anesthetics (GA-cPVB) are equally effective in acute postoperative pain relief. Patients receiving GACPVB used a significantly lower amount of systemic opioids as compared to patients in GA-LWI group. The increased amount of systemic opioids was, however, not associated with an increased incidence of postoperative PONV in group GA-LWI.

In the present study, correct placement of the paravertebral catheter was confirmed via chest X-Ray after surgery. Furthermore, PVB was performed by two members of the study team (EB, HG), in a standardized manner that contributed to the high success rate of the technique. A basic analgesic regimen was prescribed for all patients and surgery was performed by or under close supervision of a dedicated staff surgeon.

The main limitation of our study was the slow inclusion rate and a low proportion of screened patients suitable for randomization, as earlier reported. ${ }^{17}$ Another limitation might be the fact that the study was not performed in a blinded fashion. In this context it is important to note that due to the potentials risk of the PVB procedure and the eventual burden for study participants, sham PVB was not considered an option.

Relatively low pain scores were noted in both GA-LWI and GA-CPVB groups on postoperative day 1 . These low pain scores, in particular in the GA-LWI group, were not expected as a previous study of our group ${ }^{1}$ reported $22 \%$ of the patients having a mean VAS at rest $>40$ (scale $0-100$ ) on the first postoperative day. ${ }^{1}$

The combination of assistance of an oncological support team (mamma-care nurse), a dedicated study team and a motivated patient group may have been contributed to these low pain scores at postoperative day 1 . Moreover all patients received a basic analgesic regimen including paracetamol (4x1000mg) fixed dose and a non-steroidal anti-inflammatory drug (NSAID) (naproxen or diclofenac) in combination with piritramide and ondansetron as required.

Median and worst pain scores in patients undergoing different surgical procedures were analyzed recently in two cohort studies. ${ }^{2,3}$ In the subgroup of patients undergoing breast surgery, mean numeric rating scale (NRS) was 3.26 and 2.98 for major and minor breast surgery, respectively. These cohort studies did not present detailed information on the use of PVB or LWI nor is there information provided on the pain scores 24 hours after surgery. ${ }^{2}, 3$ Nevertheless, we conclude that patients in our study showed postoperative VAS scores comparable to those reported for the general population 
undergoing this type of surgery. Moreover, three RCTs addressed the same issues. Continuous wound infiltration was compared with single injection paravertebral block and low absolute postoperative VAS-pain scores in both groups up to 24 hours after surgery was reported. ${ }^{13}$ These results are in line with the present study where absolute postoperative VAS-pain scores in both GA-CPVB and GA-LWI groups were low and were comparable between the groups. It should be stressed that in the study of Sidiropou${ }_{\text {lou }}{ }^{13}$ both groups received more systemic opioids after surgery than patients from the present study. Systemic opioid use is commonly associated with an increased incidence of nausea and vomiting ${ }^{18}$ a finding that, however, cannot be supported by the results of the present study.

The results of the present study and those presented by Sidiropoulou ${ }^{13}$ differ from a number of studies in which GA alone and GA-PVB were compared. For instance, no difference between groups was found when effects of single shot PVB alone, combined with continuous PVB and placebo was studied in 74 patients undergoing breast surgery. ${ }^{17}$ The latter study includes, however, some major limitations. Not only the PVB technique used was a mixture of a single shot and a multilevel approach, also the assignment of patients to the 3 groups was stratified by surgery class, and patients were deeply sedated during the procedure and conversion to GA was necessary in $12 \%$ of the patients. Furthermore 21 patients with incomplete data were excluded from the analysis. ${ }^{17}$

Most recently, an interesting randomized controlled study ${ }^{19}$ was published which compared multilevel PVB/total intravenous anesthesia (TIVA) and a balanced volatile anesthetic technique. Here lower pain scores and improved recovery scores were reported in the PVB/TIVA group as well as a reduced incidence of nausea and vomiting. Comparison with the data from our study is difficult as study designs considerably differ. In the study of Abdallah ${ }^{19}$ patients in the volatile general anesthesia group also received nitrous oxide, whereas patients in the TIVA group received propofol and oxygen in air. Both, volatile anesthetics and nitrous oxide can contribute to the increased incidence of nausea and vomiting and can, at least in part, explain the lower recovery scores in the general volatile anesthesia group as noted in this study. ${ }^{19}$ Even more important, the patients received no local wound infiltration and no basic analgesic regimen. Interestingly, median pain scores in the PVB group ${ }^{19}$ were comparable to the results of the present study when patients met the discharge criteria from the PACU, suggesting that LWI, CPVB and multilevel single shot PVB are comparable with respect to peri-operative pain scores.

In a large observational single institution study patients with breast surgery not undergoing early reconstructive surgery, no differences in nausea, vomiting and postoperative pain scores were observed. ${ }^{20}$ However hospital charts of patients were retrospectively analyzed.

The efficacy and safety of paravertebral blocks in breast surgery was calculated based on a meta-analysis of randomized clinical trials. ${ }^{21}$ In this meta-analysis, 15 RCTs 
were included with a total of 877 patients. Then significant differences in pain scores in the initial period $(<2 h)$ as well as up to 48 hours for both the combination of PVB and general anesthesia vs. GA alone were reported. ${ }^{21}$ The observation that the funnel plot showed asymmetry might be of significant importance and suggests publications bias regarding negative study results.

Although the direct postoperative VAS scores at PACU arrival in our study were somewhat higher, we noted that VAS values dropped consistently in both GA-CPVB and GA-LWI groups. From this we may conclude that $L W I$ is a cost effective and low risk procedure and seems to be comparable to the PVB approach.

The results of our study are encouraging as LWI is easy, readily available and has almost no side effects. It is less invasive than other regional techniques like paravertebral and interpleural blocks ${ }^{22}$ and there is no need for any technical device or follow up for catheter removal. From our study we tentatively conclude that in contrast with more painful procedures the wearing off of local anesthetic effect after wound infiltration is not a major determinant for pain during the next days.

We have demonstrated that both GA-LWI and GA-CPVB techniques were effective in treatment of acute postoperative pain after major oncological breast surgery. As GALWI is easily to perform with fewer complications and it is more cost-effective it should be preferred over GA-CPVB. A possible additional value of continuous paravertebral block in more painful extended procedures has to be investigated.

\section{ACKNOWLEDGMENTS}

This study was performed with departmental funding. The elastomeric disposable infusion pumps were sponsored by B. Braun Melsungen AG, Germany.

\section{Conflict of interest}

The Department of Anaesthesiology and Pain Management, Maastricht University Medical Center+, the Netherlands received payments from Grünenthal GmbH for consultancy provided by M. Marcus.

The other authors declare that they have no conflict of interest. 


\section{REFERENCES}

1. Sommer M, de Rijke JM, van Kleef M, Kessels AG, Peters ML, Geurts JW, Gramke HF, Marcus MA. The prevalence of postoperative pain in a sample of 1490 surgical inpatients. Eur J Anaesthesiol 2008, 25(4):267-274.

2. Gerbershagen HJ, Aduckathil S, van Wijck AJ, Peelen LM, Kalkman CJ, Meissner W. Pain intensity on the first day after surgery: a prospective cohort study comparing 179 surgical procedures. Anesthesiology 2013, 118(4):934-944.

3. Gerbershagen HJ, Pogatzki-Zahn E, Aduckathil S, Peelen LM, Kappen TH, van Wijck AJ, Kalkman CJ, Meissner W. Procedure-specific risk factor analysis for the development of severe postoperative pain. Anesthesiology 2014, 120(5):1237-1245.

4. Recommendations Non-cosmetic Breast Surgery [http://www.postoppain.org/frameset.htm]

5. Boughey JC, Goravanchi F, Parris RN, Kee SS, Kowalski AM, Frenzel JC, Bedrosian I, Meric-Bernstam F, Hunt KK, Ames FC et al. Prospective randomized trial of paravertebral block for patients undergoing breast cancer surgery. Am J Surg 2009, 198(5):720-725.

6. Kairaluoma PM, Bachmann MS, Korpinen AK, Rosenberg PH, Pere PJ. Single-injection paravertebral block before general anesthesia enhances analgesia after breast cancer surgery with and without associated lymph node biopsy. Anesth Analg 2004, 99(6):1837-1843.

7. Klein SM, Bergh A, Steele SM, Georgiade GS, Greengrass RA. Thoracic paravertebral block for breast surgery. Anesth Analg 2000, 90(6):1402-1405.

8. Naja MZ, Ziade MF, Lonnqvist PA. Nerve-stimulator guided paravertebral blockade vs. general anaesthesia for breast surgery: a prospective randomized trial. Eur J Anaesthesiol 2003, 20(11):897-903.

9. Terheggen MA, Wille F, Borel Rinkes IH, lonescu TI, Knape JT. Paravertebral blockade for minor breast surgery. Anesth Analg 2002, 94(2):355-359, table of contents.

10. Kairaluoma PM, Bachmann MS, Rosenberg PH, Pere PJ. Preincisional paravertebral block reduces the prevalence of chronic pain after breast surgery. Anesth Analg 2006, 103(3):703-708.

11. Statline table: Operaties in het ziekenhuis; soort opname, leeftijd en geslacht 1995-2010 [http://statline.cbs.nl/StatWeb/publication/?DM=SLNL\&PA=80386ned\&D1=a\&D2=0\&D3=0\&D4=a\&D5=I\& $\mathrm{HDR}=\mathrm{T} \& \mathrm{STB}=\mathrm{G} 4, \mathrm{G} 1, \mathrm{G} 2, \mathrm{G} 3 \& \mathrm{VW}=\mathrm{T}]$

12. Johansson A, Kornfalt J, Nordin L, Svensson L, Ingvar C, Lundberg J. Wound infiltration with ropivacaine and fentanyl: effects on postoperative pain and PONV after breast surgery. J Clin Anesth 2003, 15(2):113118.

13. Sidiropoulou T, Buonomo O, Fabbi E, Silvi MB, Kostopanagiotou G, Sabato AF, Dauri M. A prospective comparison of continuous wound infiltration with ropivacaine versus single-injection paravertebral block after modified radical mastectomy. Anesth Analg 2008, 106(3):997-1001, table of contents.

14. Vigneau A, Salengro A, Berger J, Rouzier R, Barranger E, Marret E, Bonnet F. A double blind randomized trial of wound infiltration with ropivacaine after breast cancer surgery with axillary nodes dissection. BMC Anesthesiol 2011, 11:23.

15. Eason MJ, Wyatt R. Paravertebral thoracic block-a reappraisal. Anaesthesia 1979, 34(7):638-642.

16. Jensen MP, Chen C, Brugger AM. Interpretation of visual analog scale ratings and change scores: a reanalysis of two clinical trials of postoperative pain. J Pain 2003, 4(7):407-414.

17. Buckenmaier CC, 3rd, Kwon KH, Howard RS, McKnight GM, Shriver CD, Fritz WT, Garguilo GA, Joltes KH, Stojadinovic A. Double-blinded, placebo-controlled, prospective randomized trial evaluating the efficacy of paravertebral block with and without continuous paravertebral block analgesia in outpatient breast cancer surgery. Pain Med 2010, 11(5):790-799.

18. Miaskowski C. A review of the incidence, causes, consequences, and management of gastrointestinal effects associated with postoperative opioid administration. J Perianesth Nurs 2009, 24(4):222-228.

19. Abdallah FW, Morgan PJ, Cil T, McNaught A, Escallon JM, Semple JL, Wu W, Chan VW. Ultrasound-guided Multilevel Paravertebral Blocks and Total Intravenous Anesthesia Improve the Quality of Recovery after Ambulatory Breast Tumor Resection. Anesthesiology 2014, 120(3):703-713. 
CHAPTER 4

20. Aufforth R, Jain J, Morreale J, Baumgarten R, Falk J, Wesen C. Paravertebral blocks in breast cancer surgery: is there a difference in postoperative pain, nausea, and vomiting? Ann Surg Oncol 2012, 19(2):548-552.

21. Schnabel A, Reichl SU, Kranke P, Pogatzki-Zahn EM, Zahn PK. Efficacy and safety of paravertebral blocks in breast surgery: a meta-analysis of randomized controlled trials. Br J Anaesth 2010, 105(6):842-852.

22. Kundra P, Varadharajan R, Yuvaraj K, Vinayagam S. Comparison of paravertebral and interpleural block in patients undergoing modified radical mastectomy. J Anaesthesiol Clin Pharmacol 2013, 29(4):459-464. 


\section{CHAPTER 5}

Boundaries of the thoracic paravertebral space: potential risks and benefits of the thoracic paravertebral block from an anatomical perspective.

Esther A. Bouman, Judith M. Sieben, Andrea J. R. Balthasar, Engelbert A. Joosten, Hans-Fritz Gramke, Maarten van Kleef and Arno Lataster

Submitted 


\section{ABSTRACT}

Background: Thoracic paravertebral block (TPVB), may be an elegant alternative to thoracic epidural analgesia. In order to further understand not only the effect of the TPVB but also its possible clinical consequences, a detailed description of the anatomical boundaries and the thoracic paravertebral space (TPVS) is important. Hence, the aims of this cadaver study were: (1) to determine the anatomical boundaries of TPVS in human thorax specimens, (2) to describe the observed spread of fluid-like substances injected under ultrasound (US) guidance in the TPVS.

Methods: In two formalin-fixed thorax specimens' stratification of several layers of the TPVS was dissected, observed and photographed. In a third unembalmed human trunk, after ultrasound-guided identification of the TPVS, liquid catalyzed red plastic and methylene blue dye were injected.

Results: Our anatomical data show that TPVS communicated with all surrounding structures including the dorsal intercostal compartments, showing a segmental partition. Sub-division of TPVS in a sub-endothoracic and an extra-pleural compartment by the endothoracic fascia could not be confirmed. Injected plastic and dye were observed posteriorly to the costo-diaphragmatic recess and showed segmental intercostal spread.

Conclusions: The anatomical boundaries of the TPVS are relative borders as the TPVS does communicate with all surrounding neurological structures. This anatomical study indicates that the clinical effects and side-effects of the TPVB are related to a direct penetration of local anesthetics into the surrounding neurological structures.

\section{What we already know about this topic}

The TPVB is described with definite anatomical boundaries and is divided into an anterior and a posterior compartment by the endothoracic fascia.

Injection of an aqueous dye solution shows pre-, paravertebral and intercostal spread over multiple segments.

\section{What this article tells us that is new}

The division of the TPVB into an anterior and a posterior compartment is considered to be artificial.

A part of the effect of the TPVB can be attributed to the intercostal spread of a local anesthetic. Clinical effects and side-effects of TPVB are most likely related to a direct penetration of local anesthetics into the surrounding neurological structures. 


\section{INTRODUCTION}

The paravertebral block (PVB) is a regional anesthetic technique which revived after the publication of Eason en $\mathrm{Wyatt}^{1}$ and became very popular especially for thoracotomy, ${ }^{2,3}$ breast surgery, ${ }^{4-8}$ and inguinal hernia repair ${ }^{9-11}$ during the last 10 years. It may be an alternative to thoracic epidural analgesia as it is as effective as epidural analgesia and has less complications. ${ }^{3}$ Additionally it is more effective than local wound infiltration. ${ }^{12}$

The thoracic paravertebral space (TPVS) is commonly described as triangular-shaped in transverse cross-section or wedge-shaped in 3D lying positioned bilaterally alongside the whole length of the thoracic vertebral column. The TPVS is filled with fat and is traversed by the dorsal branches, ventral branches, communicating branches, intercostal nerves and blood vessels, (hemi) azygos vein, thoracic duct and sympathetic chain. $^{1,13,14}$

The posterolateral aspect of the vertebral column forms the base of the TPVS. The apex of the TPVS communicates with the intercostal space laterally. The anterolateral boundary is formed by the parietal pleura and the posterior boundary by the transverse process of the vertebrae, the head and neck of the ribs together with their interconnecting musculoaponeurotic tissues. ${ }^{15,16}$ The musculoaponeurotic system is formed by the superior costotransverse ligament ${ }^{17}$ and the aponeurosis of the internal intercostal muscle. The psoas muscle at L1 is considered to be the caudal boundary of the TPVS. ${ }^{18} \mathrm{~A}$ cranial boundary is not described.

Although described with these definite anatomical boundaries, the question remains if the paravertebral space is an as anatomically isolated space as assumed. In cadaver studies with contrast dye this contrast enclosed somatic and sympathetic nerves in the epidural, prevertebral, paravertebral and intercostal spaces. ${ }^{15}$ Even dispersion into the abdomen through medial and lateral arcuate ligaments arching over the psoas major muscle was shown. ${ }^{19}$ In addition radiological studies with contrast medium ${ }^{20,} 21$ and methylene blue ${ }^{22}$ showed cranial to caudal spreading of contrast along the paravertebral space, an intercostal dispersion pattern, a combination of both and an intrapleural or cloudy pattern. In a combined radiological and computer tomography study ${ }^{23}$ the radiological contrast remained restricted to the TPVS in only $18 \%$ of the cases.

\section{Aims of this anatomical cadaver study were:}

- To determine the anatomical boundaries of the TPVS in human thorax specimens by dissection of the several tissue layers from the inside to the outside.

- To describe the observed spread of fluid-like substances injected under ultrasound guidance in the TPVS. In this cadaver study plastic and dye are used as a model to mimic the dispersion of anesthetics injection fluid.

The observed findings are discussed in relation to clinical relevance. 


\section{MATERIALS AND METHODS}

For this study we used parts of three human cadavers: two formalin fixed thorax specimens and one un-embalmed fresh-frozen thawed trunk. Handwritten and signed codicils from the donors, as required by the Dutch law on body donation for scientific research, are kept at the Department of Anatomy and Embryology, Faculty of Health, Medicine and Life Sciences, Maastricht University, the Netherlands.

\section{Systematic dissection of formalin fixed thorax specimen}

The formalin fixed thorax specimens were positioned in supine position and were dissected from the inside to the outside. The anterior thoracic wall, inner organs, major blood vessels, esophagus and trachea were removed. The specimens were rinsed in running tap water. In each specimen, the stratification of the several layers from the inside to the outside was dissected, observed and photographed.

\section{Ultrasound-guided identification of TPVS in the fresh-frozen trunk}

The un-embalmed cadaver was positioned in prone position. The level of needle insertion was determined and the TPVS was localized by ultrasound using a linear array transducer of 12-5 MHz with an IU 22 ultrasound system (Philips). The sonographic orientation was standardized as described below. First, the ribs were identified from caudal to cranial and the different levels were marked..

Second, the probe was moved in a sagittal plane from lateral to medial along a specific rib. Third, the ultrasound operator identified the costo-transverse joint. Fourth, the probe was moved in a para-median and oblique direction, in a way that the ultrasound image on the proximal-cranial-medial section showed the costo-transverse transition with the rib of one level lower on the distal-caudal-lateral part. Using this procedure, it should be possible to identify the paravertebral space, the pleura and the aponeurosis of the internal intercostal muscle.

\section{Injection of plastic and dye in the TPVS in the fresh-frozen trunk}

Plastic and dye were used to model the dispersion of anesthetic injection fluid in the TPVS. To our knowledge, injection of plastic into the TVPS was not described earlier; therefore we decided to compare injection of plastic with that of methylene blue dye. ${ }^{15}$ To overcome extensive plastic and methylene blue dispersion over multiple intercostal levels, which was describe earlier, ${ }^{15}$, three levels several segments apart from each other at the left side and one level at the right side were selected. The TPVS was localized at the caudal inferior margins of rib 4, 6 and 10 on the left side and of rib 8 at the right side. An $18 \mathrm{~g}$ Tuohy needle was inserted in plane to the TPVS, with the bevel 
oriented to the cranial side. (Figure 1) After confirming the needle position sonographically and by hydro dissection with a small amount of water $(<1,0 \mathrm{ml}), 8-10 \mathrm{ml}$ of liquid catalyzed red plastic (Biodur ${ }^{\mathrm{TM}}$ epoxyresin E20, Biodur ${ }^{\mathrm{TM}}$ hardener E2) was injected on the left side. On the right side an epidural catheter was inserted and through this catheter $5 \mathrm{ml}$ methylene blue dye was injected. The physician operating the ultrasound

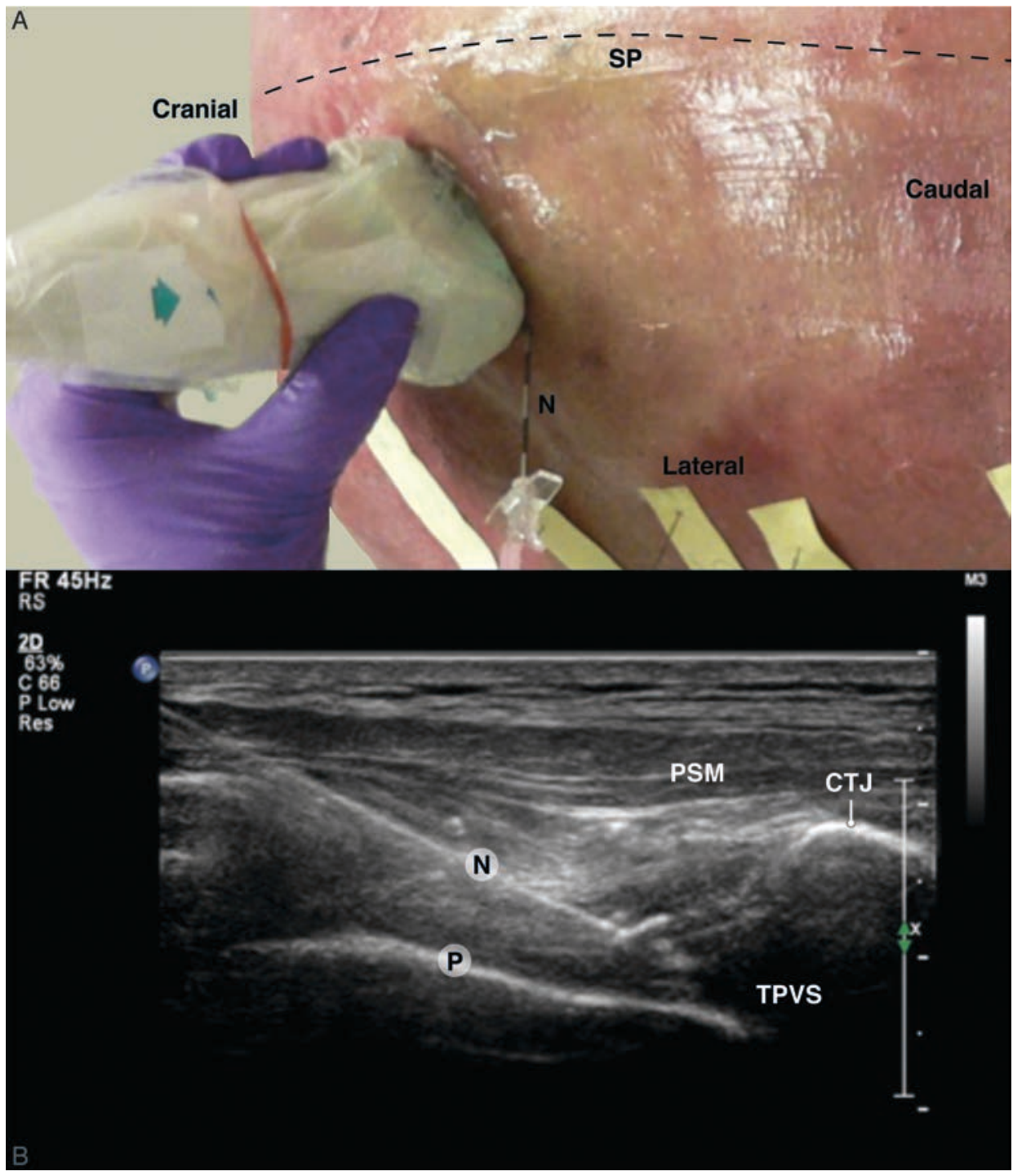

Figure 1. Ultrasound-guided injection.

A: External view (posterior) of unembalmed cadaver specimen showing ultrasound probe position B: Ultrasound-image (paramedian and oblique view) CTJ: costotransverse joint, N: needle, P: pleura, PSM: paraspinal muscle, SP: spinal column, TPVS: thoracic paravertebral space 
machine fixed the probe and needle and a second person performed the injection. In order to allow the plastic to cure, anatomical dissection was postponed until the next day.

Dissection of the TPVS was performed from posterior and anterior and locations of dye, plastic and needles were identified. Because the cadaver had to be turned for the anterior dissection it was necessary to cut the Tuohy needles.

The process of sonography-guided dye and plastic injection and posterior and anterior dissection was registered in photographs.

To consolidate tissues for further dissection and registration of the TPVS structures in detail it was necessary to fixate the un-embalmed trunk by submersion into formalin for several weeks.

\section{RESULTS}

The results are presented in two sections: (1) Stratification of the thoracic layers from the inside to the outside by anterior dissection of the formalin fixed thorax specimens, (2) Registration of the dispersion of US guided injected dye and plastic by posterior and anterior dissection of the un-embalmed trunk, followed by dissection of the TPVS structures in detail in this trunk after submersion fixation with formalin.

(1) Stratification of the thoracic layers by anterior dissection in the formalin fixed thorax specimens

The following stratification of the layers from the inside to the outside was identified and dissected: parietal pleura, endothoracic fascia, innermost intercostal muscle, neurovascular bundle (intercostal artery, vein and nerve), internal intercostal muscle and external intercostal muscle. The innermost intercostal muscle was the deep layer of the internal intercostal muscle. It was separated from the latter by the neurovascular bundle. The structure described as internal intercostal membrane in literature ${ }^{24}$ was in fact the aponeurosis of the innermost intercostal muscle. This aponeurosis was continuous with the connective tissue on the inner surface of the rib. The endothoracic fascia was a continuous connective tissue layer between the parietal pleura and the aponeurosis of the innermost intercostal muscles.

TPVS boundaries on the anterolateral side were the parietal pleura and the fibroelastic endothoracic fascia, separated from each other by a loose areolar sub serous fascia. On the posterior side the TPVS was limited by the transverse process and the superior costotransverse ligament, a thickened medial continuation of the aponeurosis of the internal intercostal muscle from the inferior aspect of the transverse process to the superior aspect of the rib tubercle below. Medially the vertebral body, the intervertebral disc and the intervertebral foramen were found as TPVS boundaries. The 
TPVS appeared to communicate with the contiguous cranial and caudal space, with the epidural space and with the contralateral paravertebral space through the intervertebral foramen or directly through the pre-vertebral space. Laterally it was found to be a continuous entity with the intercostal space.

The TPVS was found to be a non-segmental wedge shaped fat compartment alongside the thoracic vertebral column, containing the sympathetic chain at a depth of $1 \mathrm{~cm}$. Laterally it extended into lenticular shaped segmentally oriented dorsal intercostal compartments. From the costal angle each dorsal intercostal compartment narrowed to continue as an elongated fat pad along the neurovascular bundle, inferior to the adjacent rib. Each narrowing fat compartment guided the converging intercostal neurovascular bundle to the costal groove. (Figure 2)

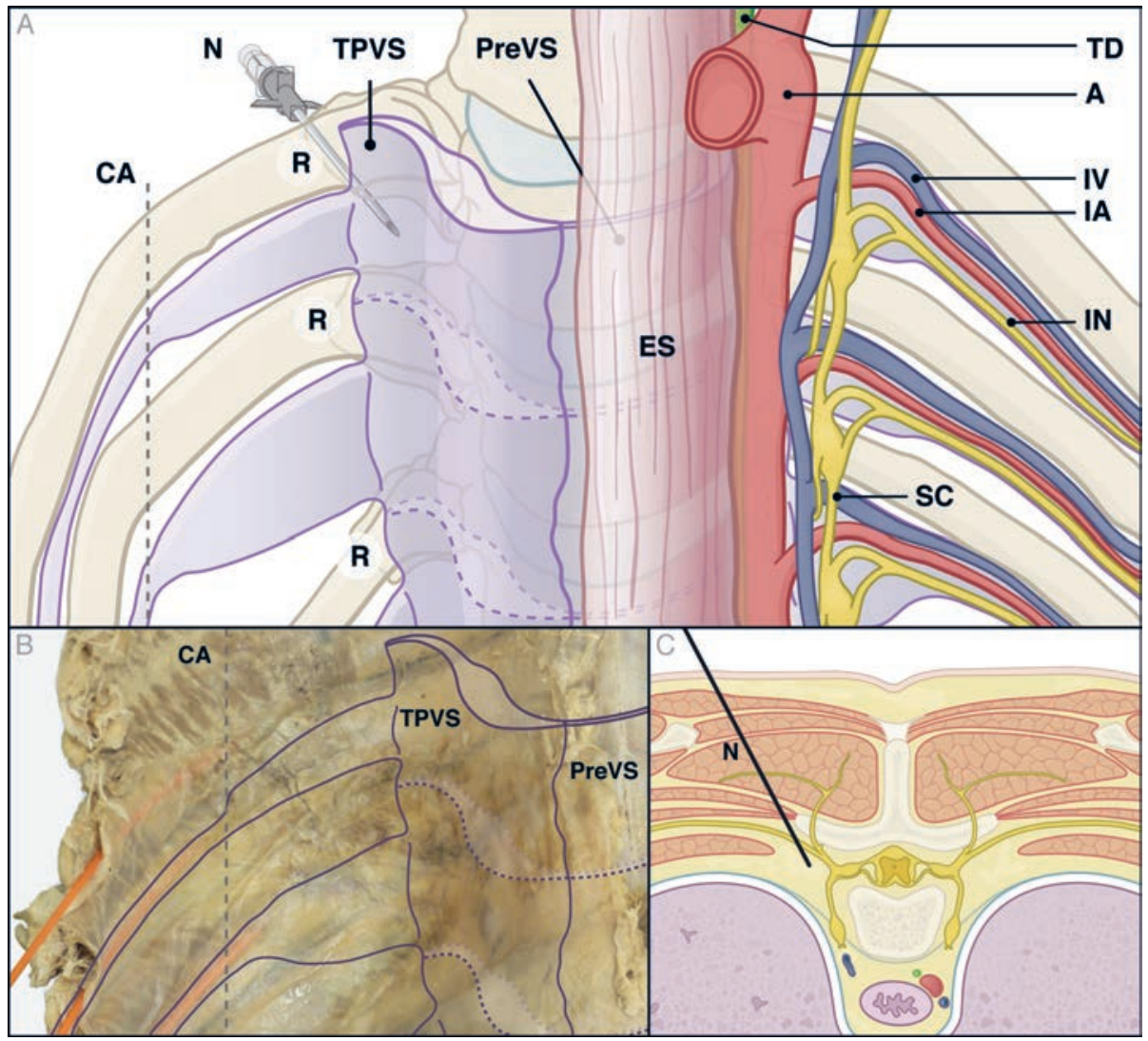

Figure 2. Schematic drawings

$(A, C)$ of thoracic paravertebral space with corresponding photograph of thoracic paravertebral space in formalin fixed thorax specimen (B) A and B: anterior view; C: transverse view.A; aorta, CA: costal angle, ES; esophagus, IA: intercostal artery, IN: intercostal nerve, IV; intercostal vein, $\mathrm{N}$ : needle, PreVS: prevertebral space, R: rib, SC: sympathetic chain, TD: thoracic duct, TPVS: thoracic paravertebral space. 
(2) Registration of the dispersion of US guided injected dye and plastic by posterior and anterior dissection of the un-embalmed trunk, followed by dissection of the TPVS structures in detail in this trunk after submersion fixation with formalin.

In the mid-thoracic region localization of the costotransverse transition, the pleura, the aponeurosis of the internal intercostal muscle and the TPVS was easy to achieve at the levels of rib 4 and 6 on the left side and rib 8 at the right side. At the level of rib 10 on the left side the clear identification of the TPVS was difficult because of the different and steep angle of the ribs. The oblique positioning of the probe obviated the disruption of the sonographic view by acoustic shadowing of the transverse process. However, hydro dissection improved the visibility. (Figure 1)

\section{Posterior injection and dissection}

Dissection from posterior revealed that the US-guided procedure resulted in correct position of the needles at the caudal inferior margins of rib 4 and 6 on the left side and rib 8 at the right side with plastic/dye along the puncture site. (Figure 3) Methylene blue was visible along the neurovascular bundle one level inferior to the insertion site. The needle tip ended up close to the lung, approximately $0.3 \mathrm{~cm}$ in vitro. In the posterior view methylene blue dye was demonstrated in the intercostal space. At the level of rib 10 on the left side a too superficial position of the Tuohy needle in the external intercostal muscles was demonstrated, with plastic distributed in the erector spinae muscle and external intercostal muscles. (Figure 3)

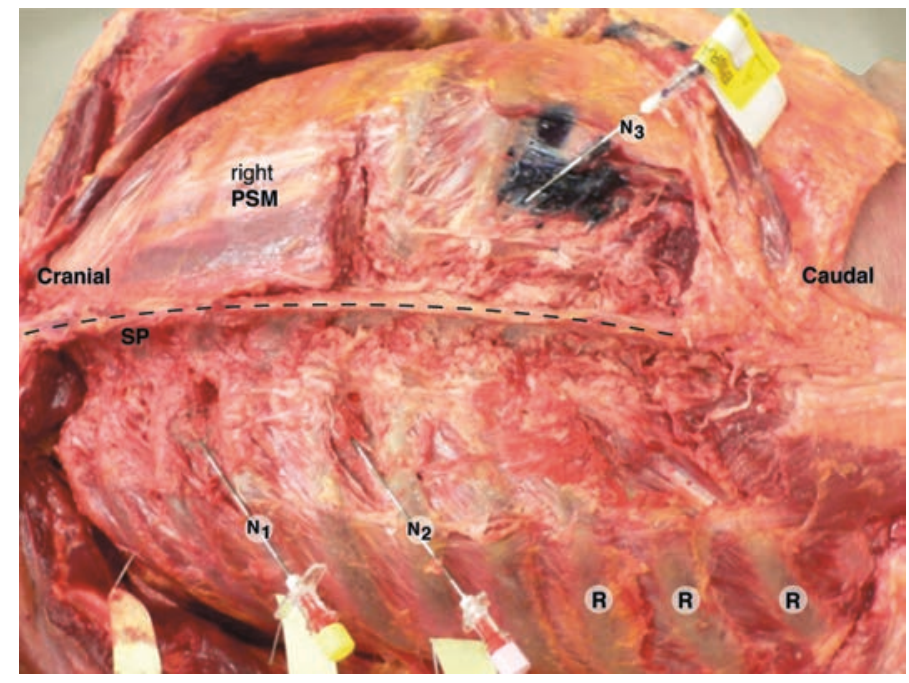

Figure 3. Dissected unembalmed cadaver (posterior view, left paraspinal muscles removed) $\mathrm{N}$ : needle, PSM: paraspinal muscle, R: rib, SP: spinal column 


\section{Registration of dye and plastic dispersion by anterior dissection}

After the removal of the anterior thoracic wall, inner organs etc. identification of the injected dye and plastic near anatomical structures was complicated by the presence of blood in the cadaver. The spread of plastic on the left side and methylene blue on the right side was directed cranially in the TPVS, towards the thoracic prevertebral space, and along the intercostal neurovascular space and stopped at the costal angle. No contralateral dispersion was found neither with plastic nor with methylene blue. Due to cured, hard plastic used in this technique it was not possible to dissect the epidural space. At the level of rib 10 no plastic was found in the TPVS. (Figure 4)

After rinsing the specimen in running tap water it became clear that the plastic on the left side had spread around the sympathetic chain and laterally beyond the costal angle. The methylene blue on the right side had spread at the level of puncture surrounding the azygos system, one level caudad along the neurovascular bundle and also posterior to the costo-diaphragmatic recess. This was shown more in detail after submersion into formalin and further dissection. (Figure $5 A$ \& B)

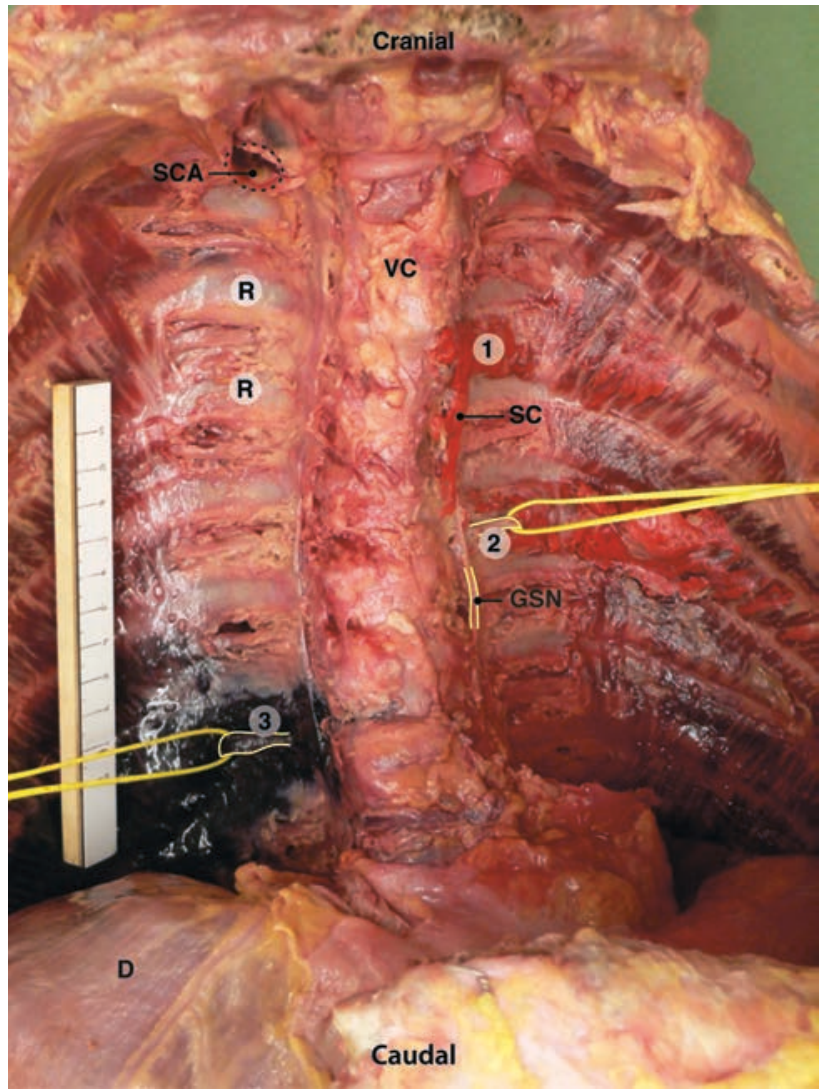

Figure 4. Dissected unembalmed cadaver (anterior view, anterior thoracic wall removed) D: diaphragm, GSN: greater splanchnic nerve, SC: sympathetic chain surrounded by plastic (N1), SCA: subclavian artery, VC: vertebral column, 1: intercostal spreading of plastic (N1), 2: intercostal nerve surrounded by plastic (N2), 3: intercostal nerve surrounded by methylene blue (N3) 


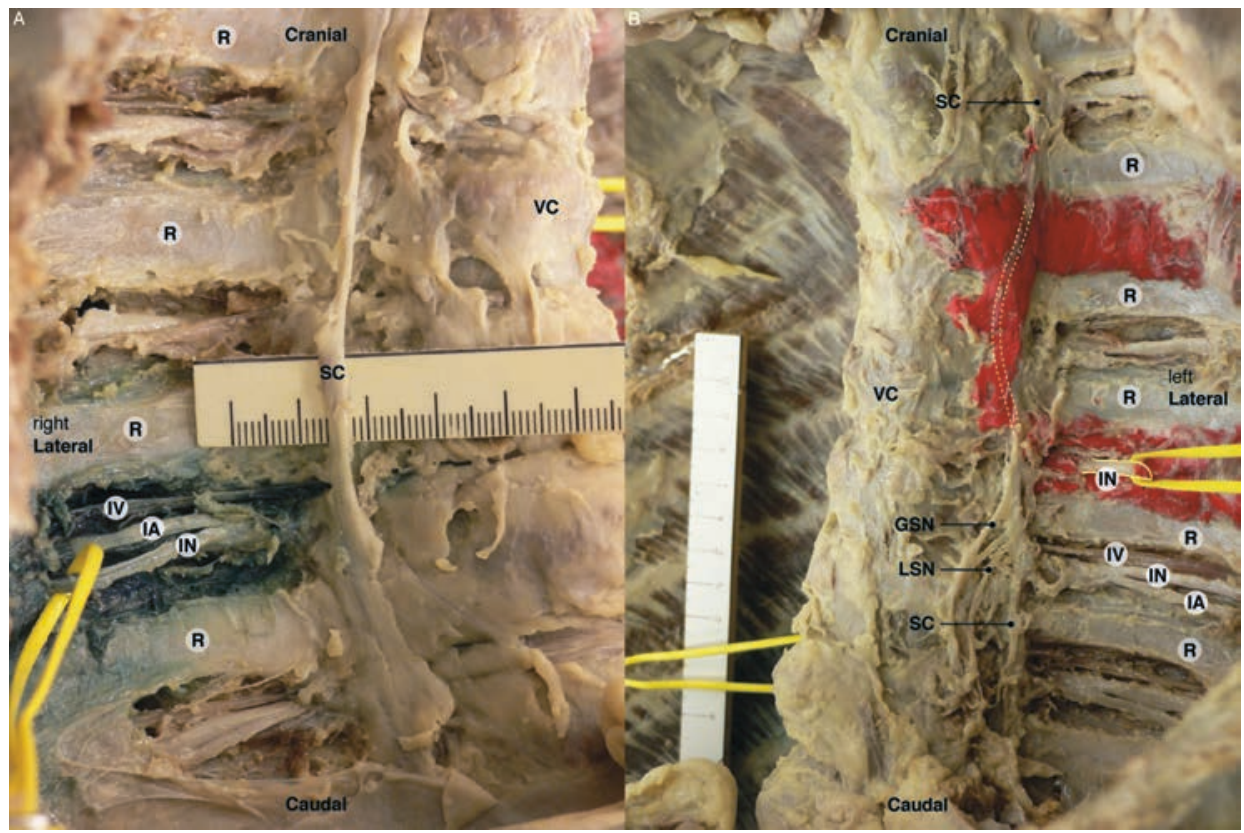

Figure 5. Deep dissection of formalin fixed cadaver (anterolateral view, right (A) and left (B) hemi- thorax, anterior thoracic wall removed)

GSN; greater splanchnic nerve, IA: intercostal artery, IN: intercostal nerve, IV: intercostal vein, LSN: lesser splanchnic nerve, SC: sympathetic chain, VC: vertebral column

\section{DISCUSSION}

The aims of this study were to determine the anatomical boundaries of TPVS and to describe the observed spread of fluid-like substances injected under ultrasound guidance in the TPVS.

\section{Summary of findings}

The anatomical boundaries of TPVS in the two formalin fixed human thorax specimens were found to be relative borders, as the TPVS appeared to communicate with all the surrounding structures. The wedge-shaped space filled with structures is in accordance with the literature. ${ }^{1,13,14}$ The TPVS was communicating with the dorsal intercostal compartments, showing a segmental partition. At the costal angle these compartments narrowed, passing into fat pads surrounding the intercostal neurovascular bundles. The separation of the TPVS in a sub-endothoracic and an extra-pleural compartment by the endothoracic fascia ${ }^{25}$ could not be confirmed.

The spread of the injected dye and plastic in the fresh frozen cadaver showed that a part of the effect of the thoracic paravertebral block can be attributed to the intercostal 
spread of the local anesthetic. The distribution of the injected dye and plastic makes a hemi blockade reasonable. The sympathetic chain is commonly included in the area involved. Furthermore we observed spread posterior to the costo-diaphragmatic recess.

\section{Methodological strengths and limitations}

Strength of this study was that we first dissected the TPVS in two formalin fixed thorax specimens and used results of this dissection to copy the clinical execution on an unembalmed human cadaver. The combination of two injection substances, methylene blue and plastic, was as far as we know not published before and made it possible to compare the spread of both. This is important because injection of an aqueous solution shows pre-, paravertebral and intercostal spread over multiple segments whereas isolated injection of viscous solution with limited spread gives a detailed picture of the regional anatomy.

The application of a cadaver specimen for the clinical execution is also a limitation of this study. Loss-of-resistance technique or neurostimulation is not feasible postmortem. The physical properties of structures identified may have altered due to post-mortem changes of the TPVS. This makes ultrasound obligatory, although, ultrasound in human cadavers differs from ultrasound in living humans, due to this change in physical properties. After all, in general cadaver studies offer the best possible approximation of clinical practice and it is possible to have a very close look at the anatomical spread after dissection.

\section{Anatomical considerations and comparison with literature}

We dissected two formalin fixed thorax specimens and an un-embalmed thawed trunk. From other anatomical studies we know that anatomical variations do exist. ${ }^{26}$ It is possible that our results are based upon such an anatomical variant. However, the extensive spread of dye along the cranial-caudal axis as described in a previous study of the thoracic vertebral spine ${ }^{15}$ was not found in our study. This could be due to the use of the smaller volume of methylene blue dye. Secondly the injection of dye and plastic was performed with the un-embalmed trunk in prone position. Furthermore the use of plastic is a different technique and due to the fact that the applied plastic is viscous, we needed a high pressure in the needle to execute it. It is possible that this high pressure caused part of the findings. Hence we used to different types of specimen fixation, three separate cadavers and two different injection substrates.

In our study the parietal pleura was located $0.3 \mathrm{~cm}$ from the insertion point of the Tuohy needle. During the opening of the thorax in a cadaver by dissection a pneumothorax occurs and therefore it must be assumed that the distance to the pleura in the in-vivo situation will be even smaller. The distance found from Tuohy needle to the parietal pleura is in concordance with a clinical study, ${ }^{27}$ which correlated the sonograph- 
ic depth of the parietal pleura with the needle depth necessary to perform an anatomical approach ${ }^{1}$ of the paravertebral block. With the technique described it was possible in human cadavers to localize the TPVS and the pleura in the upper thoracic levels. Below the level of the 8th rib the costo-transverse joint lies in a more horizontal position which hampers the sonographic view.

In line with an earlier anatomical study ${ }^{19}$ that showed spread of dye into the abdomen, we found spread of the methylene blue dye posterior to the costodiaphragmatic recess. The communication of the TPVS with the lumbar space can be explained by the fact that the abdominal transverse fascia is in fact a continuation of the endothoracic fascia.

\section{Clinical consequences}

The above mentioned theoretical considerations are important in order to understand clinical consequences of the TPVB. Direct penetration of local anesthetics into the neurological structures as the proposed mechanism of action ${ }^{28}$ is supported by the results of our study. The extensive spread of plastic and methylene blue along the sympathetic chain makes the occurrence of a Horner syndrome as a side-effect reasonable. ${ }^{29}$ The spread along the intercostal nerves may be an anatomical explanation for the abolishment of intercostal somatosensory evoked potentials ${ }^{30}$ and the prevention of chronic post-surgical pain. ${ }^{31}$

Failure rate and complications with TPVB are not systematically investigated, but some are known from two case series. ${ }^{32,33}$ Systematic investigation might be hampered by the variety of techniques used. Therefore we classified the probability of clinical consequences and complications in a 3 point rating scale based on our anatomical findings and on the technique we used. See table 1 The clinical consequences and risk of complications however depend on the technique of TPVB used: Blind performance with loss of resistance, nerve stimulator based, ultrasound based or surgical will have different implications. The likelihood of pneumothorax is probably higher with a blind or nerve stimulator based technique than with an ultrasound based one, whereas inevitable with a surgical technique. Furthermore, the consequences of a complication depend also on the surgery performed. After thoracotomy with thoracic drainage the consequences of a pneumothorax due to a TPVB are minimal, whereas in short stay programs in breast cancer surgery patients it is a major problem.

\section{Directions for future research}

It is important to evaluate the findings from this anatomical study and clinical practice, using modern imaging techniques like ultrasound, Computed Tomography and Magnetic Resonance Imaging. Clinical studies on the feasibility of ultrasound guided TPVB in patients, the effectiveness and its side-effects are needed. It is of great use to 
test if the ultrasound technique procedure used to identify the TPVS is suitable for daily clinical practice in terms of efficacy and safety.

Table 1. Probability of clinical consequences and complications in a 3-point rating scale

\begin{tabular}{llll}
\hline Structures & Spread dye/plastic & Clinical consequences/complications & $\begin{array}{l}\text { Clinical likelihood } \\
\text { with technique used }\end{array}$ \\
\hline $\begin{array}{l}\text { Neurovascular bundle } \\
\text { and intercostal space }\end{array}$ & Yes & Intercostal block & Likely \\
& Block failure & Possible \\
Endothoracic fascia & Yes & Vascular puncture & Possible \\
Parietal pleura & Yes, not penetrated & Pneumothorax & NA \\
Intervertebral foramen & Yes & Epidural or intrathecal spread LA & Possible \\
& & Hematoma & Possible \\
Prevertebral space & Limited & None & NA \\
Thoracic Duct & No & Puncture & Unlikely \\
(Hemi-)azygos vessels & No & Vascular puncture & Possible \\
Sympathetic chain & Yes & Sympatic blockade Horner syndrome & Likely \\
Paravertebral vessels & Yes & Vascular puncture & Possible \\
\hline
\end{tabular}

\section{CONCLUSIONS}

Based on this anatomical study we conclude that:

- The TPVS is a potential space which is restricted laterally by the costal angle

- The separation of the TPVS in a sub-endothoracic and an extra-pleural compartment by the endothoracic fascia could not be confirmed.

- The sympathetic chain is commonly involved in the TPVB

- Isolated injection of a catalyzed viscous polymer solution with limited spread gives a detailed picture of the topographic anatomy

\section{DISCLOSURES/FUNDING}

This study was conducted with departmental funding only. Department of Anesthesiology and Pain Management, Maastricht University Medical Center+, the Netherlands and Department of Anatomy and Embryology, Maastricht University, the Netherlands. 


\section{ACKNOWLEDGMENTS}

The authors thank Johan Hekking, B.Sc. (Department of Anatomy and Embryology, Maastricht University, Maastricht, The Netherlands), and Leon Huiberts, B.Sc. (Department of Anatomy and Embryology, Maastricht University, Maastricht, the Netherlands), for their technical assistance with the preparation, dissection, fixation of the human thorax specimens and trunk and the preparation of the liquid catalyzed red plastic. The authors also thank Greet Mommen, M.Sc. (Department of Anatomy and Embryology, Maastricht University, Maastricht, the Netherlands), for editing the ultrasound images and photographs and making the additional illustrations. 


\section{REFERENCES}

1. Eason MJ, Wyatt R. Paravertebral thoracic block-a reappraisal. Anaesthesia 1979, 34(7):638-642.

2. Kotze A, Scally A, Howell S. Efficacy and safety of different techniques of paravertebral block for analgesia after thoracotomy: a systematic review and metaregression. Br J Anaesth 2009, 103(5):626-636.

3. Davies RG, Myles PS, Graham JM. A comparison of the analgesic efficacy and side-effects of paravertebral vs epidural blockade for thoracotomy--a systematic review and meta-analysis of randomized trials. $\mathrm{Br} \mathrm{J}$ Anaesth 2006, 96(4):418-426.

4. Boezaart AP, Raw RM. Continuous Thoracic Paravertebral Block for Major Breast Surgery. Reg Anesth Pain Med 2006, 31(5):470-476.

5. Schnabel A, Reichl SU, Kranke P, Pogatzki-Zahn EM, Zahn PK. Efficacy and safety of paravertebral blocks in breast surgery: a meta-analysis of randomized controlled trials. Br J Anaesth 2010, 105(6):842-852.

6. Terheggen MA, Wille F, Borel Rinkes IH, Ionescu TI, Knape JT. Paravertebral Blockade for Minor Breast Surgery. Anesth Analg 2002, 94(2):355-359.

7. Tahiri Y, Tran de QH, Bouteaud J, Xu L, Lalonde D, Luc M, Nikolis A. General anaesthesia versus thoracic paravertebral block for breast surgery: a meta-analysis. J Plast Reconstr Aesthet Surg 2011, 64(10):12611269.

8. Buckenmaier CC, 3rd, Kwon KH, Howard RS, McKnight GM, Shriver CD, Fritz WT, Garguilo GA, Joltes KH, Stojadinovic A. Double-blinded, placebo-controlled, prospective randomized trial evaluating the efficacy of paravertebral block with and without continuous paravertebral block analgesia in outpatient breast cancer surgery. Pain Med 2010, 11(5):790-799.

9. Hadzic A, Kerimoglu B, Loreio D, Karaca PE, Claudio RE, Yufa M, Wedderburn R, Santos AC, Thys DM. Paravertebral blocks provide superior same-day recovery over general anesthesia for patients undergoing inguinal hernia repair. Anesth Analg 2006, 102(4):1076-1081.

10. Naja Z, Ziade MF, Lonnqvist PA. Bilateral paravertebral somatic nerve block for ventral hernia repair. Eur J Anaesthesiol 2002, 19(3):197-202.

11. Mandal MC, Das S, Gupta S, Ghosh TR, Basu SR. Paravertebral block can be an alternative to unilateral spinal anaesthesia for inguinal hernia repair. Indian J Anaesth 2011, 55(6):584-589.

12. Bansal P, Saxena KN, Taneja B, Sareen B. A comparative randomized study of paravertebral block versus wound infiltration of bupivacaine in modified radical mastectomy. J Anaesthesiol Clin Pharmacol 2012, 28(1):76-80.

13. Evans H KS. Paravertebral anesthesia. In: Anesthesiology. Volume 1, edn. Edited by B. D. DE Longnecker NM, Zapol WM. New York, USA: The McGraw-Hill Companies.; 2008: 1009-1024.

14. Karmakar MK. Thoracic paravertebral block. Anesthesiology 2001, 95(3):771-780.

15. Cowie B, McGlade D, Ivanusic J, Barrington MJ. Ultrasound-guided thoracic paravertebral blockade: a cadaveric study. Anesth Analg 2010, 110(6):1735-1739.

16. Richardson J, Lonnqvist PA. Thoracic paravertebral block. Br J Anaesth 1998, 81(2):230-238

17. Vallieres E. The costovertebral angle. Thorac Surg Clin 2007, 17(4):503-510.

18. Lonnqvist PA, Hildingsson $U$. The caudal boundary of the thoracic paravertebral space. A study in human cadavers. Anaesthesia 1992, 47(12):1051-1052.

19. Saito T, Den S, Tanuma K, Tanuma Y, Carney E, Carlsson C. Anatomical bases for paravertebral anesthetic block: fluid communication between the thoracic and lumbar paravertebral regions. Surg Radiol Anat 1999, 21(6):359-363.

20. Conacher ID, Kokri M. Postoperative paravertebral blocks for thoracic surgery. A radiological appraisal. Br J Anaesth 1987, 59(2):155-161.

21. Naja MZ, Ziade MF, El Rajab M, El Tayara K, Lonnqvist PA. Varying anatomical injection points within the thoracic paravertebral space: effect on spread of solution and nerve blockade. Anaesthesia 2004, 59(5):459-463.

22. Agnoletti V, Piraccini E, Corso R, Avino F, Rotondo C, Maitan S, Gambale G. Methylene blue diffusion after multilevel thoracic paravertebral blocks. J Cardiothorac Vasc Anesth 2011, 25(2):e5-6. 


\section{CHAPTER 5}

23. Purcell-Jones G, Pither CE, Justins DM. Paravertebral somatic nerve block: a clinical, radiographic, and computed tomographic study in chronic pain patients. Anesth Analg 1989, 68(1):32-39.

24. Marhofer P, Kettner SC, Hajbok L, Dubsky P, Fleischmann E. Lateral ultrasound-guided paravertebral blockade: an anatomical-based description of a new technique. Br J Anaesth 2010, 105(4):526-532.

25. Karmakar MK. Ultrasound-guided thoracic paravertebral block. Techniques in Regional Anesthesia and Pain Management 2009, 13(3):142-149.

26. Hogan QH. Epidural anatomy examined by cryomicrotome section. Influence of age, vertebral level, and disease. Reg Anesth 1996, 21(5):395-406.

27. Pusch F, Wildling E, Klimscha W, Weinstabl C. Sonographic measurement of needle insertion depth in paravertebral blocks in women. Br J Anaesth 2000, 85(6):841-843.

28. Richardson J, Lonnqvist PA, Naja Z. Bilateral thoracic paravertebral block: potential and practice. $\mathrm{Br} \mathrm{J}$ Anaesth 2011, 106(2):164-171.

29. Burlacu CL, Frizelle HP, Moriarty DC, Buggy DJ. Fentanyl and clonidine as adjunctive analgesics with levobupivacaine in paravertebral analgesia for breast surgery. Anaesthesia 2006, 61(10):932-937.

30. Richardson J, Jones J, Atkinson R. The effect of thoracic paravertebral blockade on intercostal somatosensory evoked potentials. Anesth Analg 1998, 87(2):373-376.

31. Andreae $\mathrm{MH}$, Andreae DA. Local anaesthetics and regional anaesthesia for preventing chronic pain after surgery. Cochrane Database Syst Rev 2012, 10:CD007105.

32. Lonnqvist PA, MacKenzie J, Soni AK, Conacher ID. Paravertebral blockade. Failure rate and complications. Anaesthesia 1995, 50(9):813-815.

33. Naja Z, Lonnqvist PA. Somatic paravertebral nerve blockade. Incidence of failed block and complications. Anaesthesia 2001, 56(12):1184-1188. 


\section{CHAPTER 6}

\section{Evaluation of two different epidural catheters}

in clinical practice. Narrowing down the incidence of paresthesia!

Esther A.C. Bouman, Hans-Fritz Gramke, Niels Wetzel, Theresia T.H. Vanderbroeck, Rein Bruinsma, Maurice Theunissen, Hans E.M. Kerkkamp, Marco A.E. Marcus

Acta Anaesthesiol Belg 2007, 58(2):101-105. 


\section{SUMMARY}

Although epidural anesthesia is considered safe, several complications may occur during puncture and insertion of a catheter. Incidences of paresthesia vary between 0.2 and $56 \%$.

A prospective, open, cohort-controlled pilot study was conducted in 188 patients, ASA I-III, age 19-87 years, scheduled for elective surgery and epidural anesthesia. We evaluated a $20 \mathrm{G}$ polyamide (standard) catheter and a $20 \mathrm{G}$ combined polyurethanepolyamide (new) catheter.

Spontaneous reactions upon catheter-insertion, paresthesia on questioning, inadvertent dural or intravascular puncture, and reasons for early catheter removal were recorded.

The incidence of paresthesia reported spontaneously was $21.3 \%$ with the standard catheter and $16.7 \%$ with the new catheter. Systematically asking for paresthesia almost doubled the paraesthesia rate. Intravascular cannulation occurred in 5\%. No accidental dural punctures occurred. An overall incidence of $13.3 \%$ of technical problems led to early catheter removal.

The new catheter was at least equivalent to the standard regarding epidural success rate and safety: rate of paresthesia, intravascular and dural cannulation. 


\section{INTRODUCTION}

Continuous epidural anesthesia is, besides for analgesia during labor, commonly used for postoperative analgesia. Although considered safe, several complications and problems may occur during epidural puncture and insertion of a catheter. ${ }^{1,2}$ Inadvertent dural puncture is reported between 0.04 to $6 \%$ and vascular cannulation occurs in $0.7 \%$ to $12 \%{ }^{3-5}$ Further complications are technical difficulties as breakage, kinking, coiling and entrapment during threading or removal of catheter. ${ }^{6-9}$ However the most frequently reported complication is paresthesia. Paresthesia usually does not lead to neurological sequelae but is an unpleasant sensation for the patient. ${ }^{10}$ Reported incidences of paresthesia vary between 0.2 and $56 \%$ depending on approach, patient characteristics, technique, and depth of insertion. ${ }^{4,5,11,12}$ Even an incidence as high as $89 \%$ was reported. ${ }^{13}$

Considering these high incidences of paresthesia, it would be recommendable, in the development of a new catheter, to determine the incidence of paresthesia in the replaceable catheter as well as in the new one.

To determine the incidence of paresthesia in the use of epidural catheters in two academic hospitals, we prospectively observed in a pilot study the clinical characteristics of two different epidural catheters.

\section{METHODS}

After approval of the local ethics committee we conducted a prospective, open, noninterventional clinical study on two different epidural catheters to determine the incidence of paresthesia during catheter insertion. Secondary objectives were: rate of inadvertent vascular cannulation, dural puncture, difficulties with insertion or removal of the catheter and additional complications. Reasons for removal of the epidural catheter were recorded.

In 188 surgical patients, ASA I-III, age 19-87 years, the application of two different epidural catheters in normal clinical practice in UMC Utrecht and Academic Hospital Maastricht was evaluated. A $20 \mathrm{G}$ polyamide catheter (Perifix standard, B.Braun Melsungen AG, Germany) was compared with a $20 \mathrm{G}$ combined polyurethane polyamide catheter (Perifix new, B.Braun Melsungen AG, Germany). The polyamide catheter is currently used as standard catheter in both institutions. The polyurethane polyamide catheter has an outer polyurethane liner and a polyamide body and softens reaching body temperature upon insertion. Therefore a reduced rate of paresthesia is expected. Both catheters are CE-marked. Information regarding the procedure and oral consent of epidural anesthesia for the surgery was obtained as usual.

Experienced anesthesiologists from both institutions performed all epidural procedures. An independent observer was present during puncture and catheter insertion. 
The patients were placed in a sitting position. After sterile preparation and subcutaneous infiltration with lidocaine $1 \%$ the epidural space was identified at a level between T6-T12 for thoracic epidural anesthesia (TEA) and at L1-L4 for lumbar epidural anesthesia (LEA) via the midline approach and the loss of resistance to saline technique using an $18 \mathrm{G}$ Perican ${ }^{\circledR}$ epidural needle (B.Braun Melsungen AG, Germany). Upon successful identification of the epidural space the catheter was inserted, at a depth of 4 to $5 \mathrm{~cm}$ beyond the needle tip. The patients were as opposed to daily practice not warned that they might feel an electric sensation.

Spontaneous reactions of the patient upon catheter-insertion were recorded. If the patient did not spontaneously report paresthesia, the observer asked explicitly for it.

As paresthesia we considered: pain, electric shock, discomfort, burning sensation, shooting effect, motor reactions, and similar experiences.

Intensity of paresthesia was scored using a visual analogue scale (VAS) ranging from 0 to 10 .

The insertion depth was documented. Fixation of the catheter was done according to standard hospital procedures using a transparent dressing and securing tape and the catheters were aspirated to exclude dural or intravascular positioning. The sensory block was tested 15 minutes after injection of a test dose of lidocaine $2 \%$ or bupivacaine $0.5 \%$, both with epinephrine $1: 200.000$ by cold sensation. Inadvertent dural or intravascular positioning of the catheter was recorded.

The epidural anesthesia was considered successful if a sensory blockade could be measured. If not, an extra injection of $5 \mathrm{ml}$ lidocaine $2 \%$ was given and the sensory blockade was re-evaluated. If again no block was achieved the catheter was removed.

Difficulties with catheter-insertion or removal were recorded.

\section{STATISTICAL ANALYSIS}

There are no published data on the frequency of paresthesia with the used catheters. We therefore estimated an incidence of paresthesia of $40 \%$ and assumed a clinically relevant

$50 \%$ reduction in paresthesia. For a pilot study with a power of $80 \%$ and two-tailed error of $5 \% 80$ patients per study phase were appropriate.

Statistical analysis was performed using SPSS for Windows (version 12.0) statistical package (SPSS Inc., Chicago, IL). Patient characteristics were analyzed using the Student $t$-test for independent groups (age, height, weight) and the $\chi^{2}$ test in a $2 \times 2$ contingency table (ASA-classification, sex, TEA/LEA). Paresthesia was analyzed using the $\chi^{2}$ test in a $2 \times 2$ contingency table and logistic regression; VAS was analyzed using Mann Whitney- U test.

A p value of $<0.05$ was considered statistically significant. 


\section{RESULTS}

From both institutions 188 patients were included. The standard catheter was used in 90 patients, the new one in 98 patients. Both groups were comparable regarding demographic data in age, gender, weight and ASA- classification. There was a small but significant difference in height. In the new catheter-group there were more thoracic epidural punctures. (Table 1)

Table 1. Patient characteristics, values are mean \pm SD for age, height, and weight and numbers for TEA/LEA, gender and ASA.

\begin{tabular}{llll}
\hline & Standard $(\mathrm{n}=90)$ & New $(\mathrm{n}=98)$ & $\mathrm{p}$ \\
\hline Age $($ year) & $58.5 \pm 16.3$ & $57.0 \pm 12.9$ & 0.49 \\
Height $(\mathrm{cm})$ & $169.8 \pm 8.8$ & $172.9 \pm 8.3$ & 0.015 \\
Weight $(\mathrm{kg})$ & $72.4 \pm 12.2$ & $76.2 \pm 15.8$ & 0.072 \\
TEA/LEA/missing & $62 / 27 / 1$ & $82 / 16$ & 0.023 \\
Male /Female/ missing & $48 / 39 / 3$ & $45 / 53 / 0$ & 0.21 \\
ASA status (I/II/III/missing) & $26 / 42 / 21 / 1$ & $27 / 55 / 16$ & 0.37 \\
\hline
\end{tabular}

TEA = Thoracic epidural anesthesia

LEA= Lumbar epidural anesthesia

The incidence of spontaneous paresthesia was $21.3 \%$ with the standard catheter and $16.7 \%$ with the new catheter $(p=0.42)$. Using multivariate logistic regression we found an Odds Ratio of 0.75 (95\% Cl 0.34-1.66). Adjusting for height and thoracic epidural punctures did not influence this. The incidence of paresthesia increased to $37.8 \%$ respectively $32.6 \%$ when the paresthesia on questioning was added.

The intensity of paresthesia was scored using VAS. (Figure 1)

There was no significant difference in VAS scores between the catheters.

The mean VAS of patients who reported paresthesia spontaneously was not higher than the VAS of patients who reported paresthesia on questioning. (Table 2) The most frequently reported sensation was discomfort (43.1\%) followed by pain (32.3\%) and electric shock (32.3\%), motor reactions (16.9\%), shooting effect (9.2\%) and other (7.6\%). No patient reported a burning sensation. Patients could indicate more than one option. From the patients who reported paresthesia, 35.4\% expressed more than 1 sensation. 


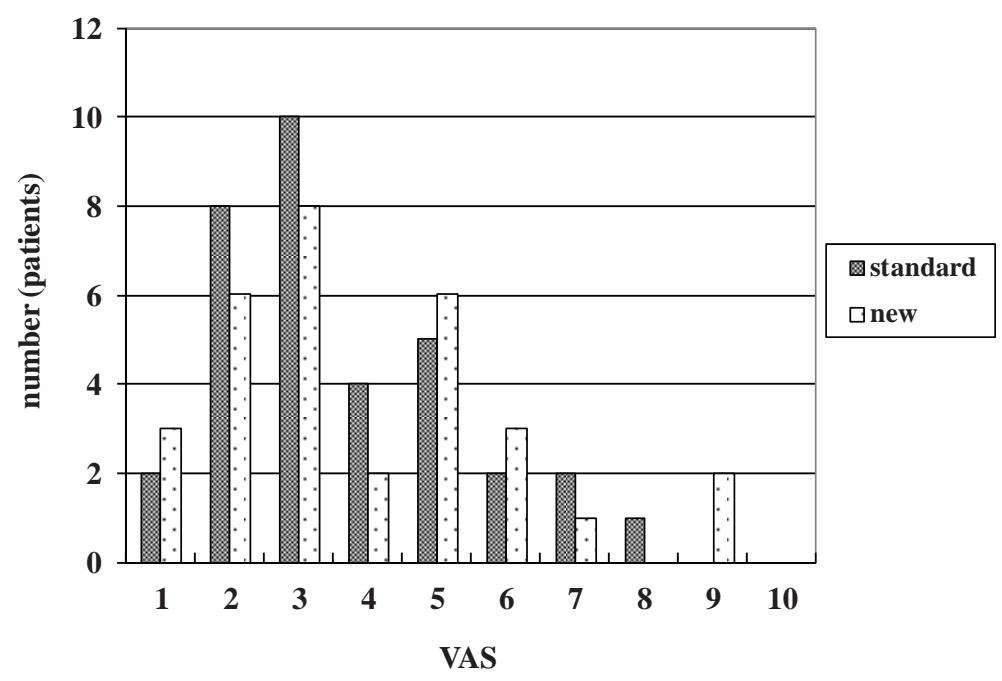

Figure 1. Intensity of paresthesia by VAS score

Table 2. VAS score of paresthesia: incidence $(n)$ and intensity of paresthesia on a visual analogue scale from 0 to 10 (mean \pm SD)

\begin{tabular}{llll}
\hline & $N$ & VAS & $p$ \\
\hline Spontaneously & 35 & $3.97 \pm 2.1$ & \\
Only on questioning & 28 & $3.57 \pm 1.6$ & 0.66 \\
\hline
\end{tabular}

With the standard catheter in 8 patients $(8,9 \%)$ there was blood in the catheter after aspiration, which persisted even after $1 \mathrm{~cm}$ withdrawal in 2 patients. With the new catheter in only 3 patients $(3,2 \%)$ inadvertent intravascular cannulation occurred, which persisted after $1 \mathrm{~cm}$ withdrawal in 2 patients. In 8 (72.7\%) cases in which the catheter was placed intravascular the level of catheter insertion was between T10 and L1. (Figure 2)

No dural punctures or cannulation occurred.

With both catheters a high success rate of epidural analgesia was achieved. $(91.1 \%$ and $87.8 \%$ respectively)

Reasons for removal of the epidural catheter were: catheter not epidural, insufficient analgesia or dislodged catheter, disconnection, obstruction or occlusion, accidental removal, kinking, and backflow of local anesthetic. We observed an overall incidence of $13.3 \%$ technical problems leading to early catheter removal. 


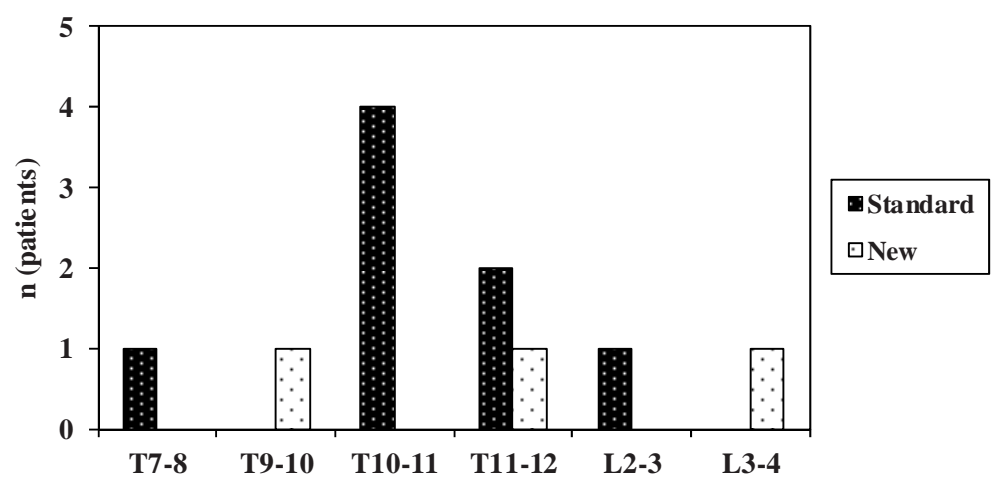

Figure 2. Intravascular cannulation and level of catheter insertion

\section{DISCUSSION}

This study showed that the new catheter was at least equivalent to the standard catheter in success rate of epidural anesthesia, rate of paresthesia, intravascular cannulation and dural puncture.

The incidence of spontaneous paresthesia varied between 16.7 and $21.3 \%$ and almost doubled by systematically asking for it.

The incidence of intravascular cannulation was 3,2 and 8,9\% respectively. This was not significant.

Despite a well-functioning acute pain service we report an incidence of treatment failures due to technical problems of $13.3 \%$.

We are aware that the study design is not optimal to compare different epidural catheters.

However as we were not aware of the incidences of paresthesia, rate of inadvertent vascular cannulation, dural puncture, difficulties with insertion or removal of the used catheter, we decided to evaluate it in a pilot study. The incidences of spontaneous paresthesia and intravascular cannulation were similar as reported in previous studies. $^{11,14}$

We found a surprisingly high overall paresthesia rate. In daily practice we warn patients that they might feel an electrical sensation. The clinical relevance is not very well known, but as patients do report mean VAS scores of almost 4 (on a scale from 0 to 10) the sensation is at least relevant for the patient. Therefore reduction of paresthesia could attribute to improvement of quality of care.

Striking was that with both catheters about $50 \%$ of the patients, who experienced paresthesia did not report this spontaneously, but only on questioning. However the intensity of the sensation quantified by VAS was equivalent in both groups. Statistics about paresthesia therefore underestimate the real incidence of paresthesia. 
Regarding intravascular cannulation one could speculate about a possible difference due to technical aspect of the catheters. As the new catheter softens with the body temperature the new catheter is less expected to migrate intravascular. However the study was not powered to detect these differences.

The success rate of epidural analgesia is not only determined by successful introduction of catheter. The catheters ought to work as long as analgesia is required. Therefore we have to study the problems leading to early catheter removal.

A lot of articles addressing technical problems with epidural catheters e.g. coiling, ${ }^{9}$ kinking, ${ }^{15}$ and breakage ${ }^{6}$ are case reports.

Our results are consistent with a large audit in 5628 surgical patients ${ }^{16}$ where an incidence of $14 \%$ technical en $8 \%$ treatment failure was observed. However our numbers are too small to make any definitive statements. In the future we need more audits to insure a standard quality of care.

We conclude that the new catheter was at least equivalent to the standard catheter regarding epidural success rate and safety: rate of paresthesia, intravascular and dural cannulation.

Although the clinical relevance of paresthesia during epidural catheter insertion is not known the sensation is relevant to the patients as they report high VAS scores. Reduction of incidence of paresthesia could improve quality of care.

Since patients do not always report paresthesia spontaneously, structured questionnaires are required to avoid the underestimation of the overall incidence of paresthesia.

A difference regarding intravascular cannulation was not shown, due to lack of power of the study.

\section{ACKNOWLEDGMENTS}

The authors would like to thank Dr. M.J.M.Gielen for his support during the study and valuable comments and Myra Monsewije for her support during the conduct of the study.

\section{CONFLICT OF INTEREST}

For the conduct of the study the authors did not receive external financial support. 


\section{REFERENCES}

1. Puolakka R, Haasio J, Pitkanen MT, Kallio M, Rosenberg PH. Technical aspects and postoperative sequelae of spinal and epidural anesthesia: A prospective study of 3,230 orthopedic patients. Reg Anesth Pain Med 2000, 25(5):488-497.

2. Auroy Y, Narchi P, Messiah A, Litt L, Rouvier B, Samii K. Serious complications related to regional anesthesia: results of a prospective survey in France. Anesthesiology 1997, 87(3):479-486.

3. Banwell BR, Morley-Forster P, Krause R. Decreased incidence of complications in parturients with the arrow (FlexTip Plus) epidural catheter. Can J Anaesth 1998, 45(4):370-372.

4. Blomberg RG, Jaanivald A, Walther S. Advantages of the paramedian approach for lumbar epidural analgesia with catheter technique. A clinical comparison between midline and paramedian approaches. Anaesthesia 1989, 44(9):742-746.

5. Tanaka K, Watanabe R, Harada T, Dan K. Extensive application of epidural anesthesia and analgesia in a university hospital: incidence of complications related to technique. Reg Anesth 1993, 18(1):34-38.

6. Asai T, Yamamoto K, Hirose T, Taguchi H, Shingu K. Breakage of Epidural Catheters: A Comparison of an Arrow Reinforced Catheter and Other Nonreinforced Catheters. Anesth Analg 2001, 92(1):246-248.

7. Beydon L, Conreux F, Le Gall R, Safran D, Cazalaa JB. Analysis of the French health ministry's national register of incidents involving medical devices in anaesthesia and intensive care. Br J Anaesth 2001, 86(3):382-387.

8. Ates Y, Yucesoy CA, Unlu MA, Saygin B, Akkas N. The Mechanical Properties of Intact and Traumatized Epidural Catheters. Anesth Analg 2000, 90(2):393-399.

9. Lim YJ, Bahk JH, Ahn WS, Lee SC. Coiling of lumbar epidural catheters. Acta Anaesthesiol Scand 2002, 46(5):603-606.

10. Aldrete JA. Neurologic deficits and arachnoiditis following neuroaxial anesthesia. Acta Anaesthesiol Scand 2003, 47(1):3-12.

11. Leeda M, Stienstra R, Arbous MS, Dahan A, Th Veering B, Burm AG, Van Kleef JW. Lumbar epidural catheter insertion: the midline vs. the paramedian approach. Eur J Anaesthesiol 2005, 22(11):839-842.

12. Cesur M, Alici HA, Erdem AF, Silbir F, Yuksek MS. Administration of Local Anesthetic Through the Epidural Needle Before Catheter Insertion Improves the Quality of Anesthesia and Reduces Catheter-Related Complications. Anesth Analg 2005, 101(5):1501-1505.

13. Hetherington R, Stevens RA, White JL, Spitzer L, Koppel S. Subjective experiences of anesthesiologists undergoing epidural anesthesia. Reg Anesth 1994, 19(4):284-288.

14. Cartagena R, Gaiser RR. Advancing an epidural catheter $10 \mathrm{~cm}$ then retracting it $5 \mathrm{~cm}$ is no more effective than advancing it $5 \mathrm{~cm}$. J Clin Anesth 2005, 17(7):528-530.

15. Roddin MJ, Dancey FM. Kinking of epidural catheters. Anaesthesia 2000, 55(8):831.

16. Ballantyne J, McKenna J, Ryder E. Epidural analgesia--experience of 5628 patients in a large teaching hospital derived through audit. Acute Pain 2003, 4:89-97. 



\section{CHAPTER 7}

\section{Paresthesia rate of two different epidural catheters: \\ a randomized single-blind non-inferiority trial}

Esther A.C. Bouman, Hans-Fritz Gramke, Maurice Theunissen, Marco A.E. Marcus 


\section{ABSTRACT}

Background: Paresthesia with insertion of an epidural catheter is a common finding which can be disturbing to both the patient and the anesthesiologist. This study aimed to assess non-inferiority of a recently introduced polyurethane-polyamide catheter, compared to a $20 \mathrm{G}$ polyamide catheter with regard to incidence of spontaneous paresthesia with insertion. Secondary endpoints were incidence of accidental dural puncture, inadvertent vascular puncture, and handling characteristics.

Methods: A randomized, prospective, single-blind non-inferiority trial was conducted in 131 patients, ASA I-III, age 18 to 90 years, who were scheduled for elective surgery under thoracic epidural anesthesia (TEA) at level from T4 toT10. Spontaneous reactions by patients upon catheter insertion were recorded, as well as inadvertent dural, intravascular positioning of the catheter and handling characteristics. Per protocol analysis was performed in 121 patients, using a non-inferiority margin of 0.20 .

Results: Paresthesia was reported spontaneously in $12.3 \%$ of the patients which were inserted with the $20 \mathrm{G}$ polyamide catheter and $20.3 \%$ of the patients receiving the polyurethane-polyamide catheter. This resulted in a risk difference of $0.08(95 \% \mathrm{Cl}-$ $0.05-0.21$ ). No accidental dural punctures occurred. No significant differences with regard to inadvertent vascular puncture were noted nor reasons for the early discontinuation of postoperative epidural analgesia treatment. However, flow problems occurred more frequently with the polyurethane-polyamide as compared to the $20 \mathrm{G}$ catheter, 7 versus $0(p=0.01)$.

Conclusion: The present study was not conclusive in establishing (non-)inferiority of the recently introduced polyurethane-polyamide catheter regarding paresthesia at insertion.

Trial registration: www.clinicaltrials.gov, NCT00394459 


\section{BACKGROUND}

Medical companies often change the materials used for the production of invasive devices like epidural catheters. Currently, only a CE marking is required to replace epidural catheters used in daily practice. However, due to the different physical properties in vitro ${ }^{1}$ and in vivo ${ }^{2}$, complication rates and handling characteristics of epidural catheters may vary. Common features of epidural catheters are tensile strength, stretch resistance, shaft stability, and visualization of blood or spinal fluid, no risk of forming loops or knots, and pliability.

To our knowledge, there is a lack of studies that investigate whether a change in materials of the epidural catheter, for example from polyamide to a combined polyurethane-polyamide catheter, may influence the complication rates and handling characteristics. Due to the polyurethane outer layer, the combined polyurethanepolyamide catheter, with an outer polyurethane liner and an inner polyamide body, softens while reaching the body temperature and as a consequence a lower incidence of spontaneous paresthesia is expected. In a previous cohort study, we evaluated the complications related to the use of both polyamide and of polyurethane-polyamide catheters $^{3}$ and reported an $18.9 \%$ overall incidence of spontaneous paresthesia, a $5 \%$ incidence of intravascular cannulation, and a $13.3 \%$ incidence of treatment failures. However no statistical significant differences in complications were noted after use of polyurethane-polyamide and polyamide catheters. ${ }^{3}$ Whereas these observations were based on a non- randomized and not controlled study in which both thoracic and lumbar epidural catheters were used a randomized controlled trial with only thoracic epidural catheters is needed to provide more conclusive results. Hence, the aim of the present study was to perform a randomized controlled trial on non-inferiority of a new $20 \mathrm{G}$ epidural catheter with an outer polyurethane liner and an inner polyamide body in particular with respect to spontaneously reported paresthesia after insertion, as compared to a $20 \mathrm{G}$ polyamide standard epidural catheter.

\section{METHODS}

After approval by the ethics committee of the University Hospital Maastricht/Maastricht University, and with registration at www.clinicaltrials.gov, NCT00394459, a randomized, prospective, parallel group, single-blind non-inferiority trial was conducted. We evaluated the rate of spontaneously reported paresthesia upon insertion of two different epidural catheters in 131 patients, ASA I-III, age 18-90 years, who were scheduled for elective surgery using thoracic epidural anesthesia. (TEA) Written informed consent was obtained from the participants. Exclusion criteria were: all contraindications for epidural analgesia, severe scoliosis, previous surgery on the spine, ankylosing spondylitis, non-competent and non-cooperative patients, drug abuse, 
communication problems, and participation in other clinical studies. Patients were enrolled between May 2005 and November 2007.

We compared a $20 \mathrm{G}$ polyamide catheter (Perifix Standard, B. Braun Melsungen AG, Germany) with a $20 \mathrm{G}$ combined polyurethane-polyamide catheter (Perifix ONE, B. Braun Melsungen AG, Germany). Both catheters are CE marked.

After sterile preparation, local analgesia of the puncture site was provided by subcutaneous infiltration of lidocaine $4 \mathrm{ml}$ 1\%. An epidural puncture was performed with the patient in sitting position between levels T4-T10 using an $18 \mathrm{G}$ Tuohy needle (B. Braun Melsungen AG, Germany). A midline or paramedian approach was allowed, depending on the personal preference of the anesthesiologist. In the event of puncture difficulties at the first attempt, one second attempt at another level was allowed. Assignment to one of the two catheter groups took place immediately before placement. A substitute catheter from the same group was used for the second attempt in the event of catheter placement failure. Insertion depth of the epidural catheter was restricted to a range of $4-5 \mathrm{~cm}$ beyond the needle tip, measured by the distance markings on the catheter. The insertion was carried out by experienced anesthesiologists or residents who were in at least their third year of training. Staff members of the study informed the patient when the catheter insertion started but made no reference to paresthesia at that point in the procedure. The staff members first observed to see if there was a spontaneous reaction from the patient. If the patient did not give a spontaneous reaction, the observer systematically inquired if the patient felt or experienced anything like shooting effect, any electrical sensation, discomfort, burning sensation, pain, motor reaction, pressure, or otherwise. For each patient, these questions were asked in the same manner and at the same time after the catheter insertion. Patients were visited postoperatively by the hospital acute pain service (APS) in order to provide adequate pain relief and to identify possible handling problems on the ward.

The null hypothesis was that the combined polyurethane-polyamide catheter for TEA is inferior to the polyamide catheter, and results in more spontaneous reported paresthesia at insertion. The primary outcome measure was the incidence of spontaneous paresthesia upon catheter insertion. The secondary outcome measures were the incidence of paresthesia both spontaneously reported or upon questioning (total paresthesia), intensity of paresthesia (VAS 0-10), and characteristics of paresthesia. The efficacy of epidural analgesia was assessed by measuring the level of sensory blockade 15 minutes after administration of a test dose and by evaluating whether epidural analgesia was effective postoperatively. Inadvertent dural or intravascular positioning of the catheter was recorded as well as handling features (classified as either: no difficulties at catheter insertion, minor difficulties, major difficulties, or unable to threat), early discontinuation, and damage to the catheter. The characteristics of the patients and details of the surgical procedure were collected. 
Based on the data of a previous pilot study with the polyamide catheter for epidural anesthesia, ${ }^{3}$ we found a proportion of patients without complaints at 0.74 in the subgroup of TEA. At an alpha of $5 \%$, and a power of $80 \%$, we calculated a minimum of 60 patients per group.

Because of the wide range of reported incidences of paresthesia up to $56 \%{ }^{3}$ a noninferiority margin of 0.2 for spontaneous paresthesia caused by the polyurethanepolyamide catheter was chosen. Block randomization was determined by a computer generated list. The manufacturer provided sealed envelopes numbered for the purpose of randomization. Anesthesiologists were not blinded for type of catheter due to logistical reasons; the polyamide catheter is achromatic while the combined polyurethane-polyamide catheter is yellow. Per protocol analyses were performed. Patients were excluded in the case of catheter insertion depth of $\geq 6 \mathrm{~cm}$. Statistical analyses were performed using the Student's t-test for parametric data, Mann-Whitney U test for non-parametric data, and Chi-square test and Fisher Exact test for categorical data. Statistical analyses were performed using the Statistical Package for the Social Sciences (SPSS ${ }^{\oplus}$ version 15, Chicago, Illinois, USA). Risk difference and 95\% confidence interval (Cl) of the incidence of spontaneous paresthesia were calculated using STATA 11 (StataCorp, College Station, Texas, USA). A p-value $<0.05$ was considered to be statistically significant.

\section{RESULTS}

The participant flow is described in Figure 1. Due to a catheter insertion of $6 \mathrm{~cm}$ or more six patients in the polyurethane-polyamide group and three patients in the polyamide group were excluded. In the polyamide group one patient was excluded because the epidural space could not be localized. No differences in baseline data between the two groups were noted, except for ASA classification. (Table 1)

Main results are summarized in Table 2. The risk difference for incidence of spontaneous paresthesia was $0.08(-0.05-0.21)$. As the $\mathrm{Cl}$ exceeds the non-inferiority margin of 0.2 , this study is inconclusive with regard to testing (non-)inferiority.

No significant effect of catheter insertion depth on paresthesia rates was observed (Chi-square $0.061 \mathrm{df} 4 \mathrm{p}=0.96$ ). The following characteristics of paresthesia were noted (polyurethane-polyamide versus polyamide group): electrical sensation 11 versus 8, pressure 7 versus 5 , pain 5 versus 2, discomfort 2 versus 2 , shooting effect 2 versus 1 , burning 2 versus 1 , motor reaction 0 versus 0 , otherwise 4 versus 3 , missing 2 versus 1 . No dural puncture or spinal cannulation occurred. Additional secondary outcomes, like dislocation, non-satisfactory block and co-morbidity are included into Table 3. As the flow problems using the polyurethane-polyamide catheter, like high resistance, catheter occlusion, and kinking of the catheter could not be attributed to an in vitro obstruction; the reason for malfunctioning of the catheters remains unknown. 


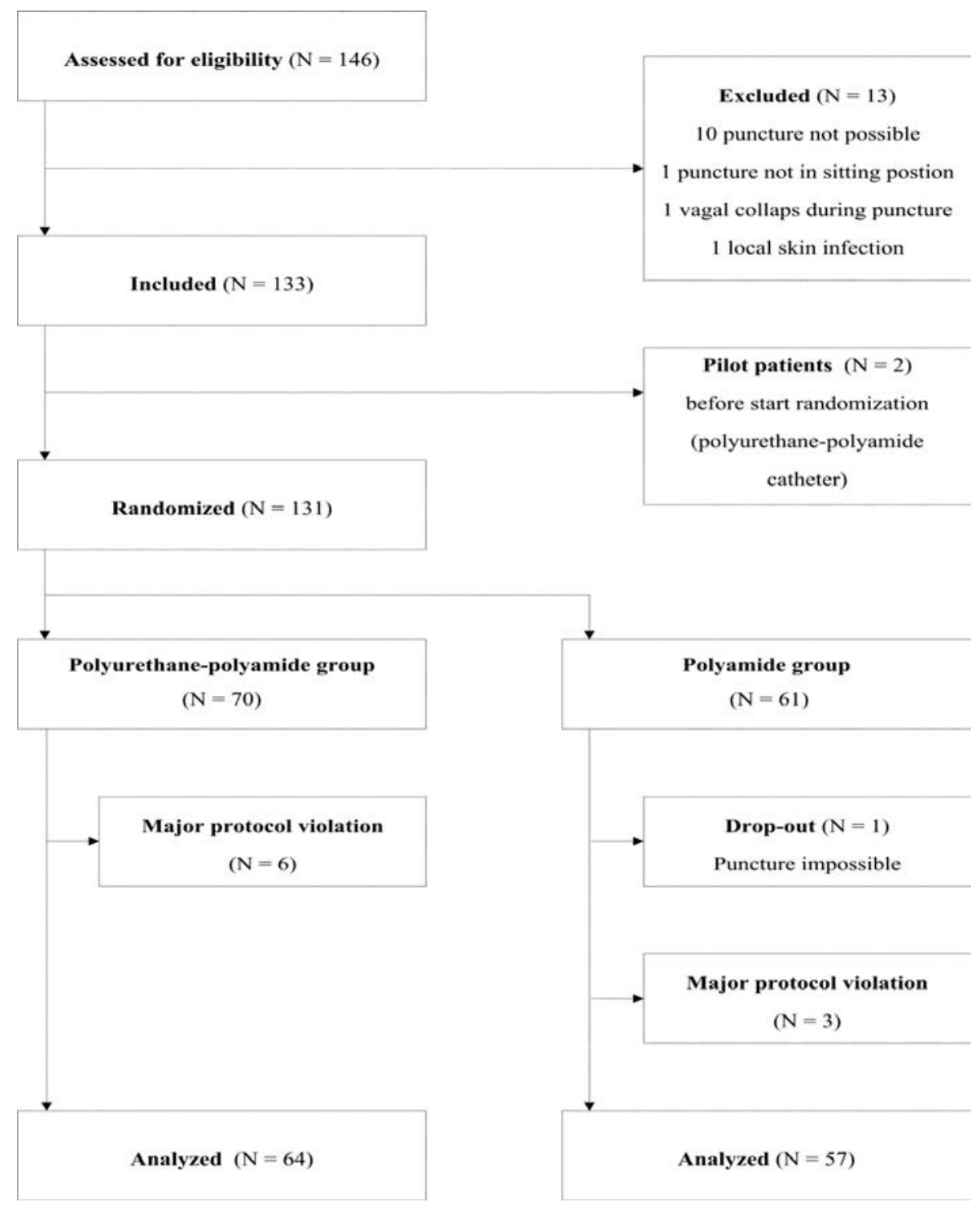

Figure 1. Flow diagram of participants and recruitment 
Table 1. Baseline characteristics ( $N=121)$

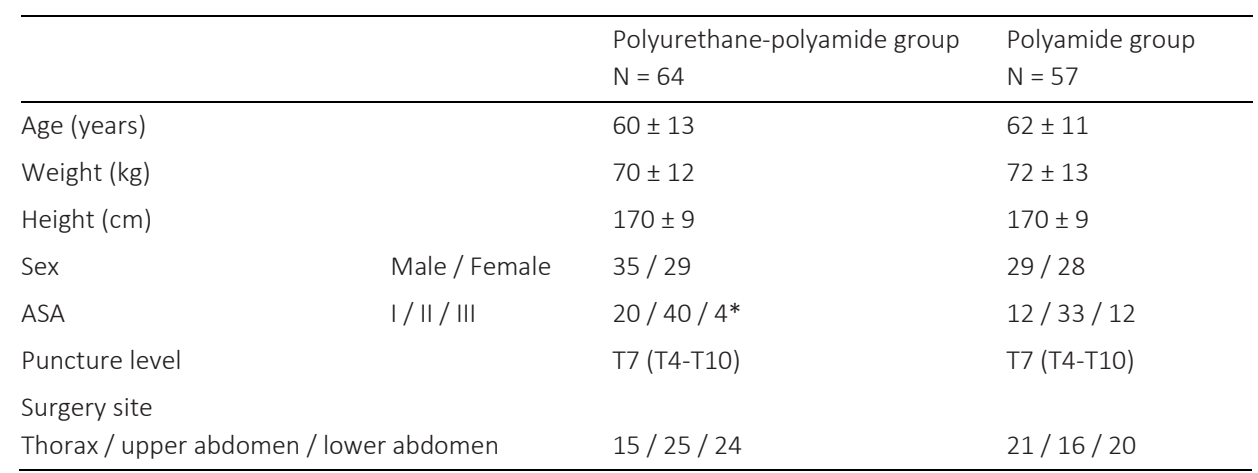

Age, weight and height: mean \pm standard deviation. Gender, ASA, and surgery site: number. The median of the puncture level is represented within the range (T4-T10). ${ }^{*} p=0.04$

Table 2. The incidence of paresthesia (Per protocol analysis, $\mathrm{N}=121$ )

\begin{tabular}{lll}
\hline & $\begin{array}{l}\text { Polyurethane-polyamide group } \\
\mathrm{N}=64\end{array}$ & $\begin{array}{l}\text { Polyamide group } \\
\mathrm{N}=57\end{array}$ \\
\hline $\begin{array}{l}\text { Spontaneous paresthesia* } \\
\text { Yes }\end{array}$ & $13(20.3)$ & $7(12.3)$ \\
No & $51(79.7)$ & $50(87.7)$ \\
Total paresthesia** & & \\
Yes & $35(54.7)$ & $23(40.4)$ \\
No & $29(55.3)$ & $34(59.6)$ \\
\hline
\end{tabular}

*Odds ratio $(95 \% \mathrm{Cl}) 1.82(0.67-4.94)$, risk difference $(95 \% \mathrm{Cl}) 0.08$ (-0.05- 0.21). **Odds ratio $(95 \% \mathrm{Cl}) 1.78$ (0.87-3.68), risk difference $(95 \% \mathrm{Cl}) 0.14$ (-.03-0.32). Total paresthesia: paresthesia both spontaneously reported or upon questioning. Values are numbers $(\%) .(95 \% \mathrm{Cl})=95 \%$ confidence interval.

Handling problems consisted of problems with curling of the catheters and resistance at catheter insertion. APS reported minor difficulties handling the polyurethane-polyamide catheter in 5 patients at removal of the catheter; no problems were reported for the polyamide catheter $(p=0.04)$. Catheter-related adverse effects were: ineffective pain treatment $(n=2$, one in the polyamide group and one in the polyurethane-polyamide group) and pain at the puncture site ( $n=1$, polyamide group). None of the catheterrelated adverse effects was serious. 
Table 3 Secondary outcomes $(N=121)$

\begin{tabular}{|c|c|c|c|}
\hline & & $\begin{array}{l}\text { Polyurethane-polyamide group } \\
N=64\end{array}$ & $\begin{array}{l}\text { Polyamide group } \\
\mathrm{N}=57\end{array}$ \\
\hline Severity paresthesia & VAS $0 / 1-3 />4$ & $30 / 24 / 10$ & $35 / 13 / 9$ \\
\hline \multicolumn{2}{|l|}{ Dural cannulation } & 0 & 0 \\
\hline \multicolumn{2}{|l|}{ Intravascular placement catheter } & 4 & 5 \\
\hline \multicolumn{2}{|l|}{ Success rate (\%) } & 93.8 & 84.2 \\
\hline Handling problems at insertion & Minor / Serious & $4 / 1$ & $5 / 0$ \\
\hline \multicolumn{4}{|l|}{ Early discontinuation } \\
\hline & Disconnection & 4 & 5 \\
\hline & Flow problems & $7 *$ & 0 \\
\hline & Dislocation & 6 & 5 \\
\hline & $\begin{array}{l}\text { Non-satisfactory } \\
\text { block }\end{array}$ & 5 & 5 \\
\hline & Co-morbidity & 3 & 1 \\
\hline & $\begin{array}{l}\text { No other reason } \\
\text { described }\end{array}$ & 3 & 3 \\
\hline
\end{tabular}

Values are numbers. Severity paresthesia: Visual Analogue Scale (0-10). Flow problems*: $p=0.01$; high resistance, catheter occlusion, and kinking of the catheter after insertion. Co-morbidity: fever $(n=1)$, vasovagal collapse $(n=1)$, neurological deficit $(n=1)$, death $(n=1)$. Success rate: satisfactory block after surgery (60 out of 64 and 48 out of 57)

\section{DISCUSSION}

The present randomized controlled study was not conclusive in establishing noninferiority of the recently introduced polyurethane-polyamide catheter as compared to the polyamide catheter based on paresthesia at insertion.

Literature reports incidences of paresthesia related to insertion of catheters which vary between very low $(0.16 \%)^{4}$ to intermediate, ${ }^{5-8}$ and can be as high as $56 \%$ or more." 10 The incidence of paresthesia tends to be higher in older studies, ${ }^{9-12}$ which may be related to the fact that a tendency in daily practice arose for selecting the smaller sized catheters (20 G) instead of the larger $18 \mathrm{G}$ catheters over the years. In addition, manufacturers developed new materials ${ }^{13-15}$ to decrease catheter-related problems. Nevertheless, even nowadays an incidence of paresthesia of $30 \%$ is reported. ${ }^{2}$ Although paresthesia usually does not lead to neurological sequelae, it still is perceived as an unpleasant sensation for the patient. ${ }^{16}$ On the other hand studies have been presented which report a close relation between neurological deficits and paresthesia as two thirds of the patients who developed neurologic deficits had either paresthesia during needle placement or pain upon injection. ${ }^{17}$

In our view, this randomized single-blinded controlled study is well prepared, as sample size, power analysis and non-inferiority margins were based on a literature 
study and a previously published cohort study. ${ }^{3}$ Furthermore patients were well informed about the randomized controlled study and that they may feel something when the catheter is being inserted. The paresthesia was meticulously monitored.

In the reference polyamide catheter group, the incidence of spontaneous paresthesia was lower than we expected based on our previous cohort study. ${ }^{3}$ Several reasons may explain this finding. First, in order to avoid too many technical problems with localization of the epidural space, we excluded those patients who might benefit from a different catheter, as there are previous spine surgery and ankylosing spondylitis. These patients have been documented to report a higher incidence of paresthesia, traumatic needle placement and accidental dural puncture. $6,18,19$ Second, because of the overall higher incidence of complications related to low thoracic and lumbar epidural analgesia ${ }^{3,4}$ and a decreasing number of procedures suitable for lumbar epidural analgesia we only included patients with thoracic epidurals. Finally, all procedures were performed by experienced anesthesiologists or residents, although epidural catheter placements as performed by inexperienced anesthesia residents under supervision was shown not to be associated with a significantly greater number of complications than previously reported in the literature. ${ }^{20}$ As a consequence, the lower than expected paresthesia rate in combination with the non-inferiority margin used led to an inconclusive result of our study.

Another limitation of the study is the single-blind design. Unfortunately the different physical properties of the catheters did not allow to conduct this study in a double-blind way.

Regarding the secondary objectives of this study, epidural analgesia was effective regardless of the catheter used. However, statistically significant and clinically relevant handling problems in the postoperative setting occurred with the combined polyurethane-polyamide catheter during the conduct of the study. More flow problems including high resistance, catheter occlusion, and kinking were noted in patients inserted with the polyurethane-polyamide catheter as compared to those inserted with the polyamide device. Although this kind of characteristics are generally tested in vivo ${ }^{21}$ the problems in daily practice are usually not reported or reported in case reports only. $^{22-24}$

Medical companies engage in the continuing process of product development with the aim to improve materials and devices used for invasive therapy. Properties of the new materials used in these products may vary and they may influence how these devices are handled and how they affect complications. Even though a new device is CE marked before introduction, anesthesiologists are confronted with devices that look different, feel different, and might even require different skills to use them safely. As with changes in the formulation of medications, our present observations strongly suggest that also changes in materials and devices need to be tested in vivo with Phase IV clinical trials. Moreover the results of these in vivo tests should be published in 
scientific journals which then allows the anesthesiologist to make an optimal choice of materials and devices used in their clinical practice.

\section{CONCLUSIONS}

Although the present randomized controlled trial did not show a difference in spontaneous paresthesia occurring in patients inserted with thoracic epidural polyurethane-polyamide versus polyamide catheters this study was not conclusive in establishing (non-)inferiority of the polyurethane-polyamide catheter. No significant difference in the rate of satisfactory blockades after surgery was noted. Secondary outcomes of this study revealed that significantly more flow problems, like high resistance, catheter occlusion and kinking of the catheter occurred in patients inserted with the new polyurethane-polyamide catheter as compared to those inserted with the polyamide device.

\section{COMPETING INTERESTS}

E Bouman received travel support for the ESICM meeting 2012 from B. Braun Medical B.V., Oss the Netherlands. $M$ Theunissen received travel support for the ESRA meeting 2008 from B. Braun Melsungen AG, Germany. The Department of Anesthesiology (MUMC+) received financial support (Grünenthal) for consultancy activities (M Marcus).

\section{FUNDING}

This study was sponsored by B. Braun Melsungen AG, Germany.

\section{ACKNOWLEDGMENTS}

The authors would like to thank Dr. M.J.M. Gielen for his support during the study and his valuable comments, Myra Monsewije for her support during the performance of the study, and Paulien Copper of Medical Translations for her support as language editor. 


\section{REFERENCES}

1. Eckmann DM. Variations in epidural catheter manufacture: implications for bending and stiffness. Reg Anesth Pain Med 2003, 28(1):37-42.

2. Kundra P, Viswanath SK, Meena DS, Badhe A. Insertion length and resistance during advancing of epidural catheter. J Anesth 2009, 23(4):494-499.

3. Bouman EA, Gramke HF, Wetzel N, Vanderbroeck TH, Bruinsma R, Theunissen M, Kerkkamp HE, Marcus MA. Evaluation of two different epidural catheters in clinical practice. narrowing down the incidence of paresthesia! Acta Anaesthesiol Belg 2007, 58(2):101-105.

4. Tanaka K, Watanabe R, Harada T, Dan K. Extensive application of epidural anesthesia and analgesia in a university hospital: incidence of complications related to technique. Reg Anesth 1993, 18(1):34-38.

5. Cesur M, Alici HA, Erdem AF, Silbir F, Yuksek MS. Administration of local anesthetic through the epidural needle before catheter insertion improves the quality of anesthesia and reduces catheter-related complications. Anesth Analg 2005, 101(5):1501-1505.

6. Hebl JR, Kopp SL, Schroeder DR, Horlocker TT. Neurologic complications after neuraxial anesthesia or analgesia in patients with preexisting peripheral sensorimotor neuropathy or diabetic polyneuropathy. Anesth Analg 2006, 103(5):1294-1299.

7. Kim JH, Lee JS, Kim DY. Direction of catheter insertion and the incidence of paresthesia during continuous epidural anesthesia in the elderly patients. Korean journal of anesthesiology 2013, 64(5):443-447.

8. Leeda M, Stienstra R, Arbous MS, Dahan A, Th Veering B, Burm AG, Van Kleef JW. Lumbar epidural catheter insertion: the midline vs. the paramedian approach. Eur J Anaesthesiol 2005, 22(11):839-842.

9. Hetherington R, Stevens RA, White JL, Spitzer L, Koppel S. Subjective experiences of anesthesiologists undergoing epidural anesthesia. Regional anesthesia 1994, 19(4):284-288.

10. Rolbin SH, Halpern SH, Braude BM, Kapala D, Unger R, Radhakrisnan S. Fluid through the epidural needle does not reduce complications of epidural catheter insertion. Can J Anaesth 1990, 37(3):337-340.

11. Rolbin SH, Hew E, Ogilvie G. A comparison of two types of epidural catheters. Can J Anaesth 1987, 34(5):459-461.

12. Sarna MC, Smith I, James JM. Paraesthesia with lumbar epidural catheters. A comparison of air and saline in a loss-of-resistance technique. Anaesthesia 1990, 45(12):1077-1079.

13. Caldwell M, Dellaria S, Niedzwiecki C. Stretching of epidural nylon catheters on removal. Reg Anesth 1996, 21(4):379-380.

14. Kim P, Meyer U, Schupfer G, Rukwied R, Konrad C, Gerber H. Tensile strength decreases and perfusion pressure of 3-holed polyamide epidural catheters increases in long-term epidural infusion. Reg Anesth Pain Med 2011, 36(2):151-155.

15. Tsui BCH, Finucane B. Tensile Strength of 19- and 20-Gauge Arrow Epidural Catheters. Anesth Analg 2003, 97(5):1524-1526.

16. Aldrete JA. Neurologic deficits and arachnoiditis following neuroaxial anesthesia. Acta Anaesthesiol Scand 2003, 47(1):3-12.

17. Auroy Y, Narchi P, Messiah A, Litt L, Rouvier B, Samii K. Serious complications related to regional anesthesia: results of a prospective survey in France. Anesthesiology 1997, 87(3):479-486.

18. Hebl JR, Horlocker TT, Kopp SL, Schroeder DR. Neuraxial blockade in patients with preexisting spinal stenosis, lumbar disk disease, or prior spine surgery: efficacy and neurologic complications. Anesth Analg 2010, 111(6):1511-1519.

19. Tetzlaff JE, Dilger JA, Wu C, Smith MP, Bell G. Influence of lumbar spine pathology on the incidence of paresthesia during spinal anesthesia. Reg Anesth Pain Med 1998, 23(6):560-563.

20. Dalsasso M, Grandis M, Innocente F, Veronese S, Ori C. A survey of 1000 consecutive epidural catheter placements performed by inexperienced anesthesia trainees. Minerva Anestesiol 2009, 75(1-2):13-19.

21. Chiu JW, Goh MH. An in vitro evaluation of epidural catheters: tensile strength and resistance to kinking. Ann Acad Med Singapore 1999, 28(6):819-823. 


\section{CHAPTER 7}

22. Bajaj P, Raiger LK, Raman V. Kinking of epidural catheter--a case report. Middle East journal of anesthesiology 2003, 17(3):463-466.

23. Hsin ST, Chang FC, Tsou MY, Liao WW, Lee TY, Lui PW, Luk HN. Inadvertent knotting of a thoracic epidural catheter. Acta Anaesthesiol Scand 2001, 45(2):255-257.

24. Sexton AJ. Double kinking of a thoracic catheter within the epidural space. Anaesth Intensive Care 2012, 40(4):732-733. 


\section{CHAPTER 8}

General discussion and Summary 

In this thesis we analyzed and investigated various risks and benefits of regional anesthesia in relation to different type of surgery and high-risk patient populations, chronic post-surgical pain, acute pain and anesthetic device characteristics.

We addressed the following research questions.

\section{Does regional anesthesia improve outcome of peripheral vascular surgery as compared to general anesthesia?}

In Chapter 2 we present an overview of current regional anesthesia techniques and strategies in a high-risk patient population undergoing peripheral bypass surgery. Our review showed that no superiority either of general, neuraxial, or local anesthesia or peripheral nerve blocks for this type of high-risk surgery can be demonstrated. At the same time we stated in this review that, even in the high risk patient population of peripheral bypass surgery, it is complicated to study the mode of anesthesia in relation to peri-operative morbidity and mortality. Surprisingly the present literature on this subject is scarce and the most recent analysis of the Cochrane collaboration ${ }^{1}$ consisted only of 4 randomized controlled trials (RCT), analyzing studies from 1986-2007. Why is it then so difficult to perform RCT's in these peripheral bypass patients? Although the relative risk of mortality and morbidity in this patient population is relatively high, absolute numbers of patients involved in complications remain low ${ }^{2}$ and thus a lot of patients have to be included in order to make evidence based recommendations. Inclusion of patients into RCT's in general is often complicated by the fact that they are excluded to participate based on age, co-morbidity and use of therapeutic anticoagulation." ${ }^{3,4}$ Inclusion is further hampered by the fact that often the (elderly) patients are involved in other long term studies, which can make it unethical to include them in another study.

Nevertheless from our review we suggest that regional anesthesia supplemented by or in combination with either general anesthesia or monitored anesthesia care should be applied in view of a complete and comprehensive perioperative approach. This comprehensive perioperative approach includes not only combining anesthesia techniques. It is unlikely that one factor like regional anesthesia in itself may significantly change outcome. ${ }^{5}$ A comprehensive perioperative approach and enhanced recovery program matching patient health risk factors, pre-operative risk assessment, anesthesia monitoring and selecting the most appropriate type of anesthesia in combination with the anticipated abdominal surgical procedure is more likely to change outcome and is currently only standard care in colorectal surgery. A comprehensive perioperative approach has shown to reduce overall morbidity rates and shortened the length of hospital stay in patients with colorectal surgery, without increasing readmission rates. ${ }^{6}$ Regional anesthesia i.e. thoracic epidural analgesia is one of the major prerequisites of the enhanced recovery program. ${ }^{5,7}$ This fast track surgery/ accelerated or enhanced recovery program is at present incorporated in a lot of surgical pathways, like hernia 
repair, thoracic and cardiac surgery, open aortic surgery and total hip and knee arthroplasty $^{5}$, but should be extended to all procedures.

It should be noted that more focus at the individual patient and a tailored patient centered attitude is expected to significantly further improve the comprehensive perioperative approach. However, this may be difficult to prove as this inherently will lead to selection bias in studies, or a control group that may be more at risk for complications. Functional capacity of patients, whether dependent or not, may be suitable to select patients at risk for mortality and perioperative complications. ${ }^{8}$ Subdivision of ASA-III patients based on the functional capacity, independent or not, was helpful selecting the more vulnerable patients. ${ }^{8}$ For this group of vulnerable elderly patients at least additional depth of anesthesia and neuromuscular monitoring ${ }^{9}$ is indicated in case of general anesthesia. Regional anesthesia alone or in combination with monitored anesthesia care or general anesthesia may offer an alternative. However, the choice of the anesthetic technique used, either regional or general, may be limited by the continuous use of perioperative anticoagulants. ${ }^{10}$

It is without any doubt that in future developments the comprehensive perioperative approach and enhanced recovery program will be further improved based on patient individual characteristics to allow a tailor made anesthetic treatment regime and that the individual genetic print of a patient due to results of pharmacogenetic studies $^{11}$ then definitely will be included and used to perform a risk analysis based on specific patient characteristics.

\section{Does regional anesthesia reduce the incidence of chronic postsurgical pain in patients undergoing abdominal surgery?}

In order to answer RQ2 a case-control study was performed in consecutive patients scheduled for elective open abdominal surgery who either received epidural anesthesia in combination with general anesthesia or general anesthesia alone. (Chapter 3). We report an overall incidence of chronic post-surgical pain (CPSP) of $25.7 \%$, which is in accordance with that reported in literature. ${ }^{12-15}$ We furthermore noted that patients with CPSP reported a significantly lower quality of life compared to patients without CPSP. After adjustment for prominent predictors of CPSP as there are not only age and gender but also pre-operative and acute postoperative pain, postoperative epidural analgesia was associated with a reduced incidence of CPSP after abdominal surgery. Studies on the effect of epidural anesthesia compared to general anesthesia with regard to the occurrence of CPSP are limited in number because the possibilities for randomized controlled trials ( $R C T^{\prime}$ 's) are restricted as continuous epidural analgesia is superior to patient controlled intravenously administrated analgesia up to 72 hours. ${ }^{16}$ Hence cohort studies are the second best option. The obvious absence of RCTs implies that it is extremely difficult to substantiate and demonstrate a causal relationship between epidural anesthesia and the occurrence of CPSP. On the other hand reproducible 
observations based on various cohort studies can provide scientific evidence which is needed for recommendation.

In the field of acute postoperative pain several opportunities exist to elaborate a causal relationship between regional anesthesia and the occurrence of CPSP because several new complementary therapies are available. These therapies do allow the testing of clinically beneficial effect based on RCT's. Lidocaine intravenous ${ }^{17,18}$ and intraperitoneal infusion, ${ }^{19}$ transverse abdominal plane (TAP) block ${ }^{20,21}$ and rectus sheath blocks ${ }^{22}$ are in this respect, promising regional anesthetic techniques with a clinically beneficial effect based on positive RCT's. Whereas, at present, no superiority of these new complementary techniques in the field of acute pain is yet proven, RCT's are needed to compare them with established techniques as related to the occurrence of acute postoperative pain. In this respect, the focus should, however, not only be the acute postoperative pain. Clearly, future clinical studies are urgently needed to evaluate the impact of these regional anesthetic techniques and the development of CPSP.

\section{Is there an additional value of regional anesthesia (paravertebral block) with respect to acute postoperative pain as compared to local wound infiltration?}

Paravertebral block is one of the possibilities for regional anesthesia of the trunk. The majority of the studies on use of paravertebral blocks compare general anesthesia alone with regional anesthesia i.e. paravertebral block. Local wound infiltration is common clinical practice. It is therefore that we performed a randomized controlled clinical trial $(R C T)$ in unilateral major breast cancer surgery patients receiving general anesthesia (GA) either in combination with continuous thoracic paravertebral block (GA-cPVB) or single shot (GA-sPVB) as compared to GA supplemented by local wound infiltration (GALWI) and acute postoperative pain. (Chapter 4) We hypothesized that improved acute postoperative pain relief would be achieved by using a continuous paravertebral block (GA-cPVB) compared to local wound infiltration (GA-LWI). The findings, however, were not in favor of our hypothesis as GA-CPVB and GA-LWI were equally effective in treatment of acute postoperative pain in these major unilateral breast cancer surgery patients. At present PVB is not recommended for routine use and minor breast cancer surgery. ${ }^{23}$ The latter might also be the case in major oncological breast surgery as well.

It should be taken into account that our results are based on a relatively small study group and that GA-SPVB as one of the arms of this study, had to be stopped. Furthermore the conduct of this study was hampered by a slow inclusion rate, a low proportion of screened patients suitable for inclusion, and a high proportion of patients refusing participation in the study. Therefore we do not know whether our results may be extrapolated to a more general population. Consequently additional further RCT's are needed to demonstrate the effectiveness of GA-PVB versus GA-LWI focused at acute postoperative pain but also on the development of CPSP in patients scheduled for unilateral thoracic surgery. 
4. What are the anatomical boundaries of the thoracic paravertebral space in view of the potential risks and benefits of the thoracic paravertebral block?

In Chapter 5 we describe the results of a human cadaver study on the thoracic paravertebral block. We determined the anatomical boundaries of TPVS in human thorax specimens and described the observed spread of fluid-like substances injected under ultrasound (US) guidance in the thoracic paravertebral space (TPVS). Our anatomical data show that TPVS communicated with all surrounding structures including the dorsal intercostal compartments, showing a segmental partition. Subdivision of TPVS in a sub-endothoracic and an extra-pleural compartment by the endothoracic fascia could not be confirmed. Injected plastic and dye were observed posteriorly to the costo-diaphragmatic recess and showed segmental intercostal spread.

Hence we conclude that the anatomical boundaries of the TPVS were relative borders as the TPVS communicated with all surrounding neurological structures.

Although TPVB is known for a long time new clinical insights and applications warrant a closer look into the anatomical details. The anatomical data as described in Chapter 5 of this thesis result in a better insight into the clinical effects and side-effects of the TPVB and afforded a glance behind the scenes regarding a possible mechanism of action: the clinical effects and side-effects of the TPVB are related to a direct penetration of local anesthetics into the surrounding neurological structures.

\section{What is the impact of technical characteristics of catheters used in regional} anesthesia on the performance in patients scheduled for elective surgery during normal daily practice under thoracic or lumbar epidural anesthesia?

In Chapters 6 and 7 we describe the results of clinical studies with respect to the incidence of paresthesia at introduction of a recently developed epidural catheter. In a pilot study (Chapter 6) the incidence of spontaneously reported paresthesia with a standard polyamide catheter was shown to be $21.3 \%$ and $16.7 \%$ with use of a combined polyurethane-polyamide catheter. Furthermore an overall intravascular cannulation incidence of $5 \%$ and overall incidence of technical problems in $13.3 \%$ leading to premature catheter removal was noted in this pilot study. The results of the follow-up non-inferiority randomized controlled trial (Chapter 7) could partially confirm the pilot-study data. The findings of this RCT were at the end inconclusive in demonstrating non-inferiority of the polyurethane-polyamide catheter and showed significantly more flow problems postoperatively.

In the highly technical environment anesthesiologists are used to work, it is striking to see that the quality and impact of new industrial products like epidural catheters in a clinical setting are still not systematically investigated. 
Anesthetic devices account for about $2 \%$ of all new marked devices worldwide. At the same time these anesthetic devices do account for 30-40\% of all alerts. ${ }^{24,25}$ Whereas pharmacological drugs require extensive systematic clinical investigations and documentation on their effects and side-effects before approval the systematic testing and clinical data for clinical approval of anesthetic devices is extremely limited. ${ }^{26}$ Only the so-called high-risk anesthetic devices are likely to have undergone extensive and systematic clinical testing before approval. High risk or Class III devices are usually those that support or sustain human life, are of substantial importance in preventing impairment of human health, or present a potential, unreasonable risk of illness or injury. ${ }^{27}$ These high risk anesthetic devices are evaluated by the U.S. Food and Drug Association ( FDA) in the United States of America ${ }^{27}$ and by Notified Bodies i.e. standard organizations supervised by Competent Authority of each country of the European Union. ${ }^{28}$ It should be noted that based on a new Medical Device Directive of the European Community (2007/47/EC, (http://ec.europa.eu/health/medical-devices/files/ revision_docs/ 2007-47-en_en.pdf)) which was became effective March 2010 stricter acceptance norms for devices are now required before approval and use in the clinic. ${ }^{27}$ Manufacturers of high-risk anesthetic devices will now have to invest resources in conducting separate clinical trials for their devices as no longer new high-risk anesthetic devices will be CE approved just because of showing similarity with currently marketed products. The EC-directive obliges for clinical implementation of any new high risk anesthetic device (including epidural catheters) clinical studies and evidence based medicine. From our study we recommend approval of anesthetic devices based on careful study of inadvertent intravasal or dural cannulation, paresthesia rate, spontaneously and on questioning, catheter problem e.g. dislocation, kinking, disconnection, and problems with removal.

To improve patient care and to assist clinical decision making the concept of evidence based medicine was developed. ${ }^{29}$ Then the highest level of evidence is established and based on systematic review and multiple randomized controlled trials (RCT). Nevertheless the question remains, even with the use of RCT's, if the results can be generalized to the wider community e.g. our daily practice., 3, 30

In this thesis we focused on the risks and benefits of regional anesthesia. As we earlier stated recommendations on procedures and devices on safety are difficult to make because of the low incidence of complications in the general population in combination with a wide diversity in type of anesthesia, minimal invasive surgery and contraindications. This implies the execution of very large time consuming expensive clinical studies, which are needed for optimal evidence based medicine and recommendations. As within this view RCT's are very complicated and difficult to perform other trial designs as an alternative (1-33 $^{31}$ he been proposed. In view of this it is important to mention that a high risk filtered shed blood re-transfusion device is introduced in a number of hospitals in the Netherlands based on evidence collected in a prospective observational study. ${ }^{34}$ In the scope of high risk anesthetic devices one must consider a 
pragmatic rethinking of the design including RCT's needed for evidence based medicine. Hence, combining RCT's with a large observational cohort in a "cohort multiple randomized controlled trial" design would be a future interesting option. ${ }^{35}$ 


\section{REFERENCES}

1. Barbosa FT, Juca MJ, Castro AA, Cavalcante JC. Neuraxial anaesthesia for lower-limb revascularization. Cochrane Database Syst Rev 2013, 7:CD007083.

2. LaMuraglia GM, Conrad MF, Chung T, Hutter M, Watkins MT, Cambria RP. Significant perioperative morbidity accompanies contemporary infrainguinal bypass surgery: an NSQIP report. J Vasc Surg 2009, 50(2):299-304, 304 e291-294.

3. Bosch X, Delgado V, Verbal F, Borquez E, Loma-Osorio P, Diez-Aja S, Miranda-Guardiola F, Sanchis J. Causes of ineligibility in randomized controlled trials and long-term mortality in patients with non-STsegment elevation acute coronary syndromes. International journal of cardiology 2008, 124(1):86-91.

4. Zulman DM, Sussman JB, Chen X, Cigolle CT, Blaum CS, Hayward RA. Examining the evidence: a systematic review of the inclusion and analysis of older adults in randomized controlled trials. Journal of general internal medicine 2011, 26(7):783-790.

5. Carli F, Kehlet H, Baldini G, Steel A, McRae K, Slinger P, Hemmerling T, Salinas F, Neal JM. Evidence basis for regional anesthesia in multidisciplinary fast-track surgical care pathways. Reg Anesth Pain Med 2011, 36(1):63-72.

6. Greco M, Capretti G, Beretta L, Gemma M, Pecorelli N, Braga M. Enhanced Recovery Program in Colorectal Surgery: A Meta-analysis of Randomized Controlled Trials. World journal of surgery 2014, 38(6):1531-1541.

7. Lassen K, Soop M, Nygren J, Cox PB, Hendry PO, Spies C, von Meyenfeldt MF, Fearon KC, Revhaug A, Norderval $S$ et al. Consensus review of optimal perioperative care in colorectal surgery: Enhanced Recovery After Surgery (ERAS) Group recommendations. Arch Surg 2009, 144(10):961-969.

8. Visnjevac O, Lee J, Pourafkari L, Dosluoglu HH, Nader ND. Functional Capacity as a Significant Independent Predictor of Postoperative Mortality for Octogenarian ASA-III Patients. The journals of gerontology Series A, Biological sciences and medical sciences 2014.

9. Herminghaus A, Loser S, Wilhelm W. [Anesthesia for geriatric patients : Part 2: anesthetics, patient age and anesthesia management]. Anaesthesist 2012, 61(4):363-374.

10. Bouman E, Dortangs E, Buhre W, Gramke HF. Current techniques and strategies for anesthesia in patients undergoing peripheral bypass surgery. The Journal of cardiovascular surgery 2014, 55(2 Suppl 1):207-216.

11. Landau R, Bollag LA, Kraft JC. Pharmacogenetics and anaesthesia: the value of genetic profiling. Anaesthesia 2012, 67(2):165-179.

12. Brandsborg B, Dueholm M, Nikolajsen L, Kehlet H, Jensen TS. A prospective study of risk factors for pain persisting 4 months after hysterectomy. Clin J Pain 2009, 25(4):263-268.

13. Brandsborg B, Nikolajsen L, Kehlet H, Jensen TS. Chronic pain after hysterectomy. Acta Anaesthesiol Scand 2008, 52(3):327-331.

14. Bruce J, Krukowski ZH. Quality of life and chronic pain four years after gastrointestinal surgery. Dis Colon Rectum 2006, 49(9):1362-1370.

15. Lavand'homme P, De Kock M, Waterloos H. Intraoperative epidural analgesia combined with ketamine provides effective preventive analgesia in patients undergoing major digestive surgery. Anesthesiology 2005, 103(4):813-820.

16. Werawatganon T, Charuluxanun S. Patient controlled intravenous opioid analgesia versus continuous epidural analgesia for pain after intra-abdominal surgery. Cochrane Database Syst Rev 2005(1):CD004088.

17. Swenson BR, Gottschalk A, Wells LT, Rowlingson JC, Thompson PW, Barclay M, Sawyer RG, Friel CM, Foley E, Durieux ME. Intravenous lidocaine is as effective as epidural bupivacaine in reducing ileus duration, hospital stay, and pain after open colon resection: a randomized clinical trial. Reg Anesth Pain Med 2010, 35(4):370-376.

18. Vigneault L, Turgeon AF, Cote D, Lauzier F, Zarychanski R, Moore L, Mclntyre LA, Nicole PC, Fergusson DA. Perioperative intravenous lidocaine infusion for postoperative pain control: a meta-analysis of randomized controlled trials. Can J Anaesth 2011, 58(1):22-37. 


\section{CHAPTER 8}

19. Yang SY, Kang H, Choi GJ, Shin HY, Baek CW, Jung YH, Choi YS. Efficacy of intraperitoneal and intravenous lidocaine on pain relief after laparoscopic cholecystectomy. The Journal of international medical research 2014, 42(2):307-319.

20. Charlton S, Cyna AM, Middleton P, Griffiths JD. Perioperative transversus abdominis plane (TAP) blocks for analgesia after abdominal surgery. Cochrane Database Syst Rev 2010(12):CD007705.

21. Niraj G, Kelkar A, Hart E, Horst C, Malik D, Yeow C, Singh B, Chaudhri S. Comparison of analgesic efficacy of four-quadrant transversus abdominis plane (TAP) block and continuous posterior TAP analgesia with epidural analgesia in patients undergoing laparoscopic colorectal surgery: an open-label, randomised, non-inferiority trial. Anaesthesia 2014, 69(4):348-355.

22. Cornish P, Deacon A. Rectus sheath catheters for continuous analgesia after upper abdominal surgery. ANZ journal of surgery 2007, 77(1-2):84.

23. Terheggen MA, Wille F, Borel Rinkes IH, lonescu TI, Knape JT. Paravertebral Blockade for Minor Breast Surgery. Anesth Analg 2002, 94(2):355-359.

24. Beydon L, Conreux F, Le Gall R, Safran D, Cazalaa JB. Analysis of the French health ministry's national register of incidents involving medical devices in anaesthesia and intensive care. Br J Anaesth 2001, 86(3):382-387.

25. Gilron I. Anaesthesia equipment safety in Canada: the role of government regulation. Can J Anaesth 1993, 40(10):987-992.

26. Pieterse H, De Jong M. Proper clinical development of medical devices to ensure continuity of care. Health Information Developments in the Netherlands 2006, 8:51-55.

27. Regulatory Controls Medical Devices [http://www.fda.gov/MedicalDevices/DeviceRegulationandGuidance/Overview/GeneralandSpecialControls/default.htm]

28. Jefferys DB. The regulation of medical devices and the role of the Medical Devices Agency. Br J Clin Pharmacol 2001, 52(3):229-235.

29. Pronovost PJ, Berenholtz SM, Dorman T, Merritt WT, Martinez EA, Guyatt GH. Evidence-based medicine in anesthesiology. Anesth Analg 2001, 92(3):787-794.

30. Grimes DA, Schulz KF. An overview of clinical research: the lay of the land. Lancet 2002, 359(9300):57-61.

31. Muche R, Imhof A. Das Comprehensive Cohort Design als Alternative zur randomisierten kontrollierten Studie in der Rehabilitationsforschung: Vor- und Nachteile sowie Anwendung in der SARAH-Studie. Rehabilitation (Stuttg) 2003, 42(6):343-349.

32. Olschewski M, Scheurlen H. Comprehensive Cohort Study: an alternative to randomized consent design in a breast preservation trial. Methods of information in medicine 1985, 24(3):131-134.

33. Verkooijen HM, Roes K, van Gils CH. [Cohort multiple randomized controlled trial: a solution for the evaluation of multiple interventions]. Ned Tijdschr Geneeskd 2013, 157(17):A5762.

34. Strumper D, Weber EW, Gielen Wijffels S, Van Drumpt R, Bulstra S, Slappendel R, Durieux ME, Marcus MA. Clinical efficacy of postoperative autologous transfusion of filtered shed blood in hip and knee arthroplasty. Transfusion 2004, 44(11):1567-1571.

35. Relton C, Torgerson D, O'Cathain A, Nicholl J. Rethinking pragmatic randomised controlled trials: introducing the "cohort multiple randomised controlled trial" design. BMJ 2010, 340:c1066. 


\section{Valorization addendum}

\section{RELEVANCE}

In this thesis we analyzed and investigated various risks and benefits of regional anesthesia and included not only the different type of surgery and high-risk patient populations in a context of chronic post-surgical pain and acute pain but also the characteristics and use of new anesthetic devices.

Not only the high number of operating room procedures (15,6 million in the United States of America annually ${ }^{1}$ ) but also the recent increase in the number of procedures, (from 1,1 to 1,4 million procedures in the Netherlands ${ }^{2}$ ) makes evaluation of optimal peri-operative care including anesthesia of utmost importance.

We furthermore discuss difficulties (risks) and comparison of the mode of anesthesia and relation to peri-operative mortality and morbidity. At present, recommendations for use of a specific mode of anesthesia but also for the use of specific anesthetic devices are commonly based on small-scale studies. Whereas anesthesia in general closely facilitates and directs the surgery in the operating theatre it needs no further comment that the outcome small-scale studies may have huge clinical impact. As clearly pointed out in this thesis, due to the relative low number of accidents related to anesthesia in general, large scale multicenter studies are needed to allow the demonstration of increased safety of newly developed anesthetic procedures.

As discussed before (see Chapter 2) a comparison of the risks and benefits of regional versus general anesthetics only is a manifestation of a limited approach and underestimates the potential benefits of combined regional and general anesthesia techniques in high-risk populations. The combined use of regional and general anesthesia might considerably improve the development of post-operative pain management programs for specific types of surgery like abdominal surgery and major oncological breast surgery.

To develop and improve peri-operative anesthetic techniques (regional anesthesia) a detailed knowledge of the human anatomy is essential. Therefore feasibility testing and teaching ${ }^{3}$ of regional anesthesia techniques in the anatomy laboratory is highly recommendable. 
To further implement a successful comprehensive perioperative pathway, anesthesia devices that are meant to relief pain should optimally do their job. Clearly, the proper functioning of catheters might be affected by the material characteristics. In this context it is surprising to see that until recently no systematic investigations are required for CE approval even for high-risk anesthetic devices. It is therefore that we were among the first investigators in the field of Anesthetics to carefully test anesthetic devices based on the use of a scientific study protocol. Our approach, as we think, will set the tone and might be directive in future use and implementation of new anesthetic devices in the clinic.

\section{TARGET GROUPS}

\section{Patients}

Patients and patients' associations are the most important target groups. Patients should receive the best (anesthetic) care as possible that is preferentially based on scientific evidence. The use of carefully tested and certified anesthetic devices significantly improves the quality and safety of Anesthesia.

\section{Clinicians}

It is obvious that the Anesthetists needs to be extremely careful before implementing or generalizing newly developed anesthetic procedures because the scientific evidence often is limited as the observations are based on small scale studies. Also the safety of new anesthetic devices needs carefully be evaluated before implementing into the standard anesthetic procedures. Here future CE-approval, required for implementation into the clinic, needs to be strictly based on scientific evidence.

The results and observations as reported in this thesis furthermore demonstrate that the Anesthetist needs not to completely rely on the anatomical textbooks before development and/or application of new or revived anesthetic techniques like the thoracic paravertebral block (see Chapter 5). As anatomical textbooks are basically using schematic reproductions of human anatomy our study shows that detailed anatomical post-mortem studies are absolutely required before application of a new or revived anesthetic technique.

\section{Health care policy makers and Stakeholders}

The increasing demand for optimally monitored anesthetic care and anesthetic techniques will further increase the health care costs in general. Cost-benefit analysis will form a significant part of study design and conduct in the near future. The 
recommendations with respect to the acceptance of alternative study designs should contribute to a cost effective way of monitoring quality of care.

Furthermore results from this thesis clearly show the urgent need for international standardization of regulations and procedures to assure constant quality of newly developed high tech industrial products.

Our findings support stakeholders in their efforts to contribute to a transparent and safe device development programs.

\section{Activities, Innovation and Implementation}

Identification of risks and benefits of various anesthetic techniques and devices is essential in the continuous process of improvement of anesthesia in general. Requirements for systematic investigations may lead to further standardization and certification of anesthetic devices. Furthermore results from this thesis may contribute to enhanced interest and insight into the immense problem of chronic post-surgical pain (CPSP). Accurate prevention and treatment of CPSP will be necessary to increase quality of life after surgery. 
VALORIZATION ADDENDUM

\section{REFERENCES}

1. Weiss AJ EA. Trends in Operating Room Procedures in U.S. Hospitals, 2001-2011. HCUP Statistical Brief \#171 Rockville, MD: Agency for Healthcare Research and Quality 2014.

2. Operaties in het ziekenhuis; soort opname, leeftijd en geslacht, 1995-2010 [http://statline.cbs.nl/StatWeb/publication/?DM=SLNL\&PA=80386ned\&D1=a\&D2=0\&D3=0\&D4=a\&D5=I\&HDR=T\&STB=G4,G1,G2,G $3 \& \mathrm{VW}=\mathrm{T}$ ]

3. Garcia-Tomas V, Schwengel D, Ouanes JP, Hall S, Hanna MN. Improved residents' knowledge after an advanced regional anesthesia education program. Middle East journal of anaesthesiology 2014, 22(4):419-427. 


\section{Dankwoord}

"Ko hodis, pojdi zmeraj do konca..." (als je loopt, ga altijd tot het einde.... Tone Pavček). Het was wel ver...

Daarom wil ik graag iedereen bedanken die op enigerwijze heeft bijgedragen bij het tot stand komen van dit proefschrift:

Mijn ouders Martin en Frida, die me altijd gesteund hebben mijn dromen te verwezenlijken. Helaas pap, kun je er vandaag niet meer bij zijn.

Jan van Tongeren, die zich al heel vroeg realiseerde dat een beschouwend vak voor mij waarschijnlijk niet zo geschikt zou zijn. Willem van der Ham, Prof. Dr. Bredee en Prof. Dr. Erik Korsten die me de beginselen van intensive zorg m.n. bij postoperatieve cardiothoracale patiënten hebben bijgebracht. Prof. Dr. Hans Knape, die zorggedragen heeft voor een veilig stimulerend opleidingsklimaat, waarin een kritische instelling alleen maar gestimuleerd werd, leidend tot een fantastische opleidingstijd.

Prof. Dr. Van Kleef, beste Maarten. Ik ben je in de loop der jaren steeds meer gaan waarderen voor alle steun, coördinatie, inspiratie en je no nonsens attitude.

Prof. Dr. Marcus, beste Marco. Je was als grenzeloos optimist en stimulator er heilig van overtuigd dat dit project tot een goed einde zou leiden. Helaas ben je tussentijds vertrokken, maar afstand heeft in dit geval geen verschil gemaakt.

Prof. Dr. Joosten, beste Bert. Onze communicatie is zeer efficiënt, inspirerend, en motiverend geweest. Niet alleen op wetenschappelijk vlak. En zonder onze vaste afspraak, waar zijn $80 \%$ dagen niet goed voor, was dit document nu nog niet af.

Dr. Hans-Fritz Gramke, ook wel Hans in de volksmond, kamergenoot, hoewel ondertussen weer vertrokken uit die kamer, copromotor, bedankt voor je luisterend oor en stimulerende gesprekken, in een tijd dat er andere prioriteiten waren en zijn.

Maurice Theunissen, aanvankelijk researchverpleegkundige, nu inmiddels epidemioloog, hartelijk bedankt voor al je hulp bij o.a. rekruteren van patiënten, datamanagement, statistische analyses en praktische hulp bij zaken waar clinici eigenlijk weinig kaas van gegeten hebben.

Fons Kessels, voor de statistische adviezen en analyses.

Dr. Arno Lataster, Dr. Judith Sieben, Johan Hekking, Leon Huiberts, en Greet Mommen van de afdeling anatomie voor de zeer stimulerende samenwerking waarvan 
ik hoop dat deze samenwerking na de afronding van dit proefschrift voortgezet zal worden.

Verder wil ik graag alle collega's, arts-assistenten, verpleegkundigen van zowel OK als IC, dokters-assistenten en het secretariaat anesthesiologie hartelijk bedanken voor de ondersteuning, het geduld, het overnemen van taken, de kritische houding, een altijd luisterend oor en de flauwekul.

Metka, bedankt voor het onophoudend enthousiasme ons een klein beetje Sloveens te leren.

Zonder een stabiel, gelukkig thuisfront is een meer-jaren project als dit niet mogelijk.

Arno, Axel en Rani bedankt! 


\section{Curriculum Vitae}

Esther Bouman werd geboren op 28 december 1964 te Reuver

Na een onbezorgde jeugd te Stolzenau (D) volgden de middelbare schooltijd en het VWO diploma (1983) aan het Liemers College te Zevenaar. Ze studeerde Geneeskunde aan wat destijds nog de Katholieke Universiteit Nijmegen heette. In 1990 werd het artsexamen behaald. Tijdens deze studie periode werd bij NSAV 't Haasje en Cifla niet alleen de basis gelegd voor toekomstige duursport activiteiten, maar ook voor de uiteindelijke terugkeer naar het Limburgse.

Daarna startte ze als agnio bij de afdelingen Gastro-Enterologie van het St. Radboud ziekenhuis en Intensive Care van het Catharina ziekenhuis Eindhoven. De interesse in anesthesiologie en intensive care geneeskunde werden gewekt, wat leidde tot een fantastische opleidingstijd en specialisatie tot anesthesioloog (2001) en intensivist (2002) in het AZU. Tevens werd het EDIC diploma (2002) behaald.

Sinds 2002 werkt ze als staflid bij de afdeling Anesthesiologie en Pijnbestrijding van het $\mathrm{MUMC}^{+}$en was tot januari 2015 tevens gedetacheerd als intensivist zowel te Maastricht als te Roermond.(St. Laurentius ziekenhuis) 



\section{Publications}

Bouman EA, Theunissen M, Kessels AG, et al. Continuous paravertebral block for postoperative pain compared to general anaesthesia and wound infiltration for major oncological breast surgery. Springerplus 2014; 3: 517.

Delnoij T, Veldhuijzen G, Strauch U, Van Mook WK, Bergmans DC, Bouman EA, Lance MD, Smets M, Breedveld P, Ganushchak YM, Weerwind P, Kats S, Roekaerts PM, Maessen J and Donker DW. Mobile respiratory rescue support by off-centre initiation of extracorporeal membrane oxygenation. Perfusion2014; published online 25 June 2014, DOI: $10.1177 / 0267659114540735$

Bouman E, Dortangs E, Buhre W, Gramke HF. Current techniques and strategies for anesthesia in patients undergoing peripheral bypass surgery. J Cardiovasc Surg (Torino) 2014; 55: 207-16.

Bouman EA, Theunissen M, Bons SA, Van Mook WN, Gramke H-F, Van Kleef M, Marcus MA. Reduced incidence of chronic postsurgical pain after epidural analgesia for abdominal surgery. Pain Pract 2014; 14: E76-84.

Bouman EA, Gramke HF, Marcus MA. Paraesthesia in Regional Anaesthesia. In: Imbelloni LE, ed. Paresthesia: InTech, 2012; 33-44.

Geelen CC, Bouman EA, Roekaerts PM, Breedveld P, Strauch U, Van Garsse L, Weerwind PW, Donker DW. Mobile extracorporeal membrane oxygenation after traumatic freshwater submersion using bi-caval dual lumen catheter. Intensive Care Med 2011; 37: 2054-5.

Bouman EA, Gramke HF, Wetzel N, et al. Evaluation of two different epidural catheters in clinical practice. Narrowing down the incidence of paresthesia! Acta Anaesthesiol Belg 2007; 58: 101-5. 


\section{PUBLICATIONS}

Skrabanja AT, Bouman EA, Dagnelie PC Potential value of adenosine 5 'triphosphate (ATP) and adenosine in anaesthesia and intensive care medicine. British Journal of Anaesthesia 2005; 94: 556-62.

Bouman EA, Songun I, Marcus MA A case of an anaphylactic reaction to an old substance--patent blue--for a new indication. Acta Anaesthesiol Scand 2004; 48: 1066.

Cremer OL, Moons KG, Bouman EA, Kruijswijk JE, de Smet AM, Kalkman CJ. Long-term propofol infusion and cardiac failure in adult head-injured patients. Lancet 2001; 357: 117-8.

Bouman EA, Gutierrez y Leon JA, van der Salm PC, Christiaens GC, Bruinse HW, Broeders IA [Complicated but successful resuscitation after amniotic fluid embolism]. Nederlands tijdschrift voor geneeskunde 2001; 145: 747-9. 
